University of Rhode Island

DigitalCommons@URI

Open Access Master's Theses

2019

ANTHELMINTIC EFFICACY OF PELLETED CRANBERRY VINE AGAINST GASTROINTESTINAL NEMATODES OF SHEEP

Bailey Chalut

University of Rhode Island, bailey_chalut@uri.edu

Follow this and additional works at: https://digitalcommons.uri.edu/theses

Recommended Citation

Chalut, Bailey, "ANTHELMINTIC EFFICACY OF PELLETED CRANBERRY VINE AGAINST

GASTROINTESTINAL NEMATODES OF SHEEP" (2019). Open Access Master's Theses. Paper 1518.

https://digitalcommons.uri.edu/theses/1518

This Thesis is brought to you for free and open access by DigitalCommons@URI. It has been accepted for inclusion in Open Access Master's Theses by an authorized administrator of DigitalCommons@URI. For more information, please contact digitalcommons-group@uri.edu. 


\title{
ANTHELMINTIC EFFICACY OF PELLETED CRANBERRY VINE AGAINST GASTROINTESTINAL NEMATODES OF SHEEP
}

BY

BAILEY CHALUT

\begin{abstract}
A THESIS SUBMITTED IN PARTIAL FULFILLMENT OF THE REQUIREMENTS FOR THE DEGREE OF MASTER OF SCIENCE
\end{abstract}

IN

BIOLOGICAL AND ENVIRONMENTAL SCIENCES

UNIVERSITY OF RHODE ISLAND

2019 
MASTER OF SCIENCE THESIS

OF

BAILEY CHALUT

APPROVED:

Thesis Committee:

Major Professor Katherine Petersson

Anne Zajac

Chong Lee

John Taylor

Nasser H. Zawia

DEAN OF THE GRADUATE SCHOOL

UNIVERSITY OF RHODE ISLAND

2019 


\begin{abstract}
Gastrointestinal nematodes (GIN) represent a major health concern in small ruminants as well as a constraint for producers. The prevalence of anthelmintic resistance in small ruminant GIN has increased rapidly worldwide, creating the need for alternative control methods to address the issue. The discovery that plant secondary compounds, including proanthocyanidins (PAC), suppress GIN infections has provided promise for alternative methods of GIN control. Although the mechanism is not well understood, studies have shown in vitro and in vivo evidence of anti-parasitic effects of bioactive plants. Recently a study from our laboratory provided in vitro evidence of anthelmintic activity of cranberry vine (CV) PAC organic extracts as well as CV aqueous extracts (CV-AqE) against Haemonchus contortus first stage larvae (L1) and adult worm motility and some activity of CV-AqE against egg hatching. This previous study also showed a slight suppression of fecal egg count (FEC) in vivo when chopped cranberry was fed to parasitized lambs. The current study was designed to further investigate the effects of $\mathrm{CV}$ on GIN infections in sheep. This study utilized two feeding trials in order to investigate the in vivo effects of $\mathrm{CV}$. In the first feeding trial, lambs experimentally infected with Haemonchus contortus were given a $100 \%$ CV pellet (CVP) as a supplement to their regular grain. Although the palatability and consumption of the pellet was a major issue, supplementing the CVP into the diet appeared to suppress the FEC compared to untreated sheep at the end of the six-week trial, with no difference observed in packed cell volume or total worm burden. In the second
\end{abstract}


feeding trial, lambs with a mixed natural and experimental GIN infection were fed two levels of a $50 \%$ cranberry vine pellet that had been formulated to contain equivalent amounts of digestible dry matter. Under the conditions of the study, the FEC of the lambs consuming $500 \mathrm{~g}$ of CV per day did not change over the course of the study unlike the control group and the lambs consuming $250 \mathrm{~g}$ of $\mathrm{CV}$ per day. Although further research is needed to better understand this phenomenon, it is suggested that $\mathrm{CV}$ may have potential as a viable and sustainable option for northeast sheep producers to utilize as a strategy for GIN control. 


\section{ACKNOWLEDGMENTS}

First and foremost, I would like to thank my major professor, Dr. Katherine Petersson, for supporting, encouraging, and pushing me throughout my graduate years at URI. My experiences as a graduate student have helped to shape and prepare me immensely for my future endeavors, and I am extremely grateful for that. Thank you also to Dr. Anne Zajac, Dr. Chong Lee, and Dr. John Taylor for serving on my committee and providing guidance and motivation throughout various projects.

I would also like to thank the students that have contributed to the work that has happened over the past two years. Thank you to Allison Mosichuk, Cassie Munroe, Gianna Zavota, Amy Vigneau, Gabby Bonofiglio, and all of the others who have helped along the way to keep things running smoothly and efficiently - we could not do it without you. I would like to extend a special thanks to research assistant Sydney Day for teaching me various techniques and easing my transition into the lab. A huge thank you also to my fellow graduate student, Marissa Brummett, for both contributing to my projects and helping me to maintain a certain level of sanity throughout the years - I certainly could not imagine doing all of this without you.

I would also like to extend a thank you to the wonderful FAVS department members that have supported and encouraged me throughout both my undergraduate and graduate years, especially Dr. Maria Hoffman, Dr. Christopher Card, Fred Launer, Dr. Anthony Mallilo, Dr. Justine Deming, and 
Dr. Marta Gomez-Chiarri. I also would like to extend my extreme gratitude to farm manager Nick Miniter for all of his advice, guidance, and support to ensure that (almost) all of my crazy ideas to make things more efficient could become reality. Thank you for your tireless dedication to the farm and the animals, and your unending willingness to help with any and all projects. Lastly, and perhaps most importantly, l'd like to thank my family. To my mom \& Mark, Grandma \& Grandpa, Uncle Tommy, my sister Caitlyn, my nephews Knox \& Owen, my niece Nora, my dad \& Celeste - thank you for your unconditional love, support, and guidance; I could not have done this without you all by my side. 


\section{PREFACE}

This thesis is written in Manuscript Format. Chapter 1 includes a literature review of detailed information about small ruminant gastrointestinal nematodes, bioactive plant compounds, and current alternative anthelmintic research. Chapter 2 includes a condensed paper about in vivo testing of cranberry vine on an experimental infection in lambs. Chapter 3 includes a condensed paper about cranberry vine in vivo testing on a mixed natural infection in lambs. All manuscripts are written in the style of Veterinary Parasitology. Conclusions made from both studies and future research directions are described in Chapter

4. Additional details on the methods used throughout these studies and analyses performed are included in the appendix. 


\section{TABLE OF CONTENTS}

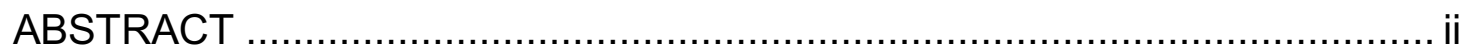

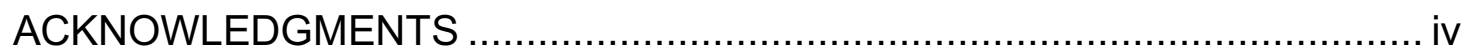

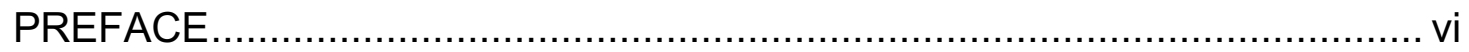

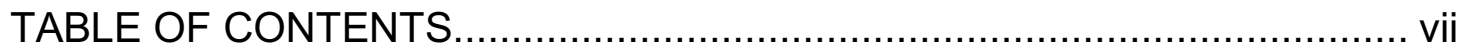

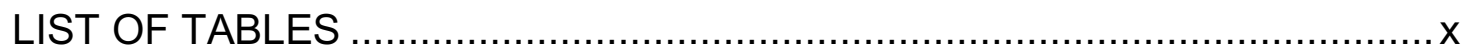

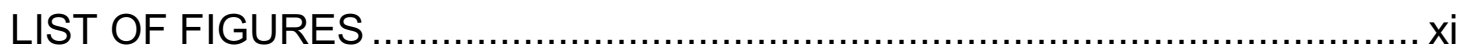

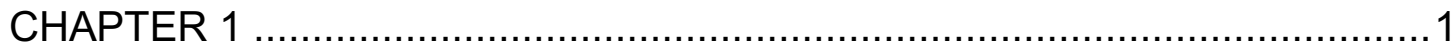

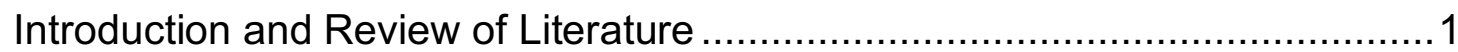

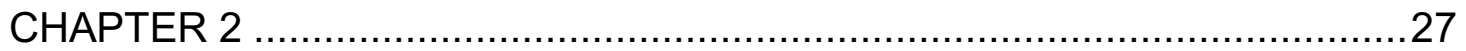

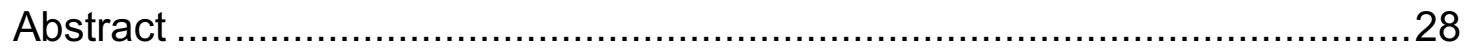

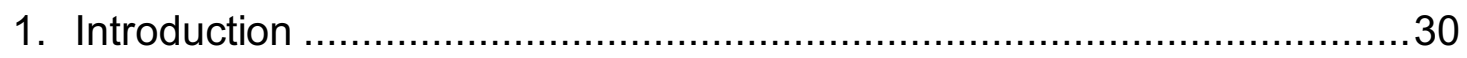

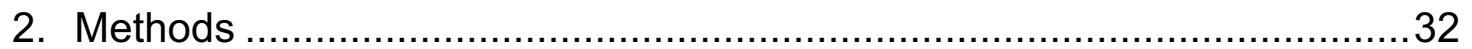

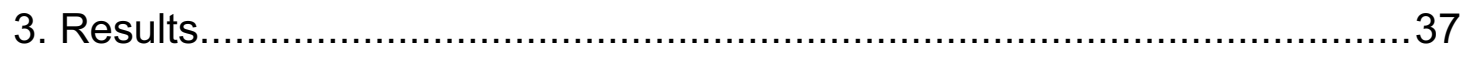

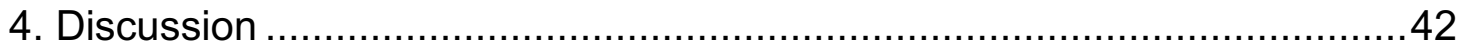

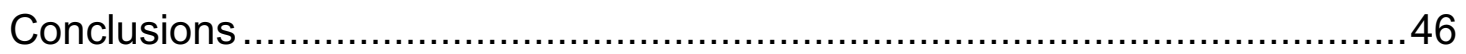

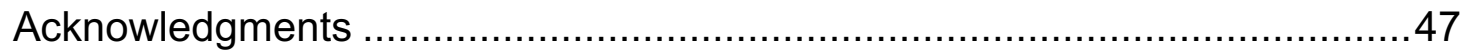

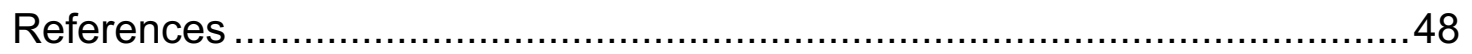

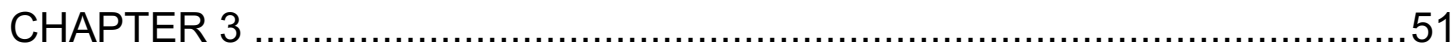

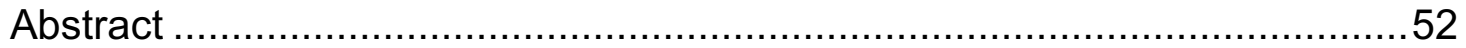

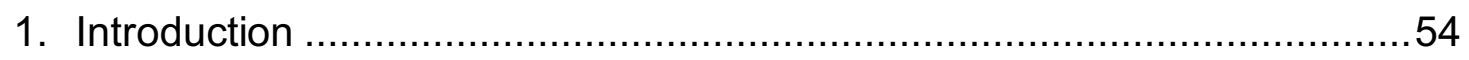

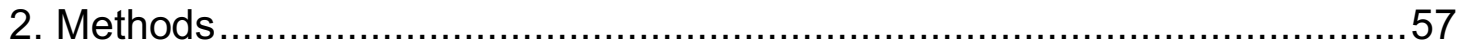




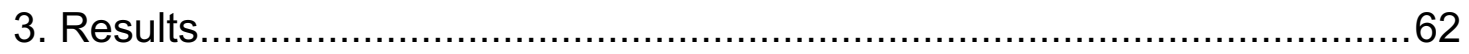

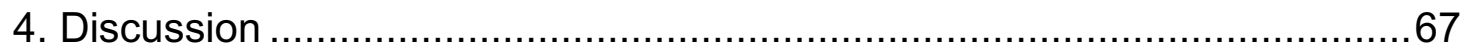

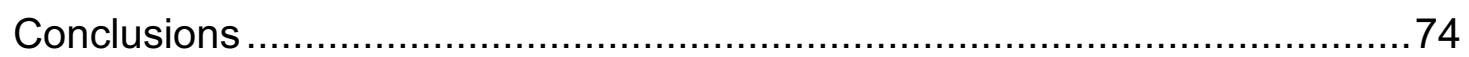

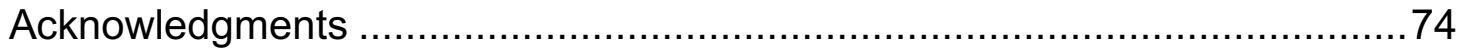

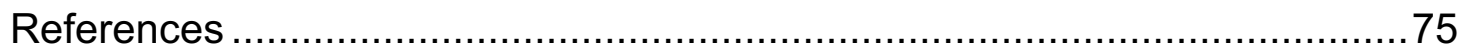

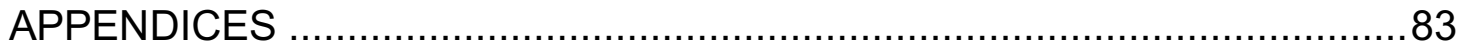

Standard Operating Procedure for Blood Collection ................................... 83

Standard Operating Procedure for Determining Packed Cell Volume ............85

Standard Operating Procedure for Fecal Egg Counts (FEC) ......................87

Standard Operating Procedure for Nematode Recovery Post Mortem ............89

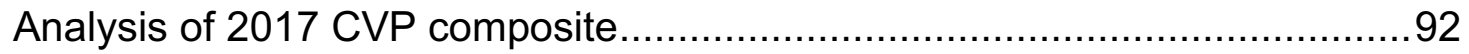

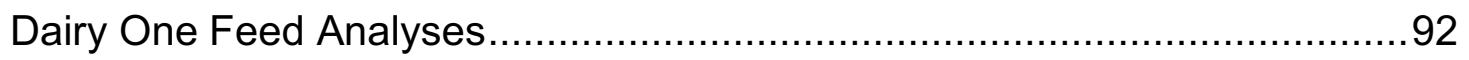

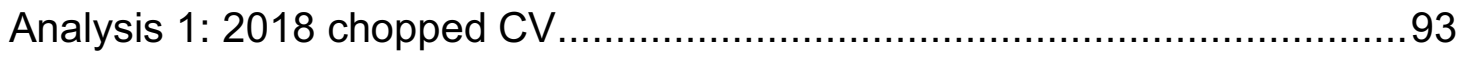

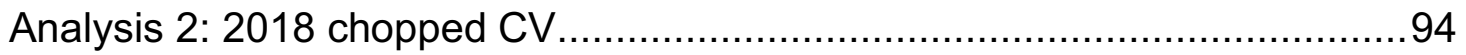

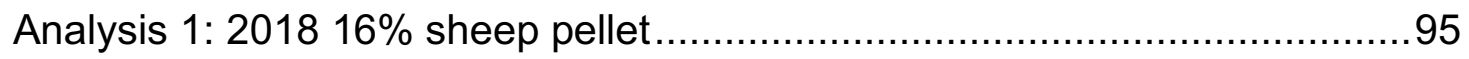

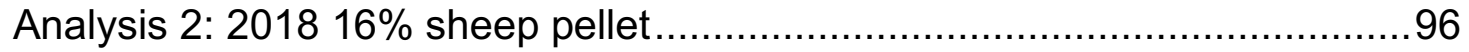

Analysis of $201816 \%$ sheep pellet composite........................................97

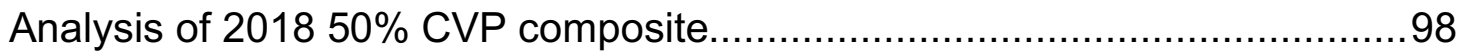

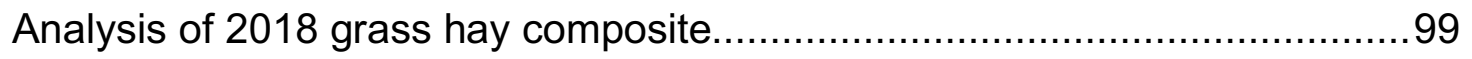

50\% Cranberry Pellet Formulation........................................................ 100

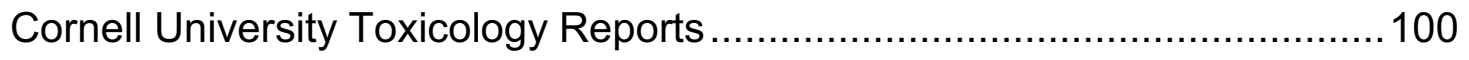

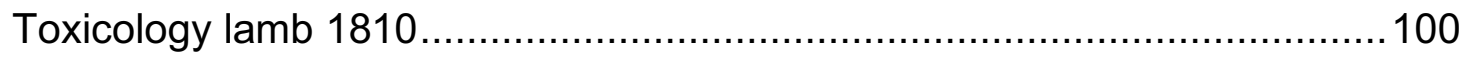

Post-mortem toxicology from control and CVP500 lambs.........................103 


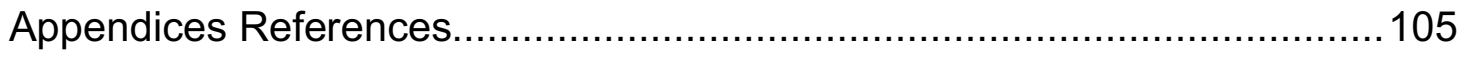




\section{LIST OF TABLES}

TABLE

PAGE

\section{CHAPTER 2}

Table 1. Nutrient content of composite hay, grain, and cranberry vine pellet

samples collected over the study period................................. 35

\section{CHAPTER 3}

Table 1. Nutrient content of composite hay, grain, and cranberry vine pellet

samples collected over the study period.............................60 


\section{LIST OF FIGURES}

FIGURE

PAGE

\section{CHAPTER 1}

Figure 1. Gastrointestinal nematode life cycle

.5

\section{CHAPTER 2}

Figure 1. Study Design

34

Figure 2. Effect of CVP on fecal egg counts of an experimental infection of $H$.

contortus. 38

Figure 3. Effect of CVP on packed cell volume of an experimental infection of

H. contortus.

Figure 4. Effect of CVP on weight during an experimental infection of $H$.

contortus.

Figure 5. Effect of CVP on adult worm burden during an experimental infection

of $H$. contortus

\section{CHAPTER 3}

Figure 1. Study Design

59

Figure 2. Effect of feeding varying amounts of a $50 \%$ CVP on FEC in lambs subjected to an experimental $H$. contortus infection (5000 L3) superimposed on a light pasture infection.

Figure 3. Effect of feeding varying amounts of a $50 \%$ CVP on PCV in lambs subjected to an experimental $H$. contortus infection (5000 L3) superimposed on a light pasture infection. 
Figure 4. Effect of feeding varying amounts of a 50\% CVP on weight in lambs subjected to an experimental $H$. contortus infection (5000 L3) superimposed

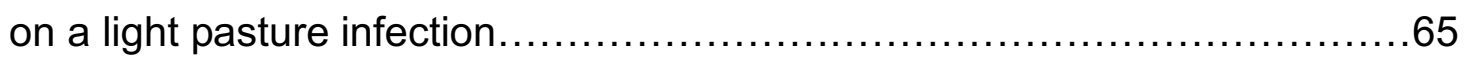

Figure 5. Effect of CVP on hepatic copper values..........................66 


\title{
CHAPTER 1
}

\author{
Introduction and Review of Literature
}

\section{Small Ruminant Parasite Problem}

\section{The Sheep Industry}

Sheep are multi-purpose animals bred and used as a source of meat, milk, wool, and other products both in the United States and globally. Historically, sheep meat was a by-product of the wool industry; however, wool production has seen a steady decline due to the introduction of synthetic fibers, causing a surge in lamb production and consumption (Chikwanha et al., 2018). The decline in the wool industry has also caused an increase in hair sheep which require little to no shearing while still producing a high-quality carcass (Aldridge et al., 2018). Although sheep meat consumption and production lags behind beef, pork, and poultry, there has been an increase in consumption, a trend expected to continue due to population growth and growing incomes (Montossi et al., 2013; Chikwanha et al., 2018). In general, meat consumption patterns vary greatly due to socio-economic and cultural trends, as well as the lifestyles of diverse groups of consumers (Bernués et al., 2012). Sheep meat has an intense and distinct species flavor and aroma which also contributes to the variability of consumption, especially across different countries (Schönfeldt et al., 1993). 


\section{Economic impact}

The United States sheep industry peaked in the 1940's when there were 52 million head, and then continued on a gradual decline starting in the 1960's. Although the sheep and lamb inventory has trended downward for an extended length of time, the number of farms has continued on an upward trend from a low of 67,630 operations in 2004 to a high of 101,387 in 2017 (USDA, 2011; USDA, National Agricultural Statistics Service, 2019). Of the current total market, 48,000 head are located in New England (including Connecticut, Maine, Massachusetts, New Hampshire, Rhode Island, and Vermont) as well as 80,000 head in New York and 95,000 head in Pennsylvania, comprising approximately $5 \%$ of the total US sheep population in the northeast region (USDA, National Agricultural Statistics Service, 2019). In the US market, sheep and lamb production and related agricultural products amounted to over $\$ 1$ billion in total economic contribution (USDA, National Agricultural Statistics Service, 2019).

\section{Production losses}

In the United States and globally, gastrointestinal nematode infection has been identified as the costliest disease to affect the sheep industry, representing great economic importance for producers (Nieuwhof and Bishop, 2005; Qamar et al., 2011). Sheep are able to graze in areas that are not well suited for most other species and in conjunction help to prevent wildfires by grazing brush and vegetation (USDA, 2011; Aldridge et al., 2018); however, gastrointestinal nematode (GIN) infections have been identified as one of the 
major limitations faced in pasture-raised production of small ruminants (Hoste et al. 2006; Fontenot et al. 2003; Besier 2012; Nieuwhof and Bishop 2005). The costs associated with GIN are twofold, and are comprised of both direct and indirect expenses. Direct expenses are those associated with decreases in production, decreases in gain, and host mortality; the indirect expenses are those such as treatment costs and increased labor (Torres-Acosta and Hoste, 2008).

According to the USDA (2015), the percentage of death losses in both lambs and adult sheep due to internal parasites has been steadily increasing in recent years. Sheep and lamb death losses are categorized by predator and nonpredator losses. In 2014, death losses reached 585,000 sheep and lambs in the US, and nonpredator losses represented 71.9 percent and 63.6 percent of those losses in adult sheep and lambs, respectively. Internal parasites caused $8.6 \%$ of the adult sheep deaths, equaling 13,543 sheep and approximately $\$ 32$ million USD. In lambs, internal parasites caused $9.2 \%$ of the nonpredator deaths, equaling 21,239 lambs and approximately $\$ 36$ million USD.

Gastrointestinal nematodes of small ruminants

Introduction

Gastrointestinal helminth infections are the most prevalent parasitic diseases affecting small ruminants worldwide (Torres-Acosta and Hoste, 2008; Traversa and von Samson-Himmelstjerna, 2016). Haemonchus contortus (the 
barber pole worm), Teladorsagia circumcincta (the brown stomach worm) and Trichostrongylus colubriformis (the bankrupt worm) are the most abundant gastrointestinal nematodes in sheep, and account for the greatest amount of economic and production losses (O'Connor et al., 2006). The infections can have both direct (mortality, decreased production) and indirect (treatment costs, labor, housing) impacts (Torres-Acosta and Hoste, 2008), making them a major constraint for sheep producers. The life cycle of these three parasites is similar, although they each vary in developmental requirements, prepatent periods, and predilection sites.

Life cycle

Trichostrongyle nematodes (of the suborder Trichostrongylina) are parasites affecting the gastrointestinal tract and lungs of pasture-raised animals, as well as wild animals and birds (Hoste et al., 2006). Pastures become infected with GIN when eggs are shed in the feces of grazing animals. Fertilized female worms found in the gastrointestinal tract can lay $200-10,000$ eggs per day, depending on the species (Roeber et al., 2013; Kearney et al., 2016), contributing to rapid pasture contamination. The larvae hatch from the eggs within the feces as the L1 stage and then develop into L2 and L3 larvae within the feces. The infective L3 larvae migrate from the feces onto the pasture where they can be readily consumed by grazing animals (Figure 1). The L3 larvae is ensheathed within a cuticular outer layer which helps to protect them from the environment but also prevents them from feeding (Roeber et al., 2013). Once inside the host, the larvae undergo a process 
known as exsheathment where the protective sheath is lost and they can mature into adult worms (Nikolaou and Gasser, 2006). The L4 and adult stages of the worm are parasitic inside the host. Mature female worms will begin to lay eggs approximately two to four weeks after infection, thus continuing the cycle through pasture contamination.

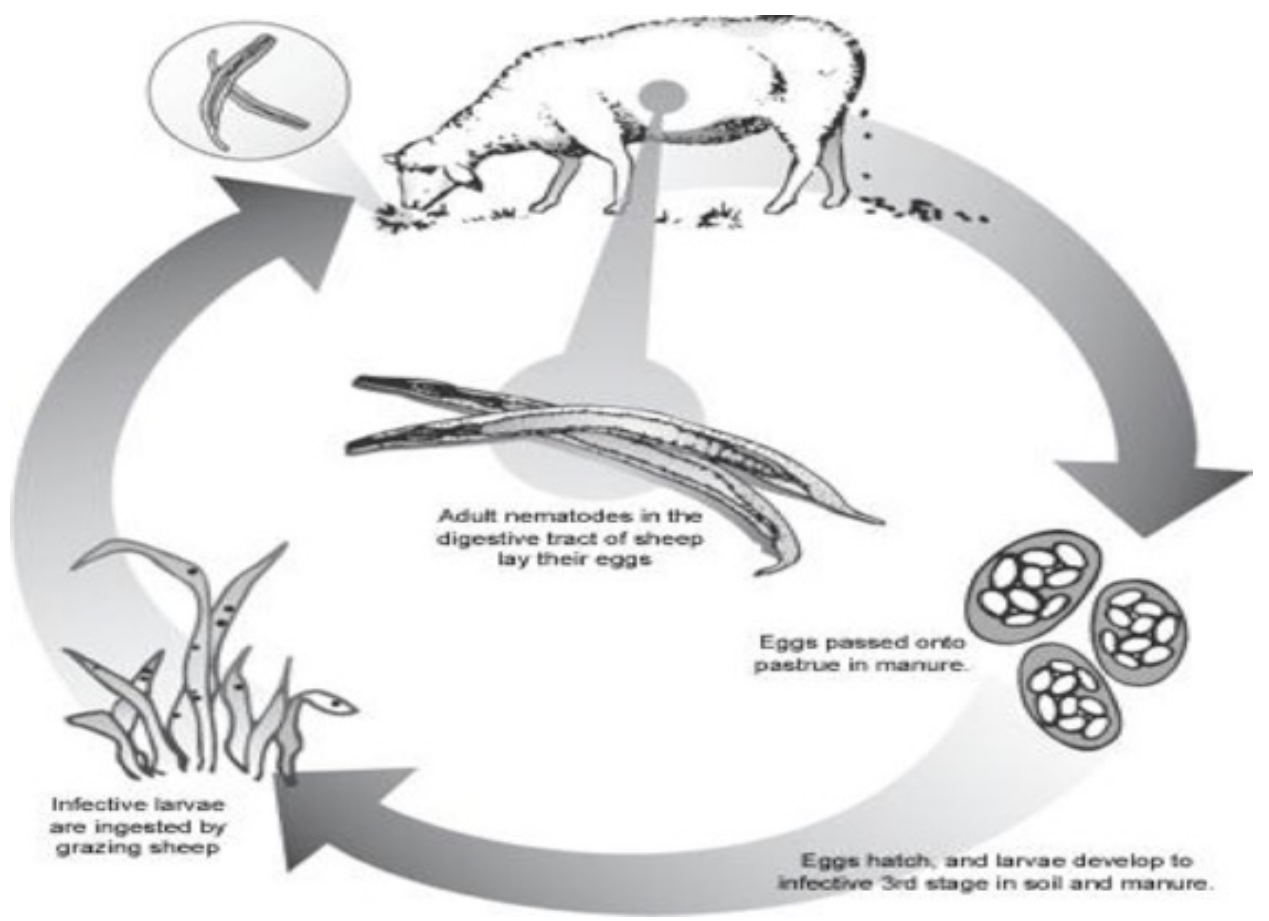

Figure 1: Gastrointestinal nematode life cycle.

(http://bio390parasitology.blogspot.com/2012/03/haemonchus-contortus-bitein-gut.html, 2019)

Although these parasites are well suited to warm and moist climates, the larvae of GIN have developed adaptations that contribute to the survival and continuation of the life cycle. Hypobiosis is an adaptation that occurs when the external climate is too cold, dry, or is not well suited for the development and survival of larvae on pasture. During hypobiosis, larvae in 
the L4 stage go into an arrested state inside the animal and cease progression of the life cycle (Nikolaou and Gasser, 2006). The larvae can stay in the arrested state inside the animal until external conditions improve in order to support development. Winter hypobiosis of Haemonchus contortus in the northern United States is an obligatory survival mechanism that occurs in order to survive adverse conditions, and external environmental cues may or may not trigger the onset (Capitini et al. 1990; Nikolaou and Gasser 2006; Sommerville and Davey 2002).

Haemonchus contortus

Of the three most common GIN of small ruminants, Haemonchus contortus is the most pathogenic species causing issues such as anemia, reduced nutrient absorption, production losses, and in severe cases death (Veríssimo et al., 2012; Kearney et al., 2016). Haemonchus contortus is a blood-feeding parasite which inhabits the abomasum (the fourth chamber of the ruminant stomach), and one adult worm can consume up to $30 \mu \mathrm{L}$ of blood each day (Emery et al., 2016; Kearney et al., 2016). The abomasum is also the site where adult worms mate and produce eggs. Unique to $H$. contortus is the high level of fecundity in females; one adult female alone can lay between 5000-15,000 eggs per day (Emery et al., 2016; Kearney et al., 2016). The eggs are then shed in the feces of the animal leading to rapid pasture contamination even with low infection levels, thus continuing the parasite life cycle. 
Young lambs and periparturient ewes are particularly susceptible to overwhelming worm burdens and anemia (Santos et al., 2014), although any sheep infected heavily can be subject to hemorrhage of the abomasum and potentially fatal anemia (Ortolani et al., 2013). Due to the pathogenicity of these parasites, proper and effective control methods are needed to ensure good health and adequate production levels for farmers.

Teladorsagia circumcincta and Trichostrongylus colubriformis

Sheep infected with Teladorsagia circumcincta are challenged with increased fluid secretion and increased flow rate of digesta at the abomasum, although most of this can be reabsorbed in the distal parts of the small intestine (Williams et al., 2010). Trichostrongylus colubriformis infection increases the flow of protein and minerals through the small intestine, blocking absorption and thereby increasing the animal's energy demand (Bown et al., 1991). Both $T$. circumcincta and $T$. colubriformis can cause immune-mediated diarrhea in infected animals, and a mixed infection can lead to increased inflammatory cells in the small intestine (Williams et al., 2010). Decreased nutrient absorption and diarrhea associated with these GI worms lead to decreased gain and production losses. As previously mentioned, the life cycle of $T$. circumcincta and $T$. colubriformis are similar to $H$. contortus, but diarrhea or scouring in infected animals is an observable clinical symptom which is generally not associated with $H$. contortus, unless in mixed infections (Roeber et al., 2013). 


\section{Current control options}

\section{Commercially produced anthelmintics}

The use of broad-spectrum anthelmintics has been the primary strategy for treatment of GIN in small ruminants for many years. The anthelmintic drugs available for use in small ruminants belong to three broad classes: benzimidazoles (including albendazole and fenbendazole), cholinergic agonists (such as levamisole), and macrocyclic lactones (including ivermectin and moxidectin) (Kaplan, 2004; Howell et al., 2008). These drugs are inexpensive, safe, and are generally effective across a broad spectrum (Zajac et al., 2000; Kaplan, 2004; McKellar and Jackson, 2004; Ketzis et al., 2006) and many farmers choose to treat all of their animals prophylactically every 34 weeks regardless of infection level in order to promote productivity and increase profits (da Cruz et al., 2010; Šimpraga et al., 2015).

Anthelmintic resistance

The overuse and improper use of commercial anthelmintics have led to the development and increasing prevalence of multiple drug resistance in $H$. contortus and other GIN worldwide, creating the need for alternative control methods (Fleming et al., 2006; Jackson and Miller, 2006; Howell et al., 2008). Additionally, there is a push by the public to move away from traditional chemical anthelmintics due to the possibility that the synthetic drugs can leave residues in animal products as well as accumulate in the environment (Ketzis et al., 2006; Silveira et al., 2012). Parasites that are resistant to multiple or all 
available anthelmintic drugs are becoming increasingly more prevalent all over the world (Kaplan and Vidyashankar, 2012).

In the United States and globally, drug resistant and multiple drug resistant nematodes are now widespread (Jackson and Miller, 2006; Kaplan and Vidyashankar, 2012; Crook et al., 2016). Resistance has been reported to all classes of anthelmintic drugs in several parasite species, and some isolates have been identified as resistant to all drug classes; drugs which were once greater than $99.9 \%$ effective have decreased to $0-70 \%$ effective (Sangster, 2001). Anthelmintic resistance and multiple drug resistance has been reported across the United States (Fleming et al., 2006; Howell et al., 2008; Crook et al., 2016) as well as Canada (Falzon et al., 2013), Australia (Roeber et al., 2013; Leathwick and Besier, 2014), New Zealand (McKenna, 2010), South Africa (Tsotetsi et al., 2013), Scotland (Sargison et al., 2007), Brazil (da Cruz et al., 2010; Veríssimo et al., 2012) and across multiple countries in Europe (Geurden et al., 2014; Traversa and von Samson-Himmelstjerna, 2016; Ploeger and Everts, 2018).

Genetic variability in parasites leads to anthelmintic resistance, and human actions such as the overuse of anthelmintics contributes to more rapid accumulation of this resistance (da Cruz et al., 2010). Gastrointestinal nematodes of small ruminants have a number of genetic characteristics contributing to their resistance; high fecundity rates result in rapid nucleotide sequence evolution and there are high levels of gene flow due to host movement from farm to farm, helping to not only select for resistant genes but 
also to spread the resistant populations (Sangster, 2001; Fleming et al., 2006).

Alternative anthelmintic options

Screening methods (in vitro/in vivo)

The worldwide emergence of anthelmintic resistant parasites has motivated the investigation into alternative control options for gastrointestinal nematodes. Preliminary screening is done through in vitro testing with controlled laboratory settings. In vitro assays have several advantages such as low cost and rapid turnover which allows for multiple compounds to be tested simultaneously (Githiori et al., 2006). Several in vitro assays are commonly used in laboratories in order to test the anthelmintic activity of potential alternative treatment candidates (Marie-Magdeleine et al., 2009). The in vitro assays commonly employed for this testing include the egg hatch assay (Hubert and Kerboeuf, 1984), larval development assay (Hubert and Kerboeuf, 1992), larval migration inhibition assay (Wagland et al., 1992; Rabel et al., 1994), adult worm motility assay (Hounzangbe-Adote et al., 2005), and exsheathment assay (Conder and Johnson 1996). The hypothesis is that nematicidal activity observed in vitro will correspond to activity and then be reproducible in vivo (Marie-Magdeleine et al., 2009).

Copper oxide wire particles

Copper oxide wire particles (COWP) are a product marketed as a livestock supplement for animals living in copper deficient areas (Fleming et 
al., 2006). The COWP are given orally as a bolus containing a designated amount based on species requirements (Fleming et al., 2006). The COWP become lodged in the abomasal mucosa of the animal allowing for extended copper release (Jackson and Miller, 2006). Studies have been conducted to determine whether the copper supplementation from the copper oxide wire particles has an effect on the establishment of gastrointestinal nematode infections in sheep or goats. In a study conducted by (Bang et al., 1990) in 1990, a $96 \%$ reduction of $H$. contortus and a $56 \%$ reduction of $T$. circumcincta establishment was observed in lambs treated with $5 \mathrm{~g}$ COWP compared to untreated control lambs, with no significant effect on $T$. colubriformis (Bang et al., 1990). Several studies have shown reduction in both fecal egg counts and adult worm burdens in $H$. contortus infections in sheep (Knox, 2002; Burke et al., 2004) as well as goats (Chartier et al., 2000; Martínez Ortiz de Montellano et al., 2007). Additionally, a large-scale three-year survey of organically raised sheep in Sweden showed that sheep fed a mineral supplement containing copper had lower fecal egg counts when compared to unsupplemented sheep (Lindqvist et al., 2001). A follow-up study, however, found that there was no significant effect of copper supplementation on established or developing parasite infection (Waller et al., 2004). The study also examined the effects of COWP in a mature infection in lambs, showing a $97 \%$ reduction in $H$. contortus as well as a $74 \%$ reduction in $T$. circumcincta when compared to untreated control lambs (Waller et al., 2004). Interestingly, it has also been shown that COWP combined with a traditional treatment of albendazole 
increases the efficacy against several GIN genera when compared to either treatment given separately (Burke et al., 2016), providing an effective combination treatment which could be useful in anthelmintic resistant parasite populations.

Although COWP have shown anthelmintic activity and reduced establishment of GIN in multiple studies, the potential use is limited. Copper must be used cautiously in sheep because they are at high risk for copper toxicosis when levels build up in the liver (Terrill et al., 2012; Burke et al., 2016; Kearney et al., 2016); for this reason only one minimal dose per year is recommended (Fleming et al., 2006). Goats are browsers and have a higher tolerance for copper compared to sheep, as browse plants tend to have higher copper levels (Kearney et al., 2016). For this reason, toxicosis is likely not a concern in goats, and they could potentially receive higher or more frequent doses than sheep could (Fleming et al., 2006).

Nematophagous Fungi

Nematophagous fungi, such as Duddingtonia flagrans, have also been extensively studied as a form of biological control to target the free-living stages of parasites. Duddingtonia flagrans is a predacious fungus which has the ability to trap and destroy nematode larvae (Larsen et al., 1998; Jackson and Miller, 2006). Most research related to biological control of GIN through the use of fungi has focused on $D$. flagrans due to its particular ability to produce abundant, thick-walled intercalary chlamydospores which allow for passage through the gut of grazing livestock (Waller et al., 1994; Larsen et al., 
1998). When spores are fed to animals they are deposited in the feces of the animal after passing through the digestive tract, where they can then trap and kill larvae in order to reduce pasture contamination (Jackson and Miller, 2006; Terrill et al., 2012).

Multiple studies conducted have shown that supplementation of $D$. flagrans results in substantial $(>80 \%)$ reduction of both infective larvae collected from feces as well as reduction of infective larvae on pasture (Waller et al., 1994; Larsen et al., 1998; Waller et al., 2001; Chandrawathani et al., 2004). Dose responses have been demonstrated, however, and continuous feeding of $D$. flagrans is needed throughout the grazing season in order for sustained effects (Larsen et al., 1998; Ketzis et al., 2006). This has been seen as a potential drawback to using $D$. flagrans as a control method, due to the impracticality of daily dosage for animals out on pasture. Suggestions have been made for administration methods, such as voluntary block feeding, which showed significant reductions of larval numbers in fecal cultures in sheep with even modest and irregular block consumption (Waller et al., 2001). A recent study in Australia to determine the effects of an investigational supplement known as Bioworma (providing $3 \times 10^{4}$ viable chlamydospores of $D$. flagrans strain IAH 1297/kg bodyweight (b.w.)/ day), showed a decreased number of parasitic nematode larvae on pasture and in turn, lower infections found in tracer-lambs grazing on the pasture (Healey et al., 2018). This study still did not address the impracticality of daily dosage, as the supplement had to be fed to the sheep daily for proper dosage. A bolus administration that would allow a 
slow, extended release of fungal spores to be released could be a potential option to improve the practicality of this control method (Fleming et al., 2006). Anthelmintic plants

Previous research has shown that condensed tannins, also known as proanthocyanidins, can have an anthelmintic effect on GIN (Lange et al., 2006; Gujja et al., 2013). The discovery that plant secondary compounds, including proanthocyanidins (PAC), suppress GIN infections has provided promise for alternative methods of GIN control (Hoste et al., 2006). A warm-season perennial legume, sericea lespedeza (Lespedeza cuneata), has been extensively researched and found to have anti-parasitic effects (Lange et al., 2006; Shaik et al., 2006; Terrill et al., 2012; Gujja et al., 2013). Previous feeding trials have shown that consumption of sericea lespedeza can reduce fecal egg counts by 67-98\% (Lange et al. 2006; Gujja et al. 2013), while also reducing the abomasal worm count of $H$. contortus (Shaik et al. 2006; Lange et al. 2006). Research has also provided evidence of decreased fecal egg counts in sheep grazing on other PAC-containing plants such as birdsfoot trefoil (Lotus corniculatus), big trefoil (Lotus pedunculatus), sulla (Hedysarum coronarium) and sainfoin (Onobrychis viciifolia) (Niezen et al., 2002a; Niezen et al., 2002b; Marley et al., 2003; Hoste et al., 2015). Although research has focused mostly on tanniniferous plants, other bioactive forages have shown anthelmintic properties as well. Sheep grazing chicory (Cichorium intybus) have shown decreased fecal egg counts and adult worm burdens when compared to sheep on grass/clover pasture (Marley et al., 2003; Tzamaloukas 
et al., 2005; Ketzis et al., 2006; Houdijk et al., 2012). This evidence suggests that there are multiple bioactive compounds in plants that demonstrate anthelmintic activity, although the mechanisms behind the activity are not well understood.

The American Cranberry (Vaccinium macrocarpon)

\section{Cranberry industry}

Gastrointestinal nematode infection is one of the main causes of production constraint in tropical, developing countries (Hounzangbe-Adote et

al., 2005; Marie-Magdeleine et al., 2009; Kamaraj and Rahuman, 2011) where many of the plants that have been studied for their anthelmintic properties are grown. Unfortunately, the climate in the Northeast United States is not suitable for these plants because they cannot survive harsh winter conditions, making them impractical to use in New England. The American cranberry (Vaccinium macrocarpon), native to the United States, is grown extensively in Massachusetts, New Jersey, Wisconsin and Oregon (Suhayda et al., 2009). The cranberry contains an abundance of bioactive compounds including proanthocyanidins (PAC), anthocyanins, flavonols, and phenolic acid (Côté et al., 2010; Feliciano et al., 2016) and has been shown to have many health benefits in mammals including bacterial anti-adhesion (Howell, 2007), inhibition of tumor growth (Neto et al., 2006), decreased risk of cardiovascular disease (Porter et al., 2001), and inhibition of certain gastrointestinal diseases (Su et al., 2010; Feliciano et al., 2012). The cranberry vines (stems and 
leaves) where the fruit grows contain high levels of bioactive compounds including PAC and bioactive compounds as well (Barone et al., 2018). When cranberry bogs come out of winter dormancy there is an annual pruning of vines to prepare for the next growing season, providing a readily available source of the vines which are not currently marketed (Sandler and DeMoranville, 2009; Suhayda et al., 2009). For these reasons, cranberry vines are an ideal test candidate as an alternative anthelmintic option for Northeast producers of small ruminants.

In vitro/In vivo screening results

The use of cranberry vines as an alternative anthelmintic has been investigated recently as an option for northeast producers. A study by Barone et al. (2018) provided in vitro evidence of anthelmintic activity of CV-PAC organic extracts as well as $\mathrm{CV}$ aqueous extracts (CV-AqE) against Haemonchus contortus L1 and adult worm motility and some activity of CVAqE against egg hatching (Barone et al., 2018). These results suggest that the PAC in the cranberry vines is not the only bioactive compound present and responsible alone for the anti-parasitic effects. A preliminary in vivo study was also carried out to determine the effects of oral administration of CV on lambs infected with $H$. contortus, showing a suppression of FEC in the first two weeks post-treatment with CV (Barone et al., 2018). Due to the promising in vitro and in vivo results from the Barone et al. study (2018), further testing to evaluate the in vivo effects of cranberry vine on GIN through feeding trials is warranted and form the basis for the current study. 
Summary and conclusion

Previous studies suggest that both cranberry and cranberry vines can have health benefits due to their abundance of bioactive compounds. The purpose of this research is to further explore this phenomenon and to potentially find an alternative and sustainable GIN control method available for small ruminant producers in the northeast United States.

\section{References}

Aldridge, M. E., J. E. Fearon, B. P. Haynes, H. M. Miller, K. Y. Sanford, R. R. Scott, W. W. Anglin, L. S. Blalock, B. L. Burkes, O. L. Cohn-White, B. R. Franks, H. M. Giles, A. L. Greene, R. D. Hanby, A. G. Holliman, J. M. Kirby, A. W. Klein, C. A. Lehmann, G. J. Llyod, C. T. Lore, T. B. McMurray, Z. V. Moody, B. N. Palmer, L. V. Pansano, R. M. Pickle, L. M. Schaeffer, J. R. Seidl, J. D. Smith, H. F. Stepp, F. A. Satrio, N. A. Kutchy, E. Dechert, C. Rutherford, K. Brown, B. Purwantara, and E. Memili. 2018. Review: Solutions for Grand Challenges in Goat and Sheep Production Industry. BIOTROPIA - The Southeast Asian Journal of Tropical Biology. 26:41-49.

Bang, K. S., A. S. Familton, and A. R. Sykes. 1990. Effect of copper oxide wire particle treatment on establishment of major gastrointestinal nematodes in lambs. Res. Vet. Sci. 49:132-137.

Barone, C. D., A. M. Zajac, L. A. Manzi-Smith, A. B. Howell, J. D. Reed, C. G. Krueger, and K. H. Petersson. 2018. Anthelmintic efficacy of cranberry vine extracts on ovine Haemonchus contortus. Vet. Parasitol. 253:122129.

Bernués, A., G. Ripoll, and B. Panea. 2012. Consumer segmentation based on convenience orientation and attitudes towards quality attributes of lamb meat. Food Qual. Prefer. 26:211-220. 
Besier, R. B. 2012. Refugia-based strategies for sustainable worm control: factors affecting the acceptability to sheep and goat owners. Vet. Parasitol. 186:2-9.

Bown, D. P. Poppi, and Sykes, A. R. (Lincoln College, Canterbury (New Zealand). Animal and Veterinary Sciences Group). 1991. The effect of post-ruminal infusion of protein or energy on the pathophysiology of Trichostrongylus colubriformis infection and body composition in lambs. Aust. J. Agric. Res. 42. Available from: http://agris.fao.org/agrissearch/search.do?recordID=AU9101405

Burke, J. M., J. E. Miller, D. D. Olcott, B. M. Olcott, and T. H. Terrill. 2004. Effect of copper oxide wire particles dosage and feed supplement level on Haemonchus contortus infection in lambs. Vet. Parasitol. 123:235243.

Burke, J. M., J. E. Miller, T. H. Terrill, E. Smyth, and M. Acharya. 2016. Examination of commercially available copper oxide wire particles in combination with albendazole for control of gastrointestinal nematodes in lambs. Vet. Parasitol. 215:1-4.

Capitini, L. A., K. E. McClure, and R. P. Herd. 1990. Effect of environmental stimuli on pre-infective and infective stages of Haemonchus contortus in the northern United States for the induction of hypobiosis. Vet. Parasitol. 35:281-293.

Chandrawathani, P., O. Jamnah, M. Adnan, P. J. Waller, M. Larsen, and A. T. Gillespie. 2004. Field studies on the biological control of nematode parasites of sheep in the tropics, using the microfungus Duddingtonia flagrans. Vet. Parasitol. 120:177-187.

Chartier, C., E. Etter, H. Hoste, I. Pors, C. Koch, and B. Dellac. 2000. E, cacy of Copper Oxide Needles for the Control of Nematode Parasites in Dairy Goats. Vet. Res. Commun. 24:389-399.

Chikwanha, O. C., P. Vahmani, V. Muchenje, M. E. R. Dugan, and C. Mapiye. 2018. Nutritional enhancement of sheep meat fatty acid profile for human health and wellbeing. Food Res. Int. 104:25-38.

Conder, G. A., and S. S. Johnson. 1996. Viability of infective larvae of Haemonchus contortus, Ostertagia ostertagi, and Trichostrongylus colubriformis following exsheathment by various techniques. J. Parasitol. 82:100-102.

Côté, J., S. Caillet, G. Doyon, J.-F. Sylvain, and M. Lacroix. 2010. Analyzing cranberry bioactive compounds. Crit. Rev. Food Sci. Nutr. 50:872-888. 
Crook, E. K., D. J. O'Brien, S. B. Howell, B. E. Storey, N. C. Whitley, J. M. Burke, and R. M. Kaplan. 2016. Prevalence of anthelmintic resistance on sheep and goat farms in the mid-Atlantic region and comparison of in vivo and in vitro detection methods. Small Rumin. Res. 143:89-96.

da Cruz, D. G., L. O. da Rocha, S. S. Arruda, J. G. B. Palieraqui, R. C. Cordeiro, E. Santos Jr, M. B. Molento, and C. de P. Santos. 2010. Anthelmintic efficacy and management practices in sheep farms from the state of Rio de Janeiro, Brazil. Vet. Parasitol. 170:340-343.

Emery, D. L., P. W. Hunt, and L. F. Le Jambre. 2016. Haemonchus contortus: the then and now, and where to from here? Int. J. Parasitol. 46:755769 .

Falzon, L. C., P. I. Menzies, K. P. Shakya, A. Jones-Bitton, J. Vanleeuwen, J. Avula, H. Stewart, J. T. Jansen, M. A. Taylor, J. Learmount, and A. S. Peregrine. 2013. Anthelmintic resistance in sheep flocks in Ontario, Canada. Vet. Parasitol. 193:150-162.

Feliciano, R. P., A. Boeres, L. Massacessi, G. Istas, M. R. Ventura, C. Nunes Dos Santos, C. Heiss, and A. Rodriguez-Mateos. 2016. Identification and quantification of novel cranberry-derived plasma and urinary (poly)phenols. Arch. Biochem. Biophys. 599:31-41.

Feliciano, R. P., M. P. Shea, D. Shanmuganayagam, C. G. Krueger, A. B. Howell, and J. D. Reed. 2012. Comparison of isolated cranberry (Vaccinium macrocarpon Ait.) proanthocyanidins to catechin and procyanidins $\mathrm{A} 2$ and $\mathrm{B} 2$ for use as standards in the 4(dimethylamino)cinnamaldehyde assay. J. Agric. Food Chem. 60:45784585.

Fleming, S. A., T. Craig, R. M. Kaplan, J. E. Miller, C. Navarre, and M. Rings. 2006. Anthelmintic Resistance of Gastrointestinal Parasites in Small Ruminants. J. Vet. Intern. Med. 20:435-444.

Fontenot, M. E., J. E. Miller, M. T. Peña, M. Larsen, and A. Gillespie. 2003. Efficiency of feeding Duddingtonia flagrans chlamydospores to grazing ewes on reducing availability of parasitic nematode larvae on pasture. Vet. Parasitol. 118:203-213.

Geurden, T., H. Hoste, P. Jacquiet, D. Traversa, S. Sotiraki, A. Frangipane di Regalbono, N. Tzanidakis, D. Kostopoulou, C. Gaillac, S. Privat, A. Giangaspero, C. Zanardello, L. Noé, B. Vanimisetti, and D. Bartram. 2014. Anthelmintic resistance and multidrug resistance in sheep gastro- 
intestinal nematodes in France, Greece and Italy. Vet. Parasitol. 201:59-66.

Githiori, J. B., S. Athanasiadou, and S. M. Thamsborg. 2006. Use of plants in novel approaches for control of gastrointestinal helminths in livestock with emphasis on small ruminants. Vet. Parasitol. 139:308-320.

Gujja, S., T. H. Terrill, J. A. Mosjidis, J. E. Miller, A. Mechineni, D. S. Kommuru, S. A. Shaik, B. D. Lambert, N. M. Cherry, and J. M. Burke. 2013. Effect of supplemental sericea lespedeza leaf meal pellets on gastrointestinal nematode infection in grazing goats. Vet. Parasitol. 191:51-58.

Healey, K., C. Lawlor, M. R. Knox, M. Chambers, and J. Lamb. 2018. Field evaluation of Duddingtonia flagrans IAH 1297 for the reduction of worm burden in grazing animals: Tracer studies in sheep. Vet. Parasitol. 253:48-54.

Hoste, H., F. Jackson, S. Athanasiadou, S. M. Thamsborg, and S. O. Hoskin. 2006. The effects of tannin-rich plants on parasitic nematodes in ruminants. Trends Parasitol. 22:253-261.

Hoste, H., J. F. J. Torres-Acosta, C. A. Sandoval-Castro, I. Mueller-Harvey, S. Sotiraki, H. Louvandini, S. M. Thamsborg, and T. H. Terrill. 2015. Tannin containing legumes as a model for nutraceuticals against digestive parasites in livestock. Vet. Parasitol. 212:5-17.

Houdijk, J. G. M., I. Kyriazakis, A. Kidane, and S. Athanasiadou. 2012. Manipulating small ruminant parasite epidemiology through the combination of nutritional strategies. Vet. Parasitol. 186:38-50.

Hounzangbe-Adote, M. S., V. Paolini, I. Fouraste, K. Moutairou, and H. Hoste. 2005. In vitro effects of four tropical plants on three life-cycle stages of the parasitic nematode, Haemonchus contortus. Res. Vet. Sci. 78:155160.

Howell, A. B. 2007. Bioactive compounds in cranberries and their role in prevention of urinary tract infections. Mol. Nutr. Food Res. 51:732-737.

Howell, S. B., J. M. Burke, J. E. Miller, T. H. Terrill, E. Valencia, M. J. Williams, L. H. Williamson, A. M. Zajac, and R. M. Kaplan. 2008. Prevalence of anthelmintic resistance on sheep and goat farms in the southeastern United States. J. Am. Vet. Med. Assoc. 233:1913-1919.

http://bio390parasitology.blogspot.com/2012/03/haemonchus-contortus-bitein-gut.html. (2019). [image]. 
Hubert, J., and D. Kerboeuf. 1984. A new method for culture of larvae used in diagnosis of ruminant gastrointestinal strongylosis: comparison with fecal cultures. Can. J. Comp. Med. 48:63-71.

Hubert, J., and D. Kerboeuf. 1992. A microlarval development assay for the detection of anthelmintic resistance in sheep nematodes. Vet. Rec. 130:442-446.

Jackson, F., and J. Miller. 2006. Alternative approaches to control--quo vadit? Vet. Parasitol. 139:371-384.

Kamaraj, C., and A. A. Rahuman. 2011. Efficacy of anthelmintic properties of medicinal plant extracts against Haemonchus contortus. Res. Vet. Sci. 91:400-404.

Kaplan, R. M. 2004. Drug resistance in nematodes of veterinary importance: a status report. Trends Parasitol. 20:477-481.

Kaplan, R. M., and A. N. Vidyashankar. 2012. An inconvenient truth: global worming and anthelmintic resistance. Vet. Parasitol. 186:70-78.

Kearney, P. E., P. J. Murray, J. M. Hoy, M. Hohenhaus, and A. Kotze. 2016. The "Toolbox" of strategies for managing Haemonchus contortus in goats: What's in and what's out. Vet. Parasitol. 220:93-107.

Ketzis, J. K., J. Vercruysse, B. E. Stromberg, M. Larsen, S. Athanasiadou, and J. G. M. Houdijk. 2006. Evaluation of efficacy expectations for novel and non-chemical helminth control strategies in ruminants. Vet. Parasitol. 139:321-335.

Knox, M. R. 2002. Effectiveness of copper oxide wire particles for Haemonchus contortus control in sheep. Aust. Vet. J. 80:224-227.

Lange, K. C., D. D. Olcott, J. E. Miller, J. A. Mosjidis, T. H. Terrill, J. M. Burke, and M. T. Kearney. 2006. Effect of sericea lespedeza (Lespedeza cuneata) fed as hay, on natural and experimental Haemonchus contortus infections in lambs. Vet. Parasitol. 141:273-278.

Larsen, M., M. Faedo, P. J. Waller, and D. R. Hennessy. 1998. The potential of nematophagous fungi to control the free-living stages of nematode parasites of sheep: studies with Duddingtonia flagrans. Vet. Parasitol. 76:121-128. 
Leathwick, D. M., and R. B. Besier. 2014. The management of anthelmintic resistance in grazing ruminants in Australasia--strategies and experiences. Vet. Parasitol. 204:44-54.

Lindqvist, A., B. L. Ljungström, O. Nilsson, and P. J. Waller. 2001. The dynamics, prevalence and impact of nematode infections in organically raised sheep in Sweden. Acta Vet. Scand. 42:377-389.

Marie-Magdeleine, C., H. Hoste, M. Mahieu, H. Varo, and H. Archimede. 2009. In vitro effects of Cucurbita moschata seed extracts on Haemonchus contortus. Vet. Parasitol. 161:99-105.

Marley, C. L., R. Cook, R. Keatinge, J. Barrett, and N. H. Lampkin. 2003. The effect of birdsfoot trefoil (Lotus corniculatus) and chicory (Cichorium intybus) on parasite intensities and performance of lambs naturally infected with helminth parasites. Vet. Parasitol. 112:147-155.

Martínez Ortiz de Montellano, C., J. J. Vargas-Magaña, A. J. AguilarCaballero, C. A. Sandoval-Castro, L. Cob-Galera, M. May-Martínez, R. Miranda-Soberanis, H. Hoste, R. Cámara Sarmiento, and J. F. J. Torres-Acosta. 2007. Combining the effects of supplementary feeding and copper oxide needles for the control of gastrointestinal nematodes in browsing goats. Vet. Parasitol. 146:66-76.

McKellar, Q. A., and F. Jackson. 2004. Veterinary anthelmintics: old and new. Trends Parasitol. 20:456-461.

McKenna, P. B. 2010. Update on the prevalence of anthelmintic resistance in gastrointestinal nematodes of sheep in New Zealand. N. Z. Vet. J. 58:172-173.

Montossi, F., M. Font-i-Furnols, M. del Campo, R. San Julián, G. Brito, and C. Sañudo. 2013. Sustainable sheep production and consumer preference trends: compatibilities, contradictions, and unresolved dilemmas. Meat Sci. 95:772-789.

Neto, C. C., C. G. Krueger, T. L. Lamoureaux, M. Kondo, A. J. Vaisberg, R. A. R. Hurta, S. Curtis, M. D. Matchett, H. Yeung, M. I. Sweeney, and J. D. Reed. 2006. MALDI-TOF MS characterization of proanthocyanidins from cranberry fruit (Vaccinium macrocarpon) that inhibit tumor cell growth and matrix metalloproteinase expressionin vitro. J. Sci. Food Agric. 86:18-25.

Nieuwhof, G. J., and S. C. Bishop. 2005. Costs of the major endemic diseases of sheep in Great Britain and the potential benefits of reduction in disease impact. Anim. Sci. 81:23-29. 
Niezen, J. H., W. A. G. Charleston, H. A. Robertson, D. Shelton, G. C. Waghorn, and R. Green. 2002a. The effect of feeding sulla (Hedysarum coronarium) or lucerne (Medicago sativa) on lamb parasite burdens and development of immunity to gastrointestinal nematodes. Vet. Parasitol. 105:229-245.

Niezen, J. H., G. C. Waghorn, T. Graham, J. L. Carter, and D. M. Leathwick. 2002b. The effect of diet fed to lambs on subsequent development of Trichostrongylus colubriformis larvae in vitro and on pasture. Vet. Parasitol. 105:269-283.

Nikolaou, S., and R. B. Gasser. 2006. Prospects for exploring molecular developmental processes in Haemonchus contortus. Int. J. Parasitol. 36:859-868.

O'Connor, L. J., S. W. Walkden-Brown, and L. P. Kahn. 2006. Ecology of the free-living stages of major trichostrongylid parasites of sheep. Vet. Parasitol. 142:1-15.

Ortolani, E. L., M. L. do R. Leal, A. H. H. Minervino, A. R. Aires, R. L. Coop, F. Jackson, and N. F. Suttle. 2013. Effects of parasitism on cellular immune response in sheep experimentally infected with Haemonchus contortus. Vet. Parasitol. 196:230-234.

Ploeger, H. W., and R. R. Everts. 2018. Alarming levels of anthelmintic resistance against gastrointestinal nematodes in sheep in the Netherlands. Vet. Parasitol. 262:11-15.

Porter, M. L., C. G. Krueger, D. A. Wiebe, D. G. Cunningham, and J. D. Reed. 2001. Cranberry proanthocyanidins associate with low-density lipoprotein and inhibit in vitro Cu2+-induced oxidation. J. Sci. Food Agric. 81:1306-1313.

Qamar, M. F., A. Maqbool, and N. Ahmad. 2011. Economic losses due to haemonchosis in sheep and goats. Sci. Int. . 23:321-324.

Rabel, B., R. McGregor, and P. G. Douch. 1994. Improved bioassay for estimation of inhibitory effects of ovine gastrointestinal mucus and anthelmintics on nematode larval migration. Int. J. Parasitol. 24:671676.

Roeber, F., A. R. Jex, and R. B. Gasser. 2013. Impact of gastrointestinal parasitic nematodes of sheep, and the role of advanced molecular tools for exploring epidemiology and drug resistance - an Australian perspective. Parasit. Vectors. 6:153. 
Sandler, H. A., and C. J. DeMoranville. 2009. Economic Analysis of Nitrogen Rate on Vine Production and Fruit Yield of Pruned Cranberry Beds. Horttechnology. 572-579.

Sangster, N. C. 2001. Managing parasiticide resistance. Vet. Parasitol. 98:89109.

Santos, M. C., J. K. Xavier, M. R. V. Amarante, C. C. Bassetto, and A. F. T. Amarante. 2014. Immune response to Haemonchus contortus and Haemonchus placei in sheep and its role on parasite specificity. Vet. Parasitol. 203:127-138.

Sargison, N. D., F. Jackson, D. J. Bartley, D. J. Wilson, L. J. Stenhouse, and C. D. Penny. 2007. Observations on the emergence of multiple anthelmintic resistance in sheep flocks in the south-east of Scotland. Vet. Parasitol. 145:65-76.

Schönfeldt, H. C., R. T. Naudé, W. Bok, S. M. van Heerden, R. Smit, and E. Boshoff. 1993. Flavour- and tenderness-related quality characteristics of goat and sheep meat. Meat Sci. 34:363-379.

Shaik, S. A., T. H. Terrill, J. E. Miller, B. Kouakou, G. Kannan, R. M. Kaplan, J. M. Burke, and J. A. Mosjidis. 2006. Sericea lespedeza hay as a natural deworming agent against gastrointestinal nematode infection in goats. Vet. Parasitol. 139:150-157.

Silveira, R. X., A. C. S. Chagas, M. B. Botura, M. J. M. Batatinha, L. M. Katiki, C. O. Carvalho, C. M. L. Bevilaqua, A. Branco, E. A. A. Machado, S. L. Borges, and M. A. O. Almeida. 2012. Action of sisal (Agave sisalana, Perrine) extract in the in vitro development of sheep and goat gastrointestinal nematodes. Exp. Parasitol. 131:162-168.

Šimpraga, M., I. Ljubičić, J. P. Hlede, A. S. Vugrovečki, A. Marinculić, and S. Tkalčić. 2015. Alternative approaches for the control of gastrointestinal nematodes in sheep farming: a review. Berl. Munch. Tierarztl. Wochenschr. 128:257-270.

Sommerville, R. I., and K. G. Davey. 2002. Diapause in parasitic nematodes: a review. Can. J. Zool. 80:1817-1840.

Suhayda, B., C. J. DeMoranville, H. A. Sandler, W. R. Autio, and J. E. Vanden Heuvel. 2009. Sanding and Pruning Differentially Impact Canopy Characteristics, Yield, and Economic Returns in Cranberry. Horttechnology. 796-802. 
Su, X., A. B. Howell, and D. H. D'Souza. 2010. The effect of cranberry juice and cranberry proanthocyanidins on the infectivity of human enteric viral surrogates. Food Microbiol. 27:535-540.

Terrill, T. H., J. E. Miller, J. M. Burke, J. A. Mosjidis, and R. M. Kaplan. 2012. Experiences with integrated concepts for the control of Haemonchus contortus in sheep and goats in the United States. Vet. Parasitol. 186:28-37.

Torres-Acosta, J. F. J., and H. Hoste. 2008. Alternative or improved methods to limit gastro-intestinal parasitism in grazing sheep and goats. Small Rumin. Res. 77:159-173.

Traversa, D., and G. von Samson-Himmelstjerna. 2016. Anthelmintic resistance in sheep gastro-intestinal strongyles in Europe. Small Rumin. Res. 135:75-80.

Tsotetsi, A. M., S. Njiro, T. C. Katsande, G. Moyo, F. Baloyi, and J. Mpofu. 2013. Prevalence of gastrointestinal helminths and anthelmintic resistance on small-scale farms in Gauteng Province, South Africa. Trop. Anim. Health Prod. 45:751-761.

Tzamaloukas, O., S. Athanasiadou, I. Kyriazakis, F. Jackson, and R. L. Coop. 2005. The consequences of short-term grazing of bioactive forages on established adult and incoming larvae populations of Teladorsagia circumcincta in lambs. Int. J. Parasitol. 35:329-335.

USDA, National Agricultural Statistics Service. 2011. USDA Sheep Industry Overview.

USDA. 2015. "Sheep and Lamb Predator and Nonpredator Death Loss in the United States, 2015." USDA-APHIS-VS-CEAH-NAHMS Fort Collins, CO \#721.0915

USDA, National Agricultural Statistics Service. 2019. Sheep and goats (February 2019).

Veríssimo, C. J., S. C. M. Niciura, A. L. L. Alberti, C. F. C. Rodrigues, C. M. P. Barbosa, D. P. Chiebao, D. Cardoso, G. S. da Silva, J. R. Pereira, L. F. F. Margatho, R. L. D. da Costa, R. F. Nardon, T. E. H. Ueno, V. C. L. M. Curci, and M. B. Molento. 2012. Multidrug and multispecies resistance in sheep flocks from São Paulo state, Brazil. Vet. Parasitol. 187:209216. 
Wagland, B. M., W. O. Jones, L. Hribar, T. Bendixsen, and D. L. Emery. 1992. A new simplified assay for larval migration inhibition. Int. J. Parasitol. 22:1183-1185.

Waller, P. J., G. Bernes, L. Rudby-Martin, B.-L. Ljungström, and A. Rydzik. 2004. Evaluation of Copper Supplementation to Control Haemonchus contortusInfections of Sheep in Sweden. Acta Vet. Scand. 45:149.

Waller, P. J., M. R. Knox, and M. Faedo. 2001. The potential of nematophagous fungi to control the free-living stages of nematode parasites of sheep: feeding and block studies with Duddingtonia flagrans. Vet. Parasitol. 102:321-330.

Waller, P. J., M. Larsen, M. Faedo, and D. R. Hennessy. 1994. The potential of nematophagous fungi to control the free-living stages of nematode parasites of sheep: in vitro and in vivo studies. Vet. Parasitol. 51:289299.

Williams, A. R., D. G. Palmer, I. H. Williams, P. E. Vercoe, and L. J. E. Karlsson. 2010. Faecal dry matter, inflammatory cells and antibodies in parasite-resistant sheep challenged with either Trichostrongylus colubriformis or Teladorsagia circumcincta. Vet. Parasitol. 170:230237.

Zajac, A. M., N. C. Sangster, and T. G. Geary. 2000. Why veterinarians should care more about parasitology. Parasitol. Today. 16:504-506. 


\title{
CHAPTER 2
}

Effect of pelleted cranberry vine fed to lambs experimentally infected with Haemonchus contortus

by

Bailey Chalut ${ }^{1 *}$, Carly Barone ${ }^{2}$, Anne Zajac ${ }^{3}$, Jess Reed ${ }^{4}$, Christian Krueger ${ }^{4}$ and Katherine Petersson ${ }^{1}$

is prepared for submission to Veterinary Parasitology

\begin{abstract}
Affiliations:
${ }^{1}$ University of Rhode Island, Kingston, RI. ${ }^{2}$ Bia Diagnostics, Colchester, VT.

${ }^{3}$ Virginia Tech, Blacksburg, VA, ${ }^{4}$ University of Wisconsin, Madison, WI.
\end{abstract}




\begin{abstract}
The discovery that plant secondary compounds, including proanthocyanidins (PAC), suppress gastrointestinal nematode (GIN) infections has provided promise for alternative methods of GIN control in small ruminants. Recently a study from our laboratory provided in vitro evidence of anthelmintic activity of cranberry vine (CV) PAC organic extracts as well as CV aqueous extracts (CV-AqE) against Haemonchus contortus L1 and adult worm motility and some activity of CV-AqE against egg hatching. This study aims to expand upon those results to determine anthelmintic efficacy of a CV pellet on infection in lambs. Cranberry vine prunings were obtained and then dried, ground, and incorporated into a $100 \%$ cranberry vine pellet fed to 5-month-old lambs, as a supplement to their normal grain ration, for 6 weeks $(n=7$ per group, $600 \mathrm{~g} \mathrm{CV}$ offered/day). Lambs were initially infected with $5000 \mathrm{H}$. contortus L3, then stratified into two groups ( $\mathrm{CV}$ and control) based on fecal egg counts (FEC), sex, and weight. Lambs were subjected to a trickle infection of $H$. contortus (1000 L3 3x/week) from weeks 0 to 3 of supplementation. Weekly weight, FEC, and packed cell volume (PCV) were determined. After week 6 , the lambs abomasa were collected post mortem and abomasal contents were recovered to quantify total worm burden, sex, and stage of development. Palatability of the $\mathrm{CV}$ varied greatly between lambs with an average consumption of $281 \pm 14 \mathrm{~g}$ (mean \pm SEM; range 166 to $430 \mathrm{~g}$ ) after six weeks of supplementation. This amount was half of what was offered. There was no significant effect of treatment $(p=0.43)$ or treatment by time
\end{abstract}


$(p<0.09)$ on FEC, although the FEC of the two groups did start to diverge at week 5 , and the trial ended prior to determining whether this divergence would reach significance. As would be expected, there was an effect of week on FEC $(p<0.01)$ as the trickle infection matured during the course of the trial. There was no effect of treatment $(p=0.79)$ or treatment by time $(p=0.57)$ on packed cell volume. There was a difference by week $(p<0.001)$ as the PCV decreased over time as the infections matured. Average daily gain over the 6week trial of the two groups was not different $(p=0.52)$. There was a treatment ${ }^{*}$ week effect $(p=0.0003)$; however, all significant changes were found within the control group due to a more rapid gain of weight and there was no significant difference between the treatments at any week. There was no difference in worm burden between control $(3113 \pm 554, \mathrm{n}=7)$ and $\mathrm{CV}$ fed lambs $(2687 \pm 502, n=7)(p=0.58)$. CV has shown anthelmintic potential but further studies are needed to improve palatability to increase consumption. 


\section{Introduction}

Haemonchus contortus, commonly known as the barber pole worm, is the most pathogenic species of gastrointestinal nematode (GIN) infecting small ruminants, causing issues such as anemia, reduced nutrient absorption, production losses, and in severe cases, death. These GIN are a major economic concern for producers worldwide, causing a substantial impact on farm production and profitability (Fontenot et al. 2003; Nieuwhof and Bishop 2005; Besier 2012; Roeber et al. 2013). When compared to other GIN, $H$. contortus is the most fecund, with female worms laying up to 10,000 eggs per day contributing to rapid pasture contamination (Roeber et al., 2013; Kearney et al., 2016). Larval and adult stages of $H$. contortus are found in the abomasum and abomasal mucosa where they consume up to $30 \mu \mathrm{L}$ of blood per day, leading to anemia and in acute cases, death (Emery et al. 2016; Kearney et al. 2016). Due to the pathogenicity and economic impact associated with $H$. contortus, control is a major concern for sheep producers.

Over- and improper use of commercially produced chemical dewormers has led to the development of anthelmintic resistance in $H$. contortus as well as other GIN, creating the need for alternative control methods (Fleming et al. 2006; Jackson and Miller 2006; Howell et al. 2008). In sheep and goats, prevalence of multiple drug resistance is remarkably high, and thus threatens the viability and sustainability of the industries (Kaplan 2004; Cezar et al. 2010; Kaplan and Vidyashankar 2012). The discovery that plant secondary 
compounds, including proanthocyanidins (PAC), suppress GIN infections has shown a possible method for alternative GIN control (Hoste et al. 2006).

The American cranberry (Vaccinium macrocarpon), native to New England, contains high levels of bioactive compounds, including proanthocyanidins (Howell 2007; Côté et al. 2010; Feliciano et al. 2012). Cranberry vines and leaves, also rich in PAC (Ferlemi and Lamari 2016), are pruned off of the bogs when the plants come out of winter dormancy and are generally considered an industry by-product (Suhayda et al. 2009; Sandler and DeMoranville 2009). For these reasons, the vines are an ideal test candidate as an anthelmintic option for northeast sheep producers. Recently a study from our laboratory provided in vitro evidence of anthelmintic activity of cranberry vine (CV) PAC organic extracts as well as CV aqueous extracts (CV-AqE) against $H$. contortus L1 and adult worm motility and some activity of CV-AqE against egg hatching (Barone et al., 2018). This study aims to expand upon these results by testing the anthelmintic efficacy of a cranberry vine pellet in vivo on an adult and larval $H$. contortus experimental infection in Dorset lambs. 


\section{Methods}

\subsection{Preparation of feed}

\subsubsection{Cranberry Vines}

Clippings from bogs of 'Mullica Queen' cranberry owned by the A.D. Makepeace Company (Wareham, MA, USA) were collected following pruning in spring 2017. Pruned vines were transported to the University of Rhode Island, then washed to remove dirt and debris before they were placed into burlap bags, and dried at $22{ }^{\circ} \mathrm{C}$ in cabinet dryers with continuous exhaust. Moisture levels were monitored every other day by calculating weight changes to ensure that the vines were fully dehydrated when removed from the cabinet dryers. Vines were considered to be dry when the weight change was $<1 \%$ from the previous weight recorded.

\subsubsection{Cranberry vine pellet (CVP)}

After drying, the CV was chopped into a powder using a hammer mill (Bison, MM20030000A, Aguascalientes, MX), and sent to Dairy One CoOperative Inc. (Ithaca, NY) for nutritional analysis. Chopped CV was pelleted (Pelletpro, ZS100, Kewanee IL) at Cornell Cooperative Extension (Canton, NY) to create a $100 \%$ CV pellet (CVP).

\subsection{Study subjects}

Feeding trials were conducted with the approval of the Institutional Animal Care and Use Committee (IACUC) of the University of Rhode Island. Dorset lambs born and housed at the University of Rhode Island's Peckham Farm, (Kingston, RI) were used for this study. Lambs were weaned 
and raised indoors under trichostrongylid-free conditions. Lambs were fed $0.91 \mathrm{~kg} /$ day of $16 \%$ crude protein commercially available pelleted grain (Pleasant View Farms, Somers, CT, USA) and $2.5 \mathrm{~kg} /$ day grass hay (Peckham Farm, Kingston, RI, USA) with water available ad libitum until approximately five months of age when the trial began.

\subsection{Study Design}

The study design for this feeding trial is depicted in Figure 1. Fourteen 5-month-old lambs averaging $56 \pm 3 \mathrm{~kg}$, (range 43 to 71 ) were orally administered $5000 \mathrm{H}$. contortus L3 four weeks before the start of the feeding trial. Prior to infection, average FEC for all lambs was determined to be $21 \pm$ 13 eggs per gram (epg). The infection matured for 4 weeks before the lambs were stratified into one of two groups, $n=7$ each, based on FEC, then balanced for sex and weight: control (0 CVP)) and CVP (600g CVP/day). At Day 0 of the feeding trial, control group lambs had an average FEC of $1557 \pm$ $223 \mathrm{epg}$ and CVP lambs had an average FEC of $1507 \pm 280 \mathrm{epg}$. At the start of the feeding trial a trickle infection of $1000 \mathrm{H}$. contortus $\mathrm{L} 3$ three times per week from weeks 0 to 3 (Figure 1) was superimposed upon the lambs existing infection. 


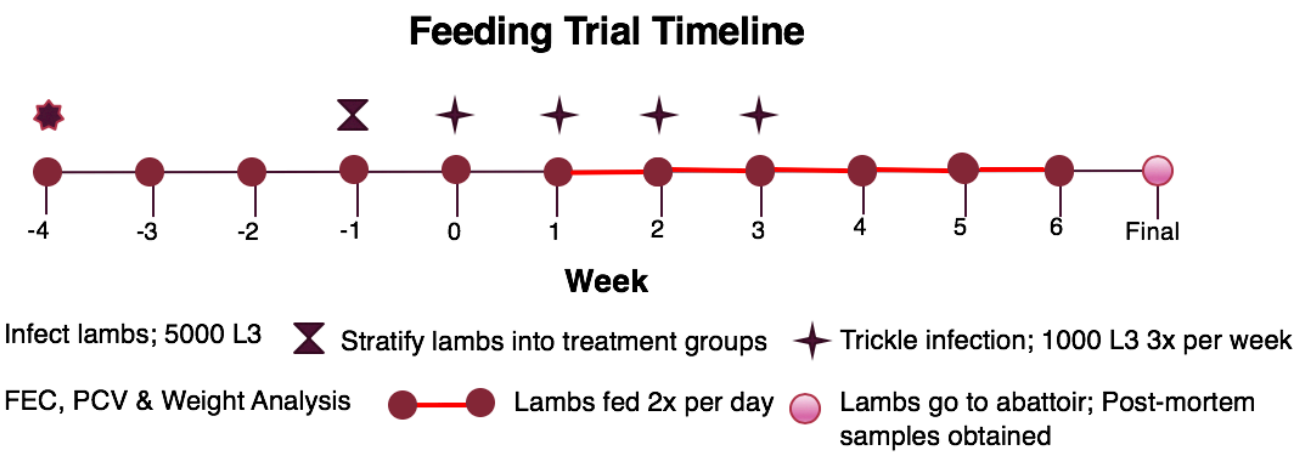

Figure 1. Study Design

Lambs were fed individually either the control $(0 \mathrm{~g}$ CVP) or CVP (300 g CVP) in addition to their daily sheep pellet $(500 \mathrm{~g})$ twice daily for 6 weeks (from W0 to W6). The amount of CVP offered per day (600 g) was roughly 3 times in vitro concentration which demonstrated efficacy against $H$. contortus egg hatch and larval motility based on a rumen volume of eight liters (Barone et al., 2018). Average CVP consumption increased over time, but only reached $281 \pm 14$ (range 166 to 430 ) per day of the $600 \mathrm{~g}$ offered per day after six weeks. FEC, PCV, and weight were measured at week 0 and weekly after the start of the feeding trial for six weeks. At the end of the six-week trial, lambs were sent to the abattoir and abomasal contents were collected for worm recovery, quantification, and identification of developmental stage and sex.

\subsection{Analyses of Feed}

Random grab samples of feed were collected daily to make weekly composite samples of CVP, grain, and hay. Weekly composite samples were used to create a composite sample for the full duration of the trial. Samples were analyzed by Dairy One Cooperative, Inc. (Ithaca, NY, USA) (Table 1). 
Table 1. Nutrient content of composite hay, grain, and cranberry vine pellet samples collected over the study period.

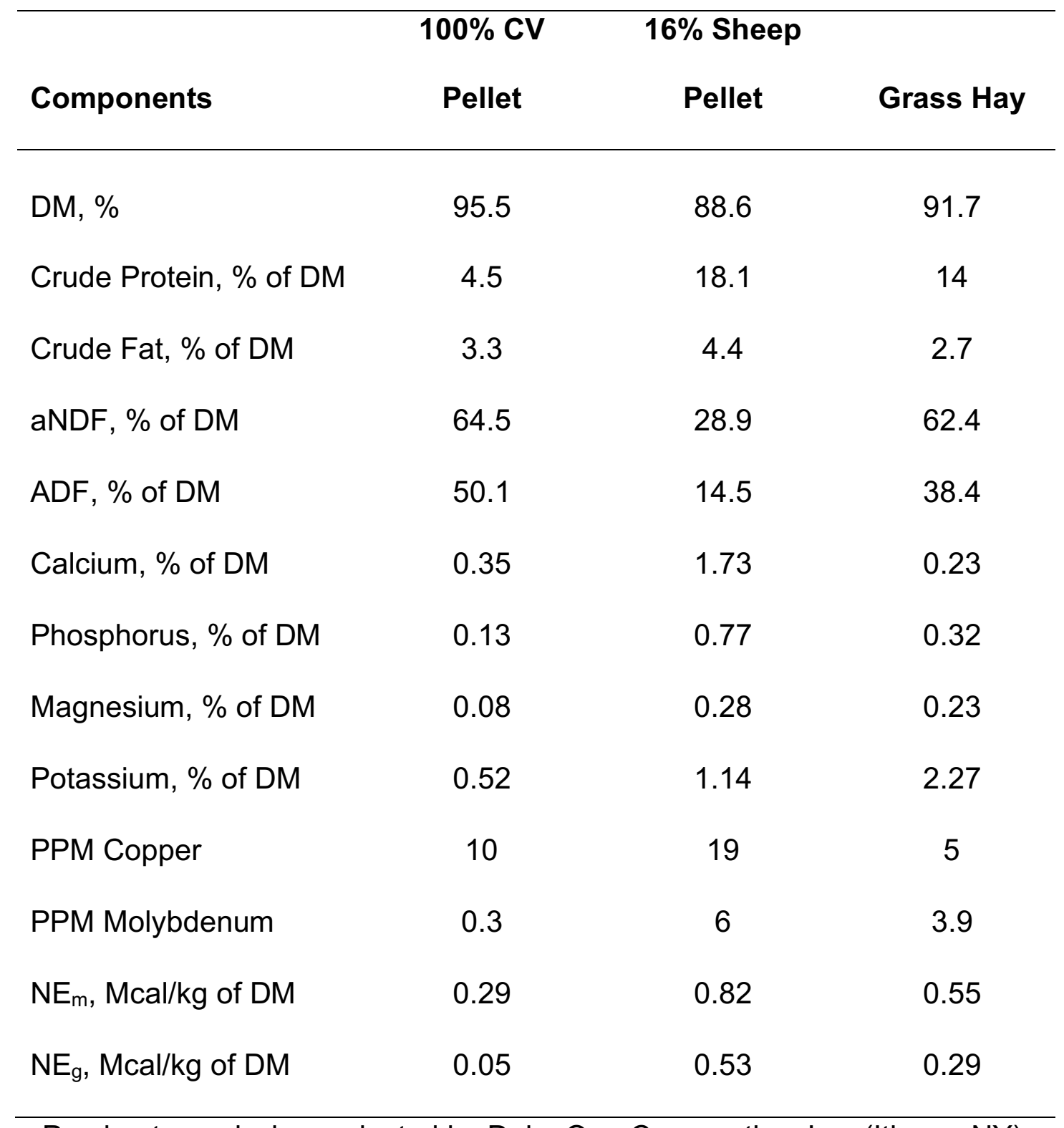

Proximate analysis conducted by Dairy One Cooperative, Inc. (Ithaca, NY). 


\subsection{Parasitology parameters}

\subsubsection{Infective Larvae}

Haemonchus contortus L3 larvae used to infect lambs in this experiment were cultured from the manure of donor lambs that had been infected with larvae originally obtained from Dr. Anne Zajac (Virginia Maryland College of Veterinary Medicine, Blacksburg, Virginia). Prior to infection, larvae were confirmed $>90 \%$ viable by observing motility for five seconds and determining motile or non-motile (Skantar et al., 2005; Katiki et al., 2013). All L3 were stored at $4^{\circ} \mathrm{C}$ for less than three months when used for infection.

\subsubsection{Blood and fecal analysis}

Blood samples were collected weekly via jugular venipuncture into sterile EDTA vacutainer tubes (BD, Franklin Lakes, NJ, USA) and PCV was determined by microhematocrit centrifugation at $35,720 \times \mathrm{g}$ for three minutes within 12 hours of sample collection. Rectal fecal samples were collected weekly for FEC determination according to the modified McMaster technique with a detection limit of 50 epg (Zajac and Conboy, 2012).

\subsubsection{Analysis of parasite burden}

At the abattoir, the abomasum of each lamb was opened along its greater curvature and a 10\% aliquot of the contents were collected and fixed with equal volume of $10 \%$ formalin buffered saline. Total worm burdens were estimated by extrapolating the number of worms in the $10 \%$ aliquots. All counted worms were also sexed. The emptied abomasa were individually soaked overnight in biological saline at $37^{\circ} \mathrm{C}$ to allow immature larvae to 
migrate out of the abomasal folds. A $10 \%$ aliquot of wash contents were collected for quantification of larval burden.

\subsection{Statistical analysis}

Weekly FEC, PCV, and average daily gain were analyzed using a mixed procedure in SAS with repeated measures and means separated with Tukey's post-hoc test (SAS Inc., Cary, NC). Each multi-variable model included terms treatment, week, and two-way interactions. Worm and larval burden were analyzed using a student's t-test in SAS. Significance was defined as $p \leq 0.05$. Results are reported as mean \pm SEM.

\section{Results}

\subsection{Feeding Trial}

\subsubsection{Consumption of CVP}

Consumption of CVP was determined in treatment lambs by monitoring orts for the duration of the trial. Lambs were offered $600 \mathrm{~g}$ of CVP per day as a supplement added to their usual grain ration of $900 \mathrm{~g}$ of $16 \%$ commercially produced pellet. During weeks 0 and 1 , consumption of the pellet was extremely limited, averaging $68 \mathrm{~g}$ of CVP consumed per lamb per day (Figure 2). Palatability of the CVP varied greatly between lambs through the entire trial, with an average consumption of $281 \mathrm{~g}$ (range 166 to 430 ) after six weeks of supplementation, approximately half of the $600 \mathrm{~g}$ that was offered. 


\subsubsection{Effect of CVP on fecal egg counts}

There was no effect of treatment $(p=0.43)$ or treatment by time $(p<0.09)$ although the FEC of the two groups did start to diverge at week 5 , and the trial ended prior to determining whether this divergence would reach significance. As would be expected, there was an effect of week $(p<0.01)$ as the trickle infection matured during the course of the trial.

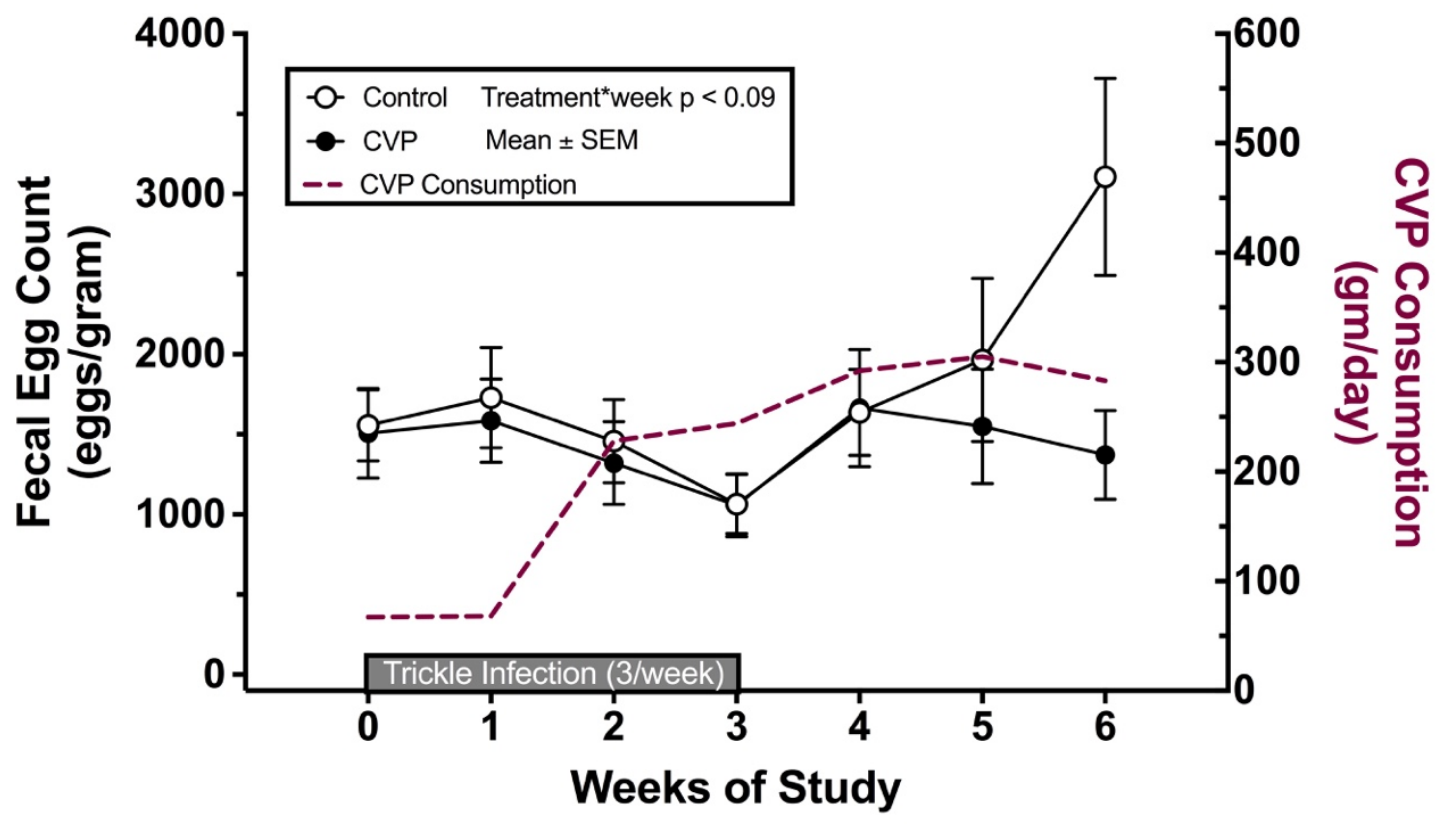

Figure 2. Effect of CVP on weekly FEC of an experimental infection of $H$. contortus. Lambs were orally administered $5000 \mathrm{H}$. contortus L3 four weeks prior to the start of the feeding trial at week 0 . Lambs were fed individually one of two diets: control $(0 \mathrm{~g} \mathrm{CV})$ or CVP $(600 \mathrm{~g} \mathrm{CV})$ for the duration of the trial. Fecal egg counts (eggs per gram) were monitored weekly for the duration of the trial. 


\subsubsection{Effect of CVP on packed cell volume}

There was no effect of treatment (control: $26 \pm 0.4 \%$; CVP: $27 \pm 0.4$; $p=0.79)$ or treatment by time $(p=0.57)$ on PCV. There was a difference by week $(p<0.001)$ as the PCV decreased over time. The PCV across treatments at weeks 0 and 2 was greater than week $5(p \leq 0.02)$; and at weeks 0 through 4 was greater than week $6(p<0.03)$.

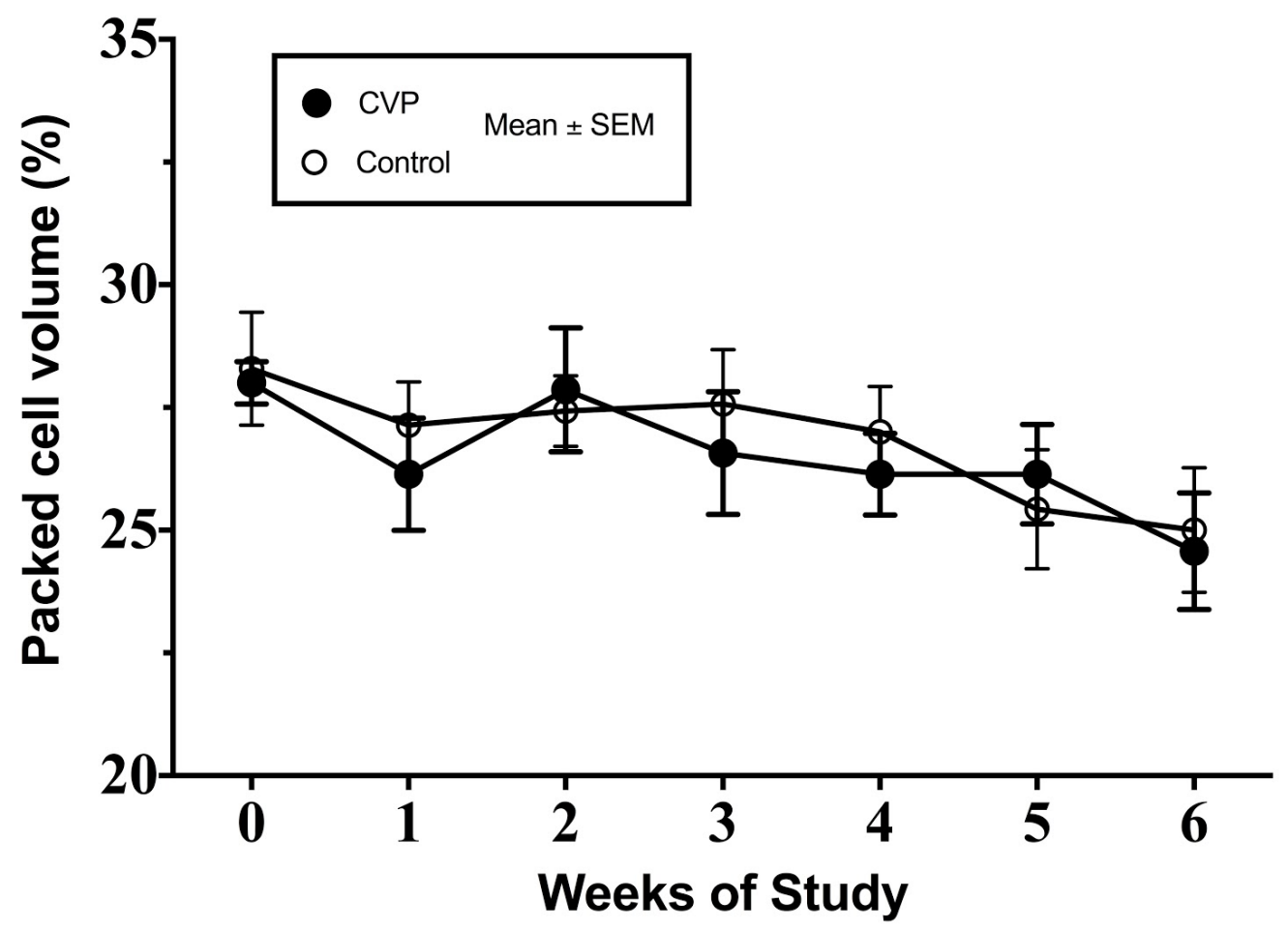

Figure 3. Effect of CVP on packed cell volume of an experimental infection of H. contortus. Lambs were fed individually one of two diets: control $(\mathrm{Og} \mathrm{CV})$ or CVP $(600 \mathrm{~g} \mathrm{CV})$ for the duration of the trial. 


\subsubsection{Effect of CVP on weight and average daily gain}

Average daily gain over the 6 -week trial of control $(0.13 \pm 0.04 \mathrm{~kg} /$ day $)$ and CVP $(0.17 \pm 0.08 \mathrm{~kg} / \mathrm{day})$ groups was not different $(p=0.52)$ when comparing CVP to control. There was a treatment ${ }^{\star}$ week effect $(p=0.0003)$; however, all significant changes were found within the control group due to a more rapid gain of weight (Figure 4). There was no significant difference between the treatments at any week.

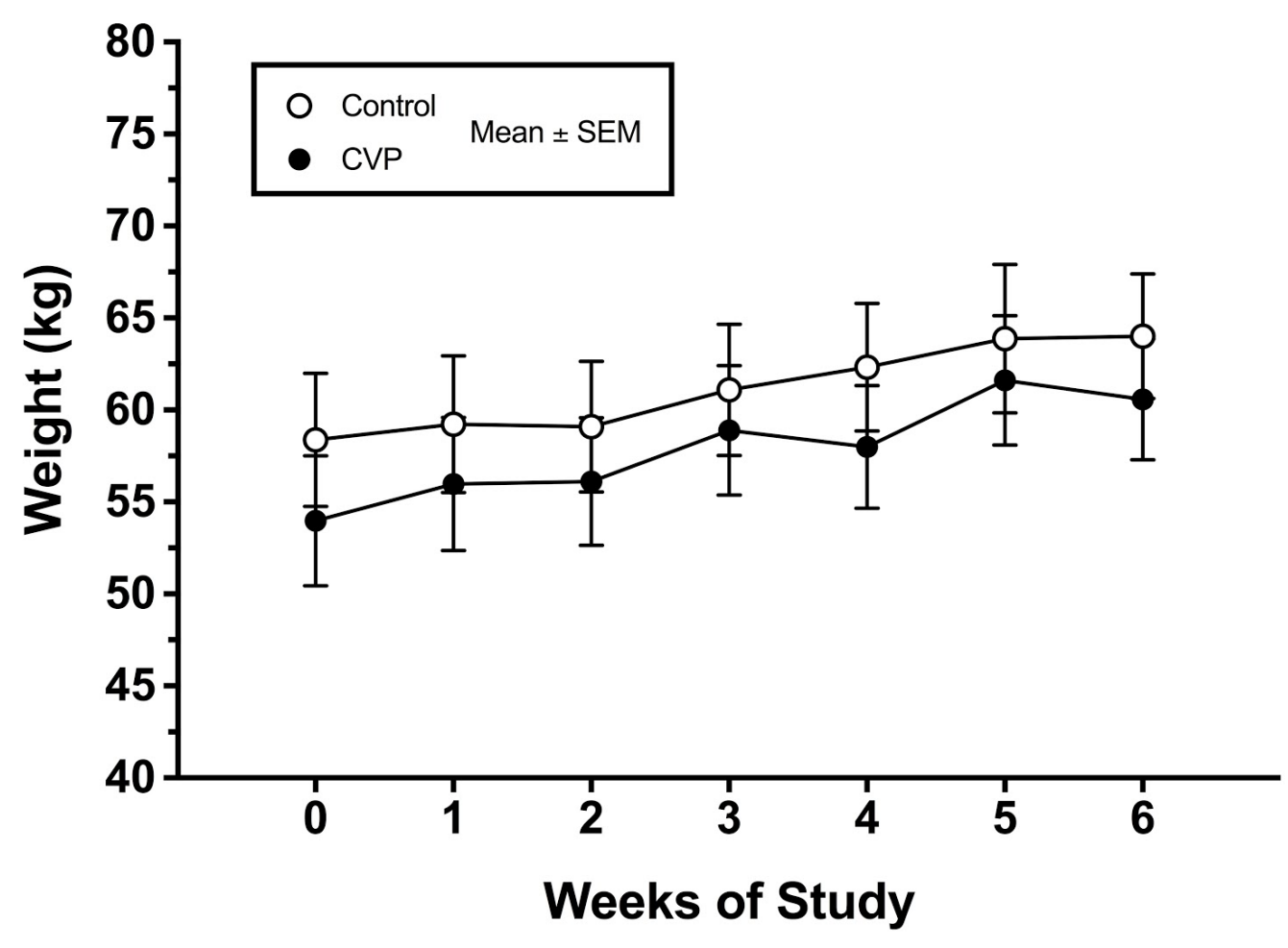

Figure 4. Effect of CVP on weight during an experimental infection of $H$. contortus. Lambs were fed individually one of two diets: control (Og CV) or CVP $(600 \mathrm{~g} \mathrm{CV})$ for the duration of the trial. 


\subsubsection{Effect of CVP on worm burden and larval burden}

The mean number of worms recovered from the control diet lambs was $2179 \pm 55$ worms, and the CVP lambs had a mean of $1881 \pm 50(p=0.58)$ (Figure 5). There was no difference between the percentage of females in the control and CVP groups ( $51 \pm 2$ vs $49 \pm 2$ respectively; $p=0.57$ ). Effect of CVP on larval burden was not included in the results, as counts in soaks of control animals were insignificant, and consequently not completed.

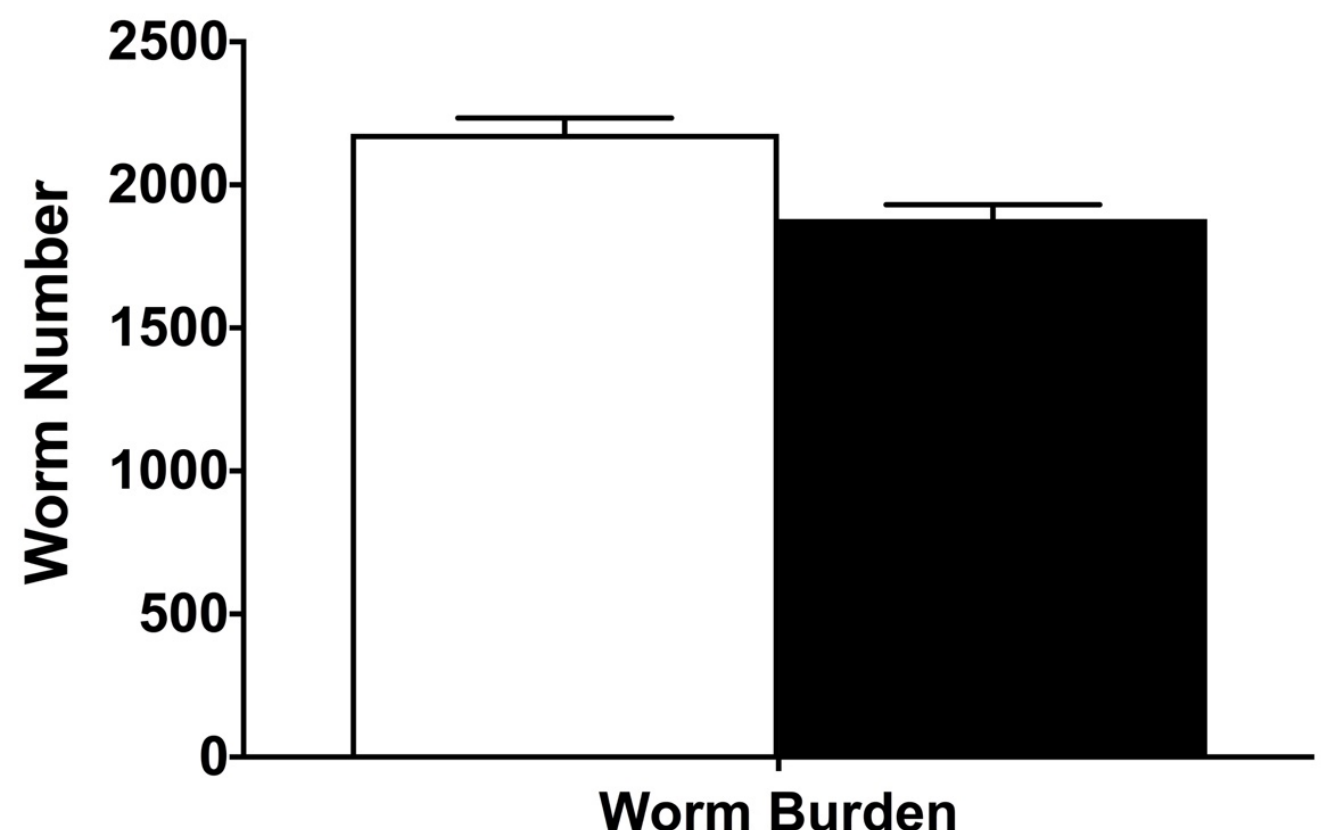

Figure 5. Effect of CVP on adult worm burden (Control-white, CVP-black) during an experimental infection of $H$. contortus $(p=0.58)$. 


\section{Discussion}

Supplementing CVP into the diet had an apparent suppressive effect on FEC by the end of the six-week trial, with no difference observed in PCV or total worm burden. Although palatability of the CVP greatly limited consumption, the results suggest that $\mathrm{CV}$ may have an anti-parasitic effect in vivo. The objective of this study was to expand upon in vitro screening results of cranberry vine extracts which showed anthelmintic activity against L1 and adult worm motility as well as some activity against egg hatching (Barone et al., 2018). The previous study also looked at the effect of orally administered cranberry vine powder, which appeared to produce slight suppression of FEC; however, limited quantities of the powder only allowed for a 3-day treatment therefore dose response or effects of feeding duration could not be investigated (Barone et al., 2018). Experimentally infected lambs were utilized for both the previous and current study. In contrast to the study by Barone et al. (2018), lambs in the current study were subjected to a trickle infection after an initial bolus infection of $H$. contortus $\mathrm{L} 3$. The trickle infection allowed for simulation of reinfection that would occur in natural infections where animals were continuously exposed to low levels of infective larvae on pasture (Pemberton et al., 2012). Additionally, this type of infection subjected several stages of the parasite ( $\mathrm{L} 3$ to adult) to the direct effects of tannin-containing CV pellets, rather than adult stage only which is the case when using a single bolus infection regime. Trickle infections are also suspected to improve 
stimulation of the local host immune response versus a single infection (Arroyo-Lopez et al., 2014).

The results of this study differed from the in vivo results from the study by Barone et al., 2018, where suppression of FEC occurred as early as oneweek post-treatment. In the current study, the treatment and control group FEC did not differ from weeks 0 to 4 , and then diverged at weeks 5 and 6 , approaching significance (treatment ${ }^{*}$ week, $p<0.09$ ), when the control group continued to rise steadily and the treatment group started to decrease. The trend of decreasing FEC in the treatment group at the end of the trial suggests that CV may have an anti-parasitic effect, and may have caused a significant decrease if the trial had continued for additional weeks. Additionally, during weeks 0 and 1 consumption of the pellet was extremely limited, averaging only $68 \mathrm{~g}$ of CVP consumed per lamb per day. Palatability of the CVP varied greatly between lambs throughout the entire trial, with an average consumption of $281 \mathrm{~g}$ (range 166 to 430 ) after six weeks of supplementation, approximately half of the $600 \mathrm{~g}$ that was offered. The amount of CVP offered per day (600 g) was roughly 3 times the in vitro concentration $(20-25 \mathrm{mg} / \mathrm{mL})$ which demonstrated efficacy against $H$. contortus egg hatch and larval motility based on a rumen volume of eight liters (Barone et al., 2018). The amount of CVP consumed in the current study was approximately 1.5 times the effective in vitro concentration; however, this was estimated based on a rumen volume of eight liters and also did not account for the potential breakdown of bioactive compounds in the rumen or due to the pelleting process. The slow acceptance 
of the CVP could have contributed to the late effects observed, and further studies to address palatability and increase consumption are warranted.

Conflicting results have similarly been observed when studying sericea lespedeza pellets. In one study an effect was observed after one week of feeding (Kommuru et al. 2015) and in another study differences were not observed until day 28 after treatment started (Gujja et al. 2013). The discrepancies have also been seen in studies using sericea lespedeza hay, where one study observed a difference in FEC after as little as one week (Shaik et al. 2006), and another study did not show a difference until day 21 (Terrill et al. 2009). It has been suggested that these differences could be due to differences in GIN species present, season when treatment occurred, or an unknown mechanistic effect based on the plant secondary compounds present in the treatment (Gujja et al. 2013; Kommuru et al. 2015). The process of sundrying, grinding, or pelleting also may have a negative impact on anthelmintic activity of bioactive forages by decreased extractability and reactivity of tannins in forages (Reed 1995); however, it has also been suggested that pelleting may actually increase effectiveness (Terrill et al. 2007). The current study, however, suggests that the pelleting process may have had a negative impact on the bioactivity of the $\mathrm{CV}$, which could be due to excess heat incurred during the pelleting process. Although pelleting increases the ease of storage and feeding, further studies must be done, perhaps cooling the pellet during processing, to ensure that the process does not have a negative impact on the desired outcome for GIN control. 
Packed cell volume was not affected by treatment in the current study, as both the treatment and control group PCV decreased over time due to the developing infections. These results are supported by findings for the total adult worm burden, which was not significantly different between the two groups by the end of the trial. The average PCV decreased from $28 \%$ to $24 \%$ from week 0 to 6 as the infections developed. Similar decrease in PCV over time has been observed in an $H$. contortus trickle infection, where PCV decreased from $30 \%$ to $20 \%$ as infections developed (Shaik et al. 2006). The reduction in FEC that was observed toward the end of the current study could have been due to reduction of fecundity in the adult worms (Lange et al. 2006), although an effect on adult worms might have been observed if the CVP had been fed longer, which would likely affect both total worm burden and PCV as well (Terrill et al. 2007). Further investigation into the mechanism of action associated with feeding $\mathrm{CV}$ to parasitized animals must be done in order to maximize the desired benefit.

Average daily gain between treatment and control groups were not different $(p=0.59)$ in the current study, although when comparing lamb weights across groups there was a treatment ${ }^{*}$ week effect $(p<0.0003)$. There was no significant difference between the treatments at any week as the lambs were all growing and gaining weight. The treatment ${ }^{*}$ week effect was likely due to the difference in gain patterns exhibited between the two groups; control lambs gained weight each week whereas treatment lambs fluctuated across weeks, eventually showing a net-gain. This fluctuation could be attributed to 
the low palatability of the CVP, which the lambs tried to eat around and sometimes also left a portion of their grain ration behind. It could also be due to the high ash-free neutral detergent fiber (aNDF) content in the CVP $(64.5 \%$ of DM), as aNDF provides animals with bulk or fill and high values usually correspond to decreased dry matter intake (Santos et al. 2015). The $600 \mathrm{~g}$ of CVP were given to lambs as a supplement in addition to their regular grain ration, and the lambs sorted their feed to consume minimal amounts of CVP. Consumption by the end of the six weeks reached only about half of the $600 \mathrm{~g}$ offered, therefore it is possible that the supplementation also affected consumption of the grain. Determining a method of CV supplementation that would not negatively affect weight gain in lambs is essential if the CV will be marketed for use by sheep producers.

\section{Conclusions}

This study provided limited in vivo evidence of anthelmintic efficacy using cranberry vine pellets as a feed additive for lambs infected with $H$. contortus. Although there was no effect on packed cell volume or worm burden, the apparent suppression of FEC at weeks 5 and 6 in CV-fed lambs suggests that CV may have anti-parasitic potential but this would need to be

confirmed by feeding the $\mathrm{CV}$ pellets for an extended period of time or increasing consumption levels of the pellet. Further studies are warranted to explore the use of CV as a feed supplement for the control of GIN in small ruminants. 


\section{Acknowledgments}

This work was supported by the USDA National Institute of Food and

Agriculture, Northeast Sustainable Agriculture Research and Education

(NESARE) project LNE15-342, Animal Health project 1007290, and

Hatch/Multi state project 1006240. 


\section{References}

Arroyo-Lopez, C., F. Manolaraki, A. Saratsis, K. Saratsi, A. Stefanakis, V. Skampardonis, N. Voutzourakis, H. Hoste, and S. Sotiraki. 2014. Anthelmintic effect of carob pods and sainfoin hay when fed to lambs after experimental trickle infections with Haemonchus contortus and Trichostrongylus colubriformis. Parasite. 21:71.

Barone, C. D., A. M. Zajac, L. A. Manzi-Smith, A. B. Howell, J. D. Reed, C. G. Krueger, and K. H. Petersson. 2018. Anthelmintic efficacy of cranberry vine extracts on ovine Haemonchus contortus. Vet. Parasitol. 253:122-129.

Besier, R. B. 2012. Refugia-based strategies for sustainable worm control: factors affecting the acceptability to sheep and goat owners. Vet. Parasitol. 186:2-9.

Cezar, A. S., G. Toscan, G. Camillo, L. A. Sangioni, H. O. Ribas, and F. S. F. Vogel. 2010. Multiple resistance of gastrointestinal nematodes to nine different drugs in a sheep flock in southern Brazil. Vet. Parasitol. 173:157-160.

Côté, J., S. Caillet, G. Doyon, J.-F. Sylvain, and M. Lacroix. 2010. Analyzing cranberry bioactive compounds. Crit. Rev. Food Sci. Nutr. 50:872-888.

Emery, D. L., P. W. Hunt, and L. F. Le Jambre. 2016. Haemonchus contortus: the then and now, and where to from here? Int. J. Parasitol. 46:755-769.

Feliciano, R. P., M. P. Shea, D. Shanmuganayagam, C. G. Krueger, A. B. Howell, and J. D. Reed. 2012. Comparison of isolated cranberry (Vaccinium macrocarpon Ait.) proanthocyanidins to catechin and procyanidins A2 and B2 for use as standards in the 4-(dimethylamino)cinnamaldehyde assay. J. Agric. Food Chem. 60:4578-4585.

Ferlemi, A.-V., and F. N. Lamari. 2016. Berry Leaves: An Alternative Source of Bioactive Natural Products of Nutritional and Medicinal Value. Antioxidants (Basel). 5. doi:10.3390/antiox5020017. Available from: http://dx.doi.org/10.3390/antiox5020017

Fleming, S. A., T. Craig, R. M. Kaplan, J. E. Miller, C. Navarre, and M. Rings. 2006. Anthelmintic Resistance of Gastrointestinal Parasites in Small Ruminants. J. Vet. Intern. Med. 20:435-444.

Fontenot, M. E., J. E. Miller, M. T. Peña, M. Larsen, and A. Gillespie. 2003. Efficiency of feeding Duddingtonia flagrans chlamydospores to grazing ewes on reducing availability of parasitic nematode larvae on pasture. Vet. Parasitol. 118:203-213. 
Gujja, S., T. H. Terrill, J. A. Mosjidis, J. E. Miller, A. Mechineni, D. S. Kommuru, S. A. Shaik, B. D. Lambert, N. M. Cherry, and J. M. Burke. 2013. Effect of supplemental sericea lespedeza leaf meal pellets on gastrointestinal nematode infection in grazing goats. Vet. Parasitol. 191:51-58.

Hoste, H., F. Jackson, S. Athanasiadou, S. M. Thamsborg, and S. O. Hoskin. 2006. The effects of tannin-rich plants on parasitic nematodes in ruminants. Trends Parasitol. 22:253-261.

Howell, A. B. 2007. Bioactive compounds in cranberries and their role in prevention of urinary tract infections. Mol. Nutr. Food Res. 51:732-737.

Howell, S. B., J. M. Burke, J. E. Miller, T. H. Terrill, E. Valencia, M. J. Williams, L. H. Williamson, A. M. Zajac, and R. M. Kaplan. 2008. Prevalence of anthelmintic resistance on sheep and goat farms in the southeastern United States. J. Am. Vet. Med. Assoc. 233:1913-1919.

Jackson, F., and J. Miller. 2006. Alternative approaches to control--quo vadit? Vet. Parasitol. 139:371-384.

Kaplan, R. M. 2004. Drug resistance in nematodes of veterinary importance: a status report. Trends Parasitol. 20:477-481.

Kaplan, R. M., and A. N. Vidyashankar. 2012. An inconvenient truth: global worming and anthelmintic resistance. Vet. Parasitol. 186:70-78.

Katiki, L.M., Ferreira, J.F., Gonzalez, J.M., Zajac, A.M., Lindsay, D.S., Chagas, A.C.S., Amarante, A.F., 2013. Anthelmintic effect of plant extracts containing condensed and hydrolyzable tannins on Caenorhabditis elegans, and their antioxidant capacity. Vet. Parasitol. 192 (1), 218-227.

Kearney, P. E., P. J. Murray, J. M. Hoy, M. Hohenhaus, and A. Kotze. 2016. The "Toolbox" of strategies for managing Haemonchus contortus in goats: What's in and what's out. Vet. Parasitol. 220:93-107.

Kommuru, D. S., N. C. Whitley, J. E. Miller, J. A. Mosjidis, J. M. Burke, S. Gujja, A. Mechineni, and T. H. Terrill. 2015. Effect of sericea lespedeza leaf meal pellets on adult female Haemonchus contortus in goats. Vet. Parasitol. 207:170-175.

Lange, K. C., D. D. Olcott, J. E. Miller, J. A. Mosjidis, T. H. Terrill, J. M. Burke, and M. T. Kearney. 2006. Effect of sericea lespedeza (Lespedeza cuneata) fed as hay, on natural and experimental Haemonchus contortus infections in lambs. Vet. Parasitol. 141:273-278. 
Nieuwhof, G. J., and S. C. Bishop. 2005. Costs of the major endemic diseases of sheep in Great Britain and the potential benefits of reduction in disease impact. Anim. Sci. 81:23-29.

Pemberton, A. D., J. K. Brown, N. M. Craig, J. Pate, K. McLean, N. F. Inglis, D. Knox, and P. A. Knight. 2012. Changes in protein expression in the sheep abomasum following trickle infection with Teladorsagia circumcincta. Parasitology. 139:375-385.

Reed, J. D. 1995. Nutritional toxicology of tannins and related polyphenols in forage legumes. J. Anim. Sci. 73:1516-1528.

Roeber, F., A. R. Jex, and R. B. Gasser. 2013. Impact of gastrointestinal parasitic nematodes of sheep, and the role of advanced molecular tools for exploring epidemiology and drug resistance - an Australian perspective. Parasit. Vectors. $6: 153$.

Sandler, H. A., and C. J. DeMoranville. 2009. Economic Analysis of Nitrogen Rate on Vine Production and Fruit Yield of Pruned Cranberry Beds. Horttechnology. $572-579$.

Santos, V. L. F., M. A. Ferreira, M. C. B. Siqueira, T. T. B. Melo, J. L. Silva, I. B. Andrade, A. A. Soares, and C. T. F. Costa. 2015. Rumen parameters of sheep fed cassava peel as a replacement for corn. Small Rumin. Res. 133:88-92.

Shaik, S. A., T. H. Terrill, J. E. Miller, B. Kouakou, G. Kannan, R. M. Kaplan, J. M. Burke, and J. A. Mosjidis. 2006. Sericea lespedeza hay as a natural deworming agent against gastrointestinal nematode infection in goats. Vet. Parasitol. 139:150-157.

Suhayda, B., C. J. DeMoranville, H. A. Sandler, W. R. Autio, and J. E. Vanden Heuvel. 2009. Sanding and Pruning Differentially Impact Canopy Characteristics, Yield, and Economic Returns in Cranberry. Horttechnology. 796-802.

Terrill, T. H., G. S. Dykes, S. A. Shaik, J. E. Miller, B. Kouakou, G. Kannan, J. M. Burke, and J. A. Mosjidis. 2009. Efficacy of sericea lespedeza hay as a natural dewormer in goats: dose titration study. Vet. Parasitol. 163:52-56.

Terrill, T. H., J. A. Mosjidis, D. A. Moore, S. A. Shaik, J. E. Miller, J. M. Burke, J. P. Muir, and R. Wolfe. 2007. Effect of pelleting on efficacy of sericea lespedeza hay as a natural dewormer in goats. Vet. Parasitol. 146:117-122.

Zajac, A.M., Conboy, G.A., 2012. Veterinary Clinical Parasitology, 8th ed. WileyBlackwell, Ames, Iowa. 


\section{CHAPTER 3}

Anthelmintic efficacy of pelleted cranberry vine against gastrointestinal strongyle infection in Dorset lambs

by

Bailey Chalut ${ }^{1 *}$, Carly Barone ${ }^{2}$, Anne Zajac $^{3}$, Michael Thonney $^{4}$, Jess Reed ${ }^{5}$, Christian Krueger ${ }^{5}$ and Katherine Petersson ${ }^{1}$

is prepared for submission to Veterinary Parasitology

Affiliations:

${ }^{1}$ University of Rhode Island, Kingston, RI. ${ }^{2}$ Bia Diagnostics, Colchester, VT. ${ }^{3}$ Virginia Tech, Blacksburg, VA, ${ }^{4}$ Cornell University, Ithaca, NY, ${ }^{5}$ University of Wisconsin, Madison, WI. 


\section{Abstract}

Plants containing secondary compounds such as proanthocyanidins have been shown to suppress gastrointestinal nematode (GIN) infections, providing promise for alternative methods of GIN control in small ruminants. To date, in vivo studies from our laboratory have suggested that consumption of CV may have a suppressive effect on fecal egg count (FEC) of Haemonchus contortus; however, palatability has limited consumption of the CV. The purpose of this study was to test the anthelmintic efficacy of feeding varying amounts of $\mathrm{CV}$ incorporated into a pellet that is nutritionally equivalent to a $16 \%$ sheep pellet on lambs naturally and experimentally infected with GIN. Cranberry vine prunings were incorporated into a feed pellet containing $500 \mathrm{~g} \mathrm{CV}$ in $1 \mathrm{~kg}$. Fivemonth-old GIN naive Dorset lambs were turned onto pasture lightly contaminated with GIN. An experimental infection ( $5000 \mathrm{H}$. contortus L3) was superimposed on the natural infection after one week on pasture to ensure adequate infection. After the infection matured, lambs were stratified by FEC, then balanced for sex, weight, and genetic variation and fed one of three levels of dietary CV ( $\mathrm{n}=7$ per group): 0 (control), 250 , or $500 \mathrm{~g} \mathrm{CV/day} \mathrm{for} 10$ weeks. The lambs were fed $1 \mathrm{~kg}$ daily using a combination of $\mathrm{CV}$ pellets and commercially produced sheep pellets to achieve the targeted CV consumption. Weekly weight, FEC, and packed cell volume (PCV) were determined. The FEC of lambs fed $500 \mathrm{~g} \mathrm{CV}$ were significantly lower than those of control lambs at week $1(p=0.02,864 \pm 205$ vs $1807 \pm 387$; mean \pm SEM $)$ and week $2(p=$ $0.03,800 \pm 273$ vs $1671 \pm 289$ ). The FEC decreased in each group over the 
duration of the trial. There was no effect on PCV or weight gain. Further research is needed to establish the optimal time to feed $\mathrm{CV}$ for maximum anthelmintic effect against GIN. 


\section{Introduction}

In the United States and globally, gastrointestinal nematode infection has been identified as the costliest disease to affect the sheep industry, representing great economic importance for producers (Nieuwhof and Bishop, 2005; Qamar et al., 2011). Gastrointestinal nematode (GIN) infections have been identified as one of the major limitations faced in pasture-raised production of small ruminants (Nieuwhof and Bishop 2005; Hoste et al. 2006). The costs associated with GIN are twofold, comprised of both direct expenses (decreases in production, decreases in gain, and host mortality) and indirect expenses (treatment costs and increased labor) (Torres-Acosta and Hoste, 2008).

Haemonchus contortus (the barber pole worm), Teladorsagia circumcincta (the brown stomach worm) and Trichostrongylus colubriformis (the bankrupt worm) are the most abundant gastrointestinal nematodes in sheep, and account for the greatest amount of economic and production losses (O'Connor et al., 2006). Haemonchus contortus is the most pathogenic species causing issues such as anemia, reduced nutrient absorption, production losses, and in severe cases death (Kearney et al., 2016). When compared to other GIN, $H$. contortus is the most fecund, with female worms laying up to 10,000 eggs per day contributing to rapid pasture contamination (Roeber et al., 2013; Kearney et al., 2016). Larval and adult stages of $H$. contortus are found in the abomasum and abomasal mucosa where they consume up to $30 \mu \mathrm{L}$ of blood per day, leading to anemia and in acute cases, 
death (Emery et al. 2016; Kearney et al. 2016). Both T. circumcincta and T. colubriformis can cause immune-mediated diarrhea in infected animals, and a mixed infection can lead to increased inflammatory cells in the small intestine (Williams et al., 2010). Decreased nutrient absorption and diarrhea associated with these GI worms lead to decreased gain and production losses as well. The life cycle of $T$. circumcincta and $T$. colubriformis are similar to $H$. contortus, but diarrhea or scouring in infected animals is an observable clinical symptom which is generally not associated with $H$. contortus, unless in mixed infections (Roeber et al., 2013).

Historically, commercially produced chemical dewormers have been the go-to treatment for GIN infections because they were highly effective, safe to use and inexpensive (Šimpraga et al. 2015). Prophylactic treatment and overuse of these anthelmintics has led to the development of multiple drug resistance in $H$. contortus as well as other $\mathrm{GIN}$, creating the need for alternative control methods (Kaplan, 2004; Zvinorova et al., 2016). Previous research has shown that condensed tannins and other plant secondary compounds, bioactive compounds found in some plants, can have an anthelmintic effect on GIN (Lange et al. 2006; Gujja et al. 2013; Váradyová et al. 2018; Tzamaloukas et al. 2005; Torres-Acosta and Hoste 2008; Houdijk et al. 2012; Olayemi et al. 2019). This discovery has provided promise for determining alternative control methods of GIN control.

The American cranberry (Vaccinium macrocarpon) and the cranberry plant contain high levels of bioactive compounds, including proanthocyanidins 
(Su et al. 2010; Côté et al. 2010; Feliciano et al. 2016; Ferlemi and Lamari 2016). Cranberry vines are pruned off of cranberry bogs when the plants come out of winter dormancy, generating a plentiful by-product of the industry (Suhayda et al. 2009; Sandler and DeMoranville 2009). As such, the vines represent an ideal test candidate as a sustainable anthelmintic option for northeast sheep producers. This study was designed to expand upon in vitro screening results of cranberry vine extracts which showed anthelmintic activity against L1 and adult worm motility as well as some activity against egg hatching (Barone et al., 2018). The study by Barone et al. (2018) also looked at the effect of cranberry vine in vivo, with CV powder orally administered to lambs showing slight suppression of FEC, although limited quantities only allowed for 3-day treatment and the study could not investigate dose response or effects of feeding duration. A follow-up study from our laboratory provided limited in vivo evidence of anthelmintic activity on an experimental infection of H. contortus where a $100 \%$ CV pellet was fed to lambs for a duration of 6 weeks. Although palatability and consumption of the pellet was an issue, results showed that there appeared to be a suppression of FEC of lambs fed $600 \mathrm{~g}$ of cranberry pellet for six weeks compared to control lambs (Chalut et al., in preparation; chapter 2). This study aims to expand upon the previous in vivo trials by testing the anthelmintic efficacy of a nutritionally balanced $50 \%$ cranberry vine pellet on a mixed natural and experimental GIN infection in Dorset lambs. 


\section{Methods}

\subsection{Preparation of feed}

\subsubsection{Cranberry Vines}

Clippings from bogs of 'Mullica Queen' and 'Howe' cranberry owned by the A.D. Makepeace Company (Wareham, MA, USA) were collected following pruning in spring and summer of 2018. Pruned vines were transported to the University of Rhode Island, then spread into windrows to dry at the University's Peckham Farm. The windrows were aerated and monitored daily until dry.

\subsubsection{Cranberry vine pellet (CVP)}

After drying, the CV was chopped into a powder using a hammer mill (Bison, MM20030000A, Aguascalientes, Mexico, 3/16" screen), and sent to Dairy One in Ithaca, NY for nutritional analysis. In order to ensure palatability a $50 \%$ CV pellet was formulated that was equivalent on a digestible dry matter basis to the commercially produced $16 \%$ sheep pellet used as the control pellet for this study (Pleasant View Farm, Somers, CT). The chopped CV was pelleted at Green Mountain Feeds (Bethel, VT). A sample of the CV pellet was sent to Dairy One in Ithaca, NY for nutritional analysis.

\subsection{Study subjects}

Feeding trials were conducted with the approval of the Institutional Animal Care and Use Committee (IACUC) of the University of Rhode Island. Dorset lambs born and housed at the University of Rhode Island Peckham Farm, located in Kingston, RI were used for this study. Spring born 
lambs were weaned and raised indoors under trichostrongylid-free conditions until approximately five months of age when the trial began.

\subsection{Study Design}

At the start of the trial, twenty-one lambs ( 5 months old; weight $51 \pm 3$ $\mathrm{kg}$ (mean \pm SEM; range 31 to 66$)$ ) were given daily access to a pasture lightly contaminated with GIN and remained on this pasture for the duration of the trial. After one week of being on pasture, an experimental infection of $5000 \mathrm{H}$. contortus was superimposed on any natural infection in order to ensure an adequate infection for the feeding trial. Four weeks after the experimental infection, the lambs were stratified by fecal egg count (FEC) into three groups fed varying amounts of the cranberry vine pellet (CVP, 0,250 or $500 \mathrm{~g}$ CVP/day). The groups were then balanced for sex and weight, with related animals (twins, triplets) split between groups. Control lambs were fed $0.9 \mathrm{~kg}$ of a $16 \%$ crude protein commercially available pellet (Pleasant View Farms, Somers, CT, USA) and the treatment group rations fed were equivalent in digestible dry matter to the commercial pellet consumption. During the trial all lambs were individually fed twice daily one of three diets $(n=7$ each): control ( 0 CVP, $0.9 \mathrm{~kg} \mathrm{16 \%} \mathrm{commercial} \mathrm{pellet/day),} 250 \mathrm{~g} \mathrm{CVP/day} \mathrm{(CVP} \mathrm{250),} \mathrm{or} 500 \mathrm{~g}$ CVP/day (CVP500) for 10 weeks. The lambs were sorted into their respective groups using a chute system to lead them into individual feeding stalls. When the lambs were finished eating, they were released back into their pen with

continuous access to pasture. As stated above, the CVP, containing 50\% CV, was formulated to be equivalent in digestible dry matter to the commercial 
$16 \%$ sheep pellet fed to the control animals. The animals in the CVP250 group received the balance of their ration in the $16 \%$ commercial sheep pellet. The lambs also received $2.5 \mathrm{~kg} / \mathrm{lamb} /$ day of grass hay, with water available ad libitum. Consumption of feed was monitored by measuring daily orts throughout the duration of the trial. Fecal egg count, packed cell volume (PCV), and weights were measured weekly. At the end of the ten-week trial lambs were sent to the abattoir and liver samples were collected from a subset of animals (Figure 1).

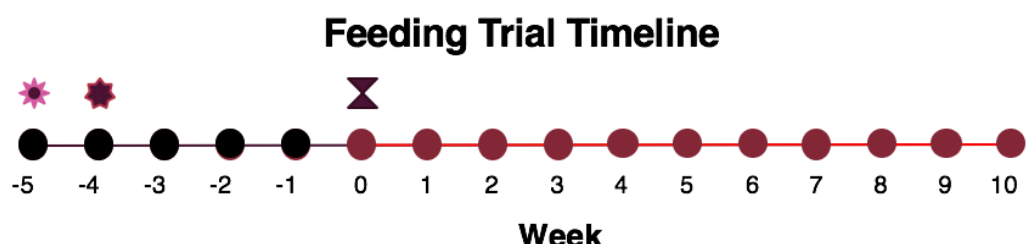

Lambs go outside onto pasture Infect lambs; $5000 \mathrm{H}$. contortus L3 $\boldsymbol{\nabla}$ Stratify lambs into treatment groups

Pre-study; FEC monitored

FEC, PCV, \& Weight Analysis Lambs fed $2 x$ per day

Figure 1. Study design

\subsection{Analyses of Feed}

Random grab samples of feed were collected daily to make weekly composite samples of CVP, grain, and hay. Weekly composite samples were used to create a composite sample for the full duration of the trial. Samples were analyzed by Dairy One Cooperative, Inc. (Ithaca, NY, USA) (Table 1). 
Table 1. Nutrient content of composite hay, grain, and cranberry vine pellet samples collected over the study period.

\begin{tabular}{lccc}
\hline Components & $\mathbf{5 0 \% \text { CV }}$ & $\mathbf{1 6 \% \text { Sheep }}$ & \\
\hline DM, \% & Pellet & Pellet & Grass Hay \\
Crude Protein, \% of DM & 22 & 90.5 & 81.4 \\
Crude Fat, \% of DM & 4.2 & 18.9 & 14.3 \\
aNDF, \% of DM & 29.8 & 4.3 & 4.2 \\
ADF, \% of DM & 23 & 27.7 & 63.5 \\
Calcium, \% of DM & 1.23 & 14.6 & 33.4 \\
Phosphorus, \% of DM & 0.57 & 0.92 & 0.42 \\
Magnesium, \% of DM & 0.32 & 0.65 & 0.41 \\
Potassium, \% of DM & 1.09 & 0.28 & 0.34 \\
PPM Copper & 31 & 1.05 & 1.97 \\
PPM Molybdenum & 1.8 & 9.5 & 8 \\
NEm, Mcal/kg of DM & 0.66 & 18.6 & 8 \\
NE, Mcal/kg of DM & 0.39 & 0.81 & 0.58 \\
\hline Proximate analys & & 0.53 & 0.33 \\
\hline
\end{tabular}

Proximate analysis conducted by Dairy One Cooperative, Inc. (Ithaca, NY). 


\subsection{Parasitology parameters}

\subsubsection{Infective Larvae}

Haemonchus contortus L3 larvae used to infect lambs in this experiment were cultured from the manure of donor lambs that had been infected with larvae originally obtained from Dr. Anne Zajac (Virginia Maryland College of Veterinary Medicine, Blacksburg, Virginia). Prior to infection, larvae were confirmed $>90 \%$ viable by observing motility for five seconds and determining motile or non-motile (Skantar et al., 2005; Katiki et al., 2013). All L3 were stored at $4^{\circ} \mathrm{C}$ and were less than three months of age when used for infection.

\subsubsection{Blood and fecal analysis}

Blood samples were collected weekly via jugular venipuncture into sterile EDTA vacutainer tubes (BD, Franklin Lakes, NJ, USA) and packed cell volume $(\mathrm{PCV})$ was determined by microhematocrit centrifugation at $35,720 \times \mathrm{g}$ for three minutes within 12 hours of sample collection. Fecal samples were collected weekly, directly from the rectum, for fecal egg count determination according to the modified McMaster technique with a detection limit of $50 \mathrm{epg}$ (Zajac and Conboy, 2012).

\subsection{Other Parameters}

\subsubsection{Analysis of Liver Copper Levels}

Due to increased levels of copper in the CV pellet, random liver samples were collected at the time of euthanasia from control and CV500 fed 
lambs and sent to Cornell University's Animal Health Diagnostic Center (Ithaca, NY) for toxicology analysis.

\subsection{Statistical analysis}

Weekly fecal egg counts, packed cell volume, and average daily gain were analyzed using a mixed procedure in SAS with repeated measures and means separated with Tukey's post-hoc test (SAS Inc., Cary, NC). Each multivariable model included terms treatment, week, and two-way interactions.

Liver copper values were analyzed using a student's t-test in SAS.

Significance was defined as $p \leq 0.05$. Results are reported as mean \pm SEM.

\section{Results}

\subsection{Feeding Trial}

\subsubsection{Consumption of CVP}

Consumption of CVP was determined in treatment lambs daily by monitoring orts for the duration of the trial. Consumption of the CVP in both the CVP250 and CVP500 groups remained at or above $95 \%$ of the daily amount offered throughout the duration of the trial, therefore it was concluded that the $50 \%$ CVP was palatable to the lambs. 


\subsubsection{Effect of CVP on FEC}

There was a treatment ${ }^{*}$ week effect $(p \leq 0.001$, Figure 2$)$. There were differences within control $(p \leq 0.05)$ and CVP250 ( $p \leq 0.01)$ lambs (Figure 2). There were no differences over time within the CVP500 group and the treatments did not differ from each other at any week.

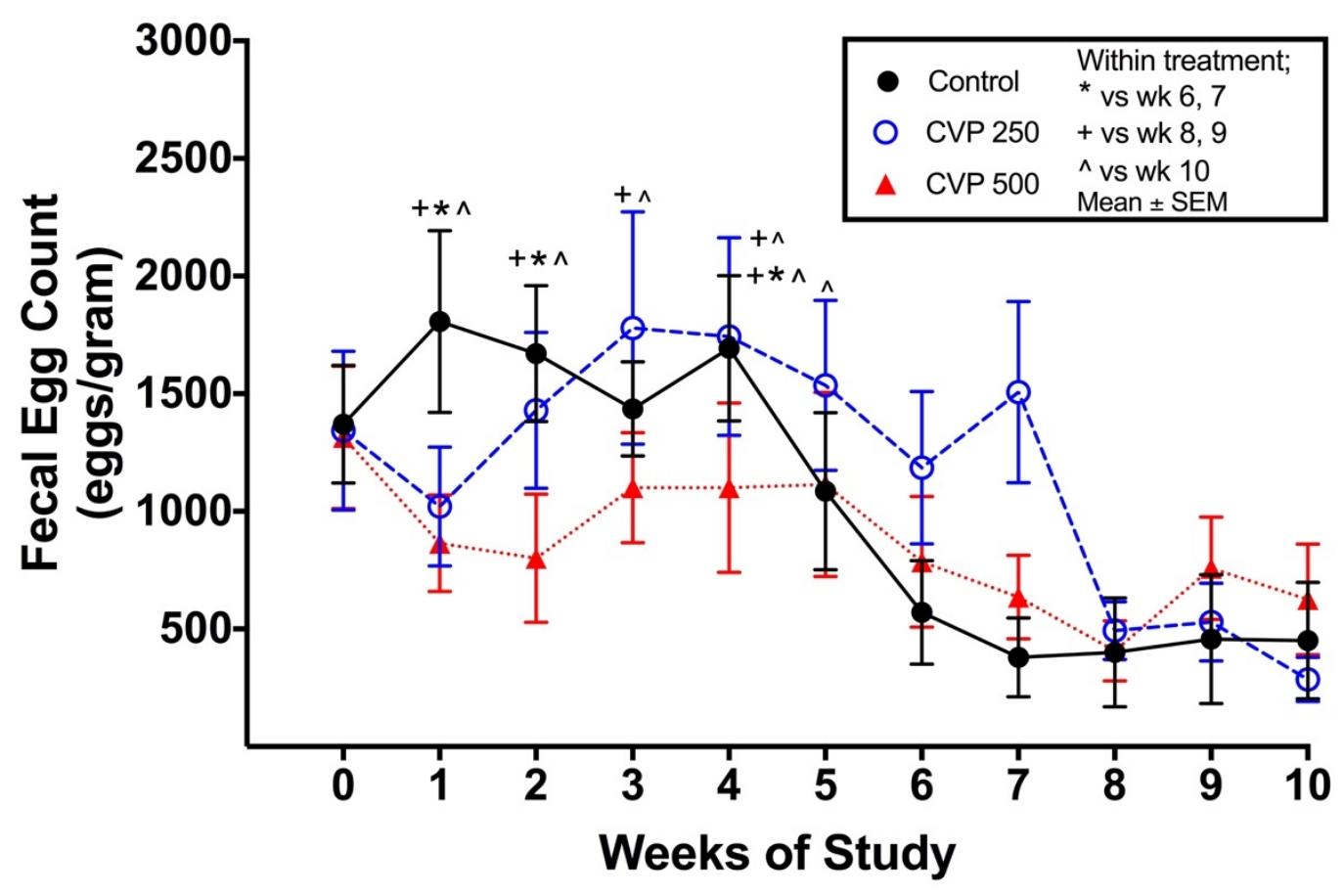

Figure 2. Effect of feeding varying amounts of a $50 \%$ CVP on FEC in lambs subjected to an experimental $H$. contortus infection (5000 L3) superimposed on a light pasture infection (four weeks prior to week 0). Lambs were fed varying amounts of cranberry vine pellet for 10 weeks ( $n=7$ per group; Control 0 g/day, CVP250: $250 \mathrm{~g} \mathrm{CV/day} \mathrm{and} \mathrm{CVP500:} 500 \mathrm{~g}$ CV/day). 


\subsubsection{Effect of CVP on packed cell volume}

The mean PCV for all groups remained relatively stable over the course of the trial (Figure 3). The control group averaged $30 \pm 1 \%$, the CVP250 group averaged $29 \pm 1 \%$ and the the CVP500 group averaged $29 \pm 1 \%$ over the entire course of the trial. There was a significant difference by week $(p<$ $0.0001)$; however, there was no difference by treatment $(p=0.16)$, or treatment ${ }^{*}$ week $(p=0.15)$. The PCV at weeks 0 and 1 was greater than the PCV at weeks $2(p \leq 0.01), 5(p \leq 0.03)$, and $6(p \leq 0.01)$ (Figure 3$)$.

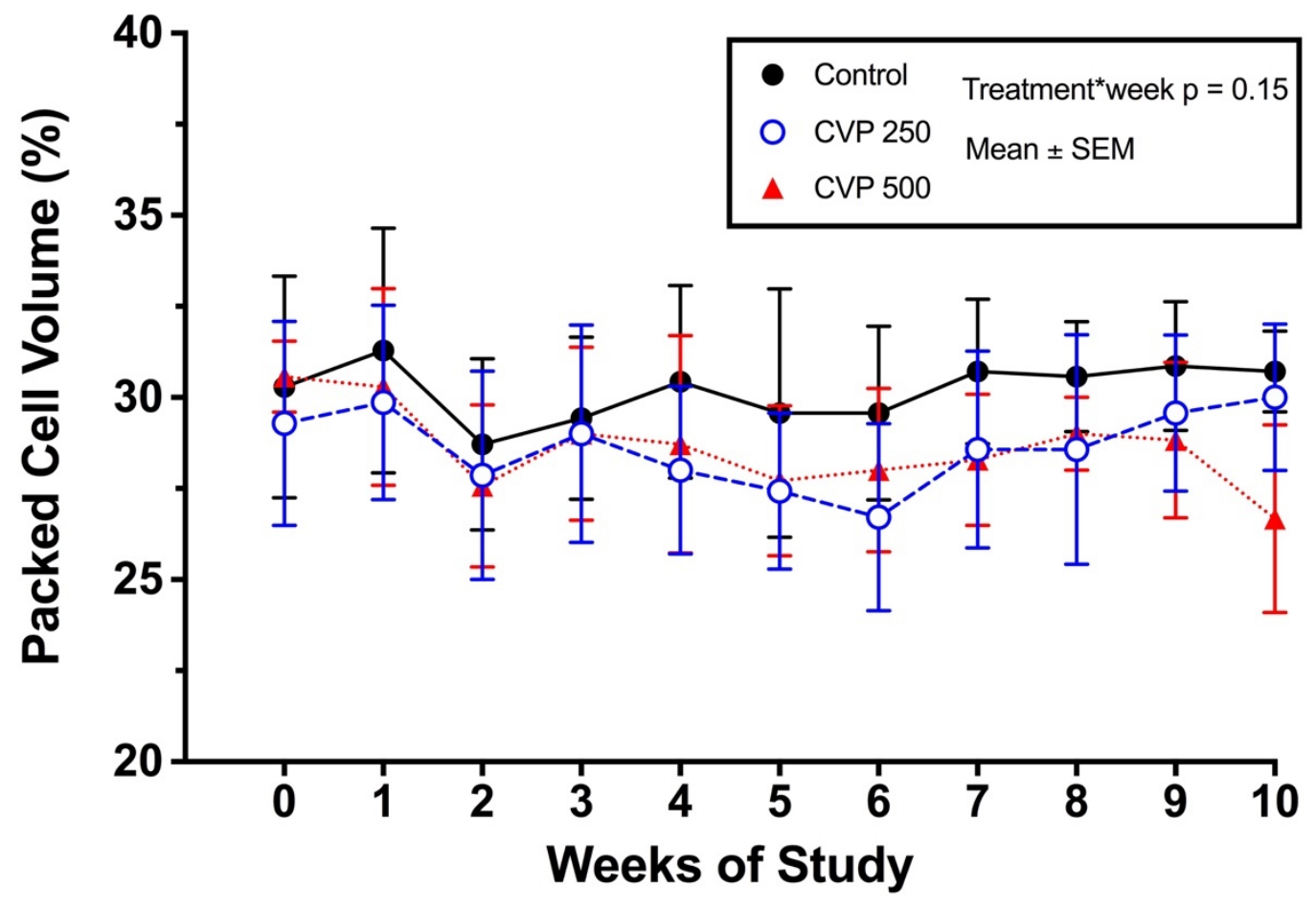

Figure 3. Effect of feeding varying amounts of a $50 \%$ CVP on PCV in lambs subjected to an experimental $H$. contortus infection (5000 L3) superimposed on a light pasture infection (four weeks prior to week 0 ). 


\subsubsection{Effect of CVP on weight and average daily gain}

Average body weight gain over the 10 -week trial of control $(0.12 \pm 0.04$ $\mathrm{kg} /$ day $), \mathrm{CV} 1(0.11 \pm 0.05 \mathrm{~kg} / \mathrm{day})$, and CV2 $(0.10 \pm 0.05 \mathrm{~kg} /$ day $)$ groups were not significantly different throughout the duration of the trial $(p=0.24)$. There was no effect of treatment $(p=0.94)$ or treatment ${ }^{*}$ week $(p=0.67)$ on weight over the course of the trial. There was a significant difference by week $(p<$ $0.0001)$ as the weights increased over the course of the feeding trial while all of the lambs were growing and gaining weight (Figure 4).

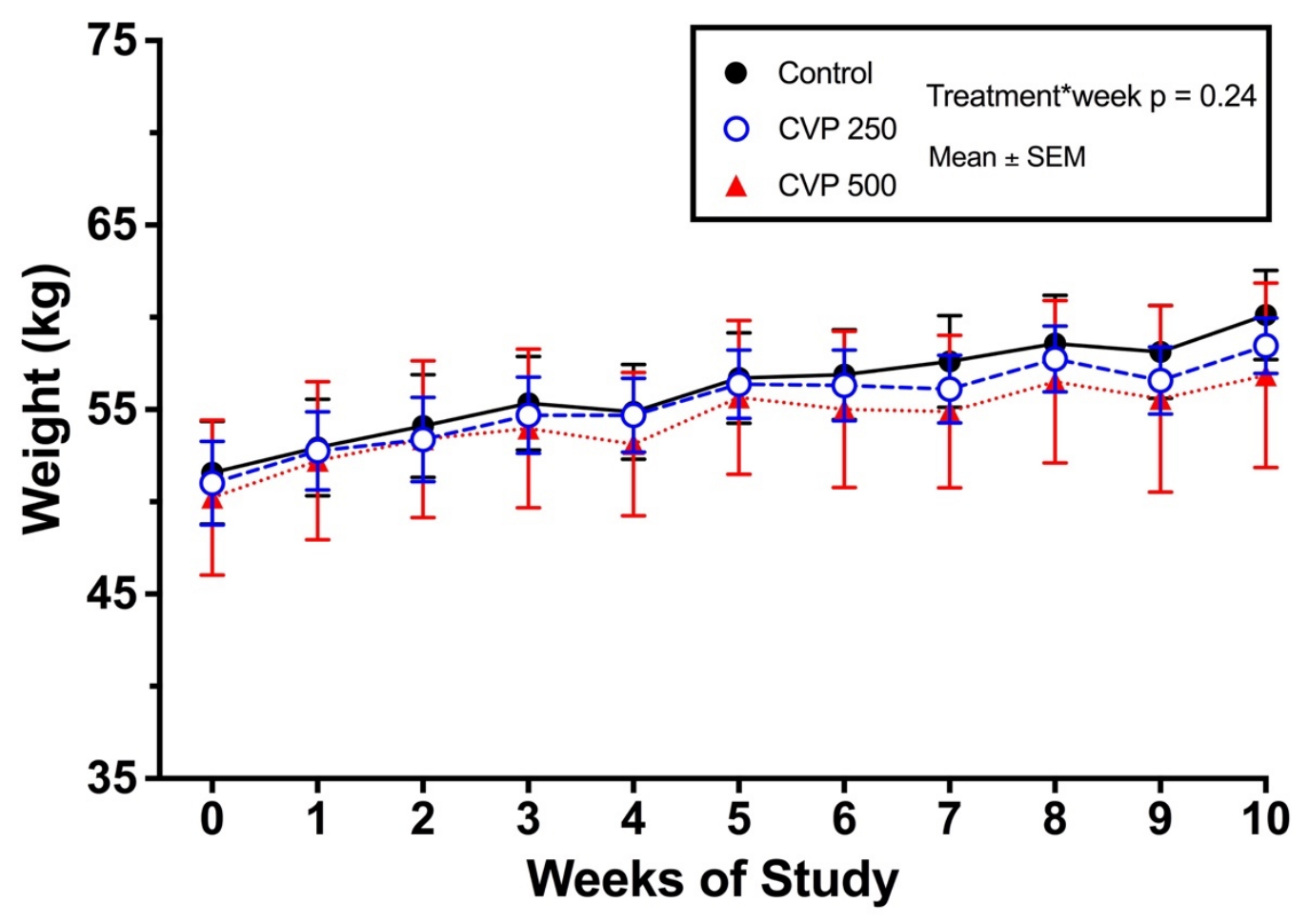

Figure 4. Effect of feeding varying amounts of a $50 \%$ CVP on weight in lambs subjected to an experimental $H$. contortus infection (5000 L3) superimposed on a light pasture infection (four weeks prior to week 0 ). 


\subsubsection{Effect of CVP on liver copper values}

At the abattoir, liver samples were obtained from six randomly selected lambs - three from control and three from CV500-fed lambs to determine if their hepatic copper levels were affected by elevated copper concentration in the CV pellet. Liver samples were sent to Cornell University's Animal Health Diagnostic Center (Ithaca, NY) for toxicology analysis. Toxicology results showed that CV500-fed lambs had significantly higher copper levels than control-fed lambs $(p \leq 0.01)$.

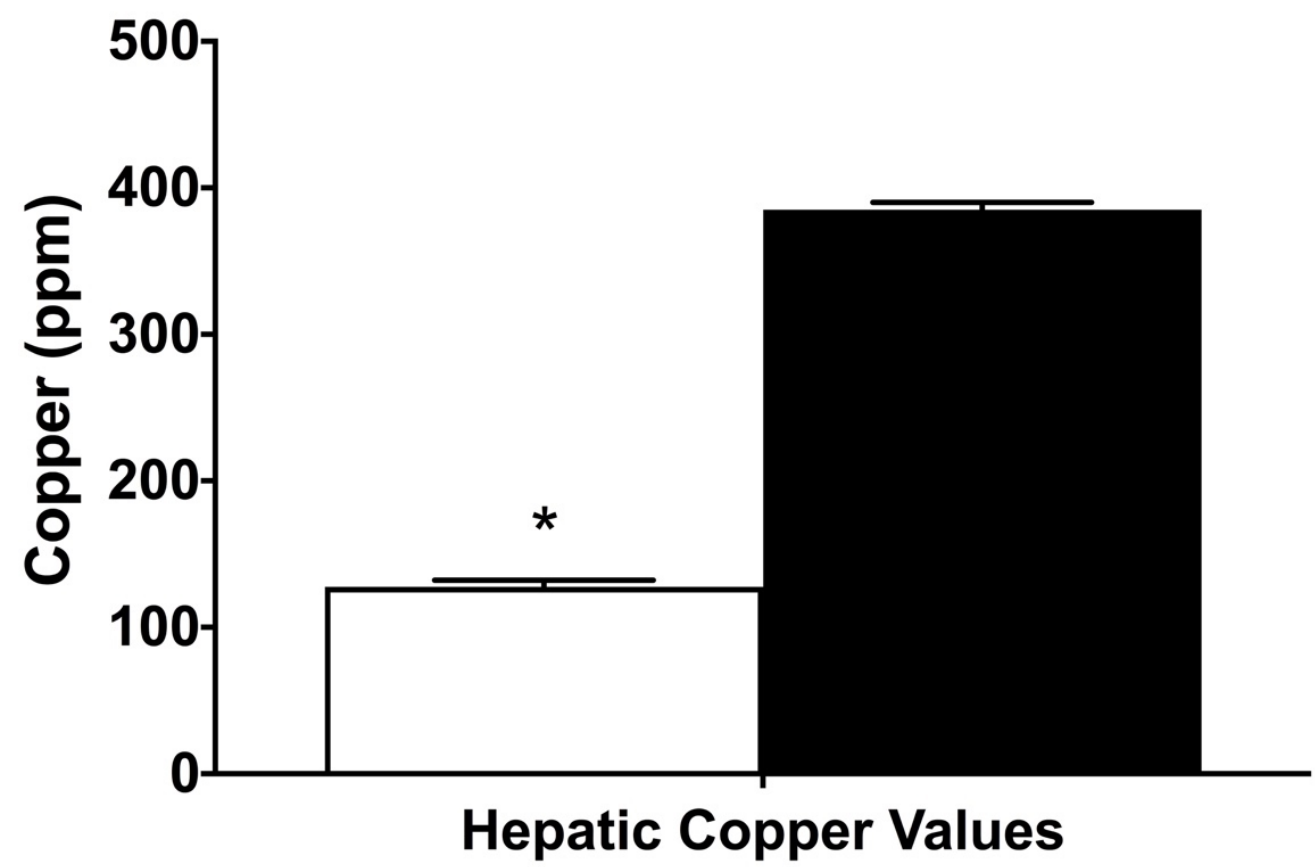

Figure 5. Effect of CVP on hepatic copper values. Liver samples were sent to Cornell University's Animal Health Diagnostic Center (Ithaca, NY) for toxicology analysis. Toxicology results showed that CVP500 lambs (black) had significantly higher hepatic copper levels than control-fed lambs (white) ( $p \leq$ 0.01 ). 


\section{Discussion}

Under the conditions of this study, cranberry vine pellets were effective at suppressing a rise in FEC in lambs fed $500 \mathrm{~g}$ of cranberry vine per day, as shown by the treatment ${ }^{*}$ week effect $(p \leq 0.001)$. At the start of the trial, average FEC across all groups was $1343 \pm 268$ epg. Lambs had access to pasture for the duration of the trial, allowing for additional natural infection to develop. In both control and CV250 groups, FEC increased from week 0 to week 4 due to developing and additional infection. At week five, FEC in all three groups steadily declined throughout the duration of the trial with the exception of an increase in the CV250 group at week 7. The CV500 FEC values remained low from the start of the trial and were not significantly different throughout the trial, whereas the control and CV250 groups showed a clear rise in FEC before decreasing, suggesting that the CV500 diet had an early suppression effect on the infection, as early as one week following the initiation of feeding. This is similar to findings in a study that fed sericea lespedeza to naturally infected goats, with an experimental infection of $H$. contortus superimposed, which showed a suppression of FEC starting one week following the start of feeding (Shaik et al. 2006). This is also similar to results of a study that fed sericea lespedeza leaf meal pellets to goats, which also showed a decrease in FEC in the treatment group after one week of feeding with the suppression continuing through the entire four weeks of the trial period (Kommuru et al. 2015). These studies differ from the current study, 
however, as they both showed a significant decrease in FEC in the treatment group before suppressing FEC for the duration of feeding.

It is unclear what caused the suppression effect in the current study; however, in the pilot study by Barone et al. (2018), a similar early suppression effect was observed in lambs with established infections that were orally dosed with chopped CV for three consecutive days. These results suggest that CV may have either caused a negative effect on the adult worms, a reduction in the number of female worms, or a reduction of fecundity. In the in vitro study performed by Barone et al. (2018), adult worms that had been incubated with CV-PAC and CV-AqE extracts showed heavy aggregate accumulation on the cuticle under scanning electron microscopy. The cuticle gives shape to the worms while also being involved in motility and metabolic exchanges within the host (Martínez-Ortíz-de-Montellano et al. 2013). Studies have shown that exposure to plants containing bioactive compounds such as tannins or alkaloids can cause damage or structural changes to the cuticle of GIN, possibly affecting their nutrition, motility, or reproductive capacity (Ribeiro et al. 2017; Andre et al. 2016; Gujja et al. 2013; Martínez-Ortíz-de-Montellano et al. 2013). If similar aggregate build-up observed in vitro occurred in vivo, this could account for reduced proliferation in the adult worms present in this study, and could account for the reduction in FEC that was observed.

The early FEC suppression observed in the current study and the study by Barone et al. (2018) differ from the results of a prior in vivo study. In a previous study, lambs were experimentally infected with $H$. contortus and then 
given a trickle infection from weeks 0 to 3 . The treatment group was offered $600 \mathrm{~g}$ of a $100 \%$ CV pellet daily, although palatability greatly limited consumption to half that amount. The treatment and control group FEC behaved the same from weeks 0 to 4 , and then began to diverge at weeks 5 and 6 where the control group continued to rise steadily and the treatment group started to decrease, suggesting the start of a suppressive effect (Chalut et al., in preparation; chapter 2). These conflicting results have similarly been observed when studying sericea lespedeza pellets, where in one study they had an effect after one week of feeding (Kommuru et al. 2015) and in another study differences were not observed until day 28 after treatment started (Gujja et al. 2013). It has been suggested that these differences could be due to differences in GIN species present, season when treatment occurred, or an unknown mechanistic effect based on the plant secondary compounds present in the treatment (Gujja et al. 2013; Kommuru et al. 2015). The pelleting process, and heat associated with it, may also have an effect on the bioactivity of the compounds found in these plants (Reed 1995; Terrill et al. 2007). This study utilized a cooling step during the pelleting of the $\mathrm{CV}$ in an attempt to minimize any negative impact that heat may have on the bioactivity of the plant secondary compounds. Further studies are warranted to explain the differences that have been observed across multiple studies using bioactive plant pellets for GIN control.

At the end of the ten-week trial, if differences in FEC were apparent between groups, lambs were to be sent to the abattoir for collection of post- 
mortem worm and larval samples. This post-mortem sampling would allow for quantification of total worm and larval burdens as well as species and sex identification to better understand the effects of $\mathrm{CV}$ on the infection. Due to the lack of difference in FEC between the groups as well as the extremely low FEC observed in all groups at the end of the trial, these post-mortem samples were not taken and effect of CVP on worm and larval burden was not included in the results.

There are several explanations for the substantial decrease in FEC across all groups at the end of the trial. Gradual exposure to low-levels of GIN can result in acquired immunity within the host (Pemberton et al. 2012), therefore it is possible that the lightly-contaminated pasture and the continuous low-level exposure to GIN in this study resulted in an acquired immunity that was demonstrated by the end of the ten-week trial. Also, based on the experimental infection in this study, $H$. contortus was presumably the main GIN infecting the lambs. At the start of the trial, the average FEC across all three groups was $1343 \pm 282$ epg representing a low to moderate infection level. In sheep infected with $H$. contortus, a FEC of greater than 2000 epg is generally considered significant or severe (Jesse et al. 2019; Colditz and Le Jambre 2008). The highest FEC observed across all groups and all weeks was observed in control lambs at week one with $1807 \pm 387$ epg. It is possible that the relatively low infections at the start of the trial combined with a minimal exposure to larvae on pasture contributed to acquired immunity and declining infections in the lambs several weeks into the trial. The transition from summer 
to fall, which occurred during the trial, may have also affected the infection in the lambs. Developmental success of GIN is limited by cold temperatures, and optimal temperature for $\mathrm{H}$. contortus development is between $25-37^{\circ} \mathrm{C}$ (O'Connor et al. 2006), and in the latter weeks of the trial there were some nights that reached $0{ }^{\circ} \mathrm{C}$. In order to survive in unsuitable environments, GIN can undergo a process known as hypobiosis where the L4 larvae go into a state of arrested development within the host for an extended period of time (Gatongi et al. 1998; O'Connor et al. 2006; Sargison et al. 2007). Hypobiosis occurs in H. contortus in the northern United States (Capitini et al. 1990), therefore it is possible that some of the larvae consumed on pasture had entered a hypobiotic state toward the end of the trial.

Throughout the duration of the trial, packed cell volume remained within a high normal range in each group. Haemonchus contortus is a blood-feeding parasite which inhabits the abomasum, and one adult worm can consume up to $30 \mu \mathrm{L}$ of blood each day, making anemia one of the primary concerns associated with heavy $H$. contortus infections (Emery et al., 2016; Kearney et al., 2016). Anemia is a decline below the normal number of red blood cells, and has been defined as a packed cell volume $\leq 15-19 \%$, depending on the exposure to $H$. contortus on pasture (Mederos et al. 2014; Kaplan et al. 2004). The packed cell volume observed in each group would be expected to be within normal range due to the low to moderate levels of infection throughout the trial. 
In the study by Chalut et al. (2017), palatability of a $100 \%$ cranberry vine pellet was a major limitation of the feeding trial, and lambs refused approximately half of the cranberry vine pellets that they were offered (Chalut et al.,in preparation). In order to address the issue of palatability associated with the bitterness of cranberry vine, likely due to the proanthocyanidins (Monagas et al. 2010), the current study formulated a 50\% CVP to be both nutritionally equivalent to a commercially produced sheep pellet as well as palatable. The formulated CVP was well accepted by the lambs throughout the duration of the trial, showing that palatability was highly enhanced as evidenced by a lack of difference in the weight gain between treatment groups. The significant difference by week observed reflects the growth of the young lambs. The similar weight gain, as well as the nutritional analysis of the pellet, show that the 50\% CVP formulated was in fact nutritionally equivalent to the commercially produced sheep feed, and could be fed to lambs as a primary diet.

Although the CVP was very close to the same as the commercially produced sheep feed, there was a slightly elevated copper level that was observed and not anticipated as the cranberry vine was analyzed prior to pelleting. Copper must be used cautiously in sheep because they are at high risk for copper toxicosis when levels build up in the liver (Terrill et al., 2012; Burke et al., 2016; Kearney et al., 2016). During week 8 of the study, one lamb from the group of CV500-fed lambs perished and a necropsy was performed to determine the cause of death. There was a concern that the 
lamb had potentially suffered from copper toxicosis due to the slightly elevated levels of copper in the CVP. The necropsy showed that the lamb had likely died as a result of an intestinal torsion; however, renal and hepatic toxicology was also performed at Cornell University's Animal Health Diagnostic Center (Ithaca, NY) for toxicology analysis. The toxicology report showed a normal renal copper concentration of $12.95 \mathrm{ppm}$ (reference range 12-25ppm dry matter) and an elevated hepatic copper concentration of 546.2ppm (reference range $120-500 p p m$ dry matter). According to the toxicology report, although the liver copper value was higher than expected in this lamb, clinical copper toxicosis was unlikely to have occurred due to the low renal copper concentration.

In order to follow-up on these findings, three randomly selected lambs were chosen from both the control and CV2 groups to obtain post-mortem liver samples for toxicology analysis at the end of the trial. Toxicology results revealed that CV500-fed lambs had significantly higher copper concentrations $(385 \pm 49 \mathrm{ppm})$ than control lambs $(128 \pm 31 \mathrm{ppm})(\mathrm{p} \leq 0.01)$. The liver copper concentration was not high enough to cause copper toxicosis; however, the elevation observed suggests that re-formulation to account for the copper level would likely be necessary if the CVP were expected to be fed on a long-term basis. Due to the promising results observed in previous studies and this study, re-formulation and follow-up studies are warranted to better understand the effects of CVP on GIN. 


\section{Conclusions}

This study provided further in vivo evidence of anthelmintic efficacy by using nutritionally balanced cranberry vine feed pellets for lambs naturally and experimentally infected with $H$. contortus and possibly other GIN species. Lambs fed a high level of the cranberry pellet showed suppression of fecal egg counts throughout the beginning weeks of the trial when compared to groups fed low levels of cranberry pellet fed or no cranberry pellets (control). There was expectedly no effect on PCV in either group due to relatively low infections throughout the trial. The effect of CVP on total worm numbers was not evaluated because lambs in all groups appeared to lose their infections by the end of the study. The results, both observed in previous studies and this study, suggest that CV could be incorporated into the diet of sheep as a way to sustainably suppress GIN infections on farms in the northeast United States. Further studies are warranted to explore the dose-response associated with the use of $\mathrm{CV}$, as well as the most appropriate timing for dosage to maximize effects.

\section{Acknowledgments}

This work was supported by the USDA National Institute of Food and Agriculture, Northeast Sustainable Agriculture Research and Education (NESARE) project LNE15-342, Animal Health project 1007290, and Hatch/Multi state project 1006240. 


\section{References}

Andre, W. P. P., W. L. C. Ribeiro, G. S. Cavalcante, J. M. L. dos Santos, I. T. F. Macedo, H. C. B. de Paula, R. M. de Freitas, S. M. de Morais, J. V. de Melo, and C. M. L. Bevilaqua. 2016. Comparative efficacy and toxic effects of carvacryl acetate and carvacrol on sheep gastrointestinal nematodes and mice. Vet. Parasitol. 218:52-58.

Barone, C. D., A. M. Zajac, L. A. Manzi-Smith, A. B. Howell, J. D. Reed, C. G. Krueger, and K. H. Petersson. 2018. Anthelmintic efficacy of cranberry vine extracts on ovine Haemonchus contortus. Vet. Parasitol. 253:122129.

Burke, J. M., J. E. Miller, T. H. Terrill, E. Smyth, and M. Acharya. 2016. Examination of commercially available copper oxide wire particles in combination with albendazole for control of gastrointestinal nematodes in lambs. Vet. Parasitol. 215:1-4.

Capitini, L. A., K. E. McClure, and R. P. Herd. 1990. Effect of environmental stimuli on pre-infective and infective stages of Haemonchus contortus in the northern United States for the induction of hypobiosis. Vet. Parasitol. 35:281-293.

Chalut, B.A., A. M. Zajac, M. Thonney, J. D.Reed, C. G. Krueger, and K. H. Petersson. 2019. Effect of pelleted cranberry vine fed to lambs experimentally infected with Haemonchus contortus. Thesis; Chapter 2. Manuscript in preparation.

Colditz, I. G., and L. F. Le Jambre. 2008. Development of a faecal occult blood test to determine the severity of Haemonchus contortus infections in sheep. Vet. Parasitol. 153:93-99.

Côté, J., S. Caillet, G. Doyon, J.-F. Sylvain, and M. Lacroix. 2010. Analyzing cranberry bioactive compounds. Crit. Rev. Food Sci. Nutr. 50:872-888.

Emery, D. L., P. W. Hunt, and L. F. Le Jambre. 2016. Haemonchus contortus: the then and now, and where to from here? Int. J. Parasitol. 46:755769 .

Feliciano, R. P., A. Boeres, L. Massacessi, G. Istas, M. R. Ventura, C. Nunes Dos Santos, C. Heiss, and A. Rodriguez-Mateos. 2016. Identification and quantification of novel cranberry-derived plasma and urinary (poly)phenols. Arch. Biochem. Biophys. 599:31-41. 
Ferlemi, A.-V., and F. N. Lamari. 2016. Berry Leaves: An Alternative Source of Bioactive Natural Products of Nutritional and Medicinal Value. Antioxidants (Basel). 5. doi:10.3390/antiox5020017. Available from: http://dx.doi.org/10.3390/antiox5020017

Gatongi, P. M., R. K. Prichard, S. Ranjan, J. M. Gathuma, W. K. Munyua, H. Cheruiyot, and M. E. Scott. 1998. Hypobiosis of Haemonchus contortus in natural infections of sheep and goats in a semi-arid area of Kenya. Vet. Parasitol. 77:49-61.

Gujja, S., T. H. Terrill, J. A. Mosjidis, J. E. Miller, A. Mechineni, D. S. Kommuru, S. A. Shaik, B. D. Lambert, N. M. Cherry, and J. M. Burke. 2013. Effect of supplemental sericea lespedeza leaf meal pellets on gastrointestinal nematode infection in grazing goats. Vet. Parasitol. 191:51-58.

Hoste, H., F. Jackson, S. Athanasiadou, S. M. Thamsborg, and S. O. Hoskin. 2006. The effects of tannin-rich plants on parasitic nematodes in ruminants. Trends Parasitol. 22:253-261.

Houdijk, J. G. M., I. Kyriazakis, A. Kidane, and S. Athanasiadou. 2012. Manipulating small ruminant parasite epidemiology through the combination of nutritional strategies. Vet. Parasitol. 186:38-50.

Jesse, F. F. A., E. L. T. Chung, Y. Abba, M. A. M. Lila, S. N. Aishah, S. Affandi, A. A. Bitrus, I. D. Peter, and I. U. Hambali. 2019. A Veterinary Clinical Case of Severe Chronic Haemonchus contortus Infection in a Goat The Clinical Management of the Case and Pathology Findings. Adv. Anim. Vet. Sci. 7. doi:10.17582/journal.aavs/2019/7.6.503.507. Available from:

http://nexusacademicpublishers.com/table_contents_detail/4/1156/html

Kaplan, R. M. 2004. Drug resistance in nematodes of veterinary importance: a status report. Trends Parasitol. 20:477-481.

Kaplan, R. M., J. M. Burke, T. H. Terrill, J. E. Miller, W. R. Getz, S. Mobini, E. Valencia, M. J. Williams, L. H. Williamson, M. Larsen, and A. F. Vatta. 2004. Validation of the FAMACHA eye color chart for detecting clinical anemia in sheep and goats on farms in the southern United States. Vet. Parasitol. 123:105-120.

Katiki, L.M., Ferreira, J.F., Gonzalez, J.M., Zajac, A.M., Lindsay, D.S., Chagas, A.C.S., Amarante, A.F., 2013. Anthelmintic effect of plant extracts containing condensed and hydrolyzable tannins on Caenorhabditis elegans, and their antioxidant capacity. Vet. Parasitol. $192(1), 218-227$. 
Kearney, P. E., P. J. Murray, J. M. Hoy, M. Hohenhaus, and A. Kotze. 2016. The "Toolbox" of strategies for managing Haemonchus contortus in goats: What's in and what's out. Vet. Parasitol. 220:93-107.

Kommuru, D. S., N. C. Whitley, J. E. Miller, J. A. Mosjidis, J. M. Burke, S. Gujja, A. Mechineni, and T. H. Terrill. 2015. Effect of sericea lespedeza leaf meal pellets on adult female Haemonchus contortus in goats. Vet. Parasitol. 207:170-175.

Lange, K. C., D. D. Olcott, J. E. Miller, J. A. Mosjidis, T. H. Terrill, J. M. Burke, and M. T. Kearney. 2006. Effect of sericea lespedeza (Lespedeza cuneata) fed as hay, on natural and experimental Haemonchus contortus infections in lambs. Vet. Parasitol. 141:273-278.

Martínez-Ortíz-de-Montellano, C., C. Arroyo-López, I. Fourquaux, J. F. J. Torres-Acosta, C. A. Sandoval-Castro, and H. Hoste. 2013. Scanning electron microscopy of Haemonchus contortus exposed to tannin-rich plants under in vivo and in vitro conditions. Exp. Parasitol. 133:281286.

Mederos, A., D. Kelton, A. S. Peregrine, J. VanLeeuwen, S. Fernández, A. LeBoeuf, P. Menzies, and R. Martin. 2014. Evaluation of the utility of subjective clinical parameters for estimating fecal egg counts and packed cell volume in Canadian sheep flocks. Vet. Parasitol. 205:568574.

Monagas, M., J. E. Quintanilla-López, C. Gómez-Cordovés, B. Bartolomé, and R. Lebrón-Aguilar. 2010. MALDI-TOF MS analysis of plant proanthocyanidins. J. Pharm. Biomed. Anal. 51:358-372.

Nieuwhof, G. J., and S. C. Bishop. 2005. Costs of the major endemic diseases of sheep in Great Britain and the potential benefits of reduction in disease impact. Anim. Sci. 81:23-29.

O'Connor, L. J., S. W. Walkden-Brown, and L. P. Kahn. 2006. Ecology of the free-living stages of major trichostrongylid parasites of sheep. Vet. Parasitol. 142:1-15.

Olayemi, D. O., M. M. Onakpa, and O. C. Jegede. 2019. Anthelmintic Activity of Hymenodictyon pachyanta Stem Bark Extracts against Haemonchus Contortus. Folia Vet. 63:30-36.

Pemberton, A. D., J. K. Brown, N. M. Craig, J. Pate, K. McLean, N. F. Inglis, D. Knox, and P. A. Knight. 2012. Changes in protein expression in the sheep abomasum following trickle infection with Teladorsagia circumcincta. Parasitology. 139:375-385. 
Qamar, M. F., A. Maqbool, and N. Ahmad. 2011. Economic losses due to haemonchosis in sheep and goats. Sci. Int. . 23:321-324.

Reed, J. D. 1995. Nutritional toxicology of tannins and related polyphenols in forage legumes. J. Anim. Sci. 73:1516-1528.

Ribeiro, W. L. C., W. P. P. Andre, G. S. Cavalcante, J. V. de Araújo-Filho, J. M. L. Santos, I. T. F. Macedo, J. V. de Melo, S. M. de Morais, and C. M. L. Bevilaqua. 2017. Effects of Spigelia anthelmia decoction on sheep gastrointestinal nematodes. Small Rumin. Res. 153:146-152.

Roeber, F., A. R. Jex, and R. B. Gasser. 2013. Impact of gastrointestinal parasitic nematodes of sheep, and the role of advanced molecular tools for exploring epidemiology and drug resistance - an Australian perspective. Parasit. Vectors. 6:153.

Sandler, H. A., and C. J. DeMoranville. 2009. Economic Analysis of Nitrogen Rate on Vine Production and Fruit Yield of Pruned Cranberry Beds. Horttechnology. 572-579.

Sargison, N. D., D. J. Wilson, D. J. Bartley, C. D. Penny, and F. Jackson. 2007. Haemonchosis and teladorsagiosis in a Scottish sheep flock putatively associated with the overwintering of hypobiotic fourth stage larvae. Vet. Parasitol. 147:326-331.

Shaik, S. A., T. H. Terrill, J. E. Miller, B. Kouakou, G. Kannan, R. M. Kaplan, J. M. Burke, and J. A. Mosjidis. 2006. Sericea lespedeza hay as a natural deworming agent against gastrointestinal nematode infection in goats. Vet. Parasitol. 139:150-157.

Šimpraga, M., I. Ljubičić, J. P. Hlede, A. S. Vugrovečki, A. Marinculić, and S. Tkalčić. 2015. Alternative approaches for the control of gastrointestinal nematodes in sheep farming: a review. Berl. Munch. Tierarztl. Wochenschr. 128:257-270.

Skantar, A.M., Agama, K., Meyer, S.L., Carta, L.K., Vinyard, B.T., 2005. Effects of geldanamycin on hatching and juvenile motility in Caenorhabditis elegans and Heterodera glycines. J. Chem. Ecol. 31 (10), 2481-2491, 10.1007/s10886-005-7114-z [doi].

Suhayda, B., C. J. DeMoranville, H. A. Sandler, W. R. Autio, and J. E. Vanden Heuvel. 2009. Sanding and Pruning Differentially Impact Canopy Characteristics, Yield, and Economic Returns in Cranberry. Horttechnology. 796-802. 
Su, X., A. B. Howell, and D. H. D'Souza. 2010. The effect of cranberry juice and cranberry proanthocyanidins on the infectivity of human enteric viral surrogates. Food Microbiol. 27:535-540.

Terrill, T. H., J. E. Miller, J. M. Burke, J. A. Mosjidis, and R. M. Kaplan. 2012. Experiences with integrated concepts for the control of Haemonchus contortus in sheep and goats in the United States. Vet. Parasitol. 186:28-37.

Terrill, T. H., J. A. Mosjidis, D. A. Moore, S. A. Shaik, J. E. Miller, J. M. Burke, J. P. Muir, and R. Wolfe. 2007. Effect of pelleting on efficacy of sericea lespedeza hay as a natural dewormer in goats. Vet. Parasitol. 146:117122.

Torres-Acosta, J. F. J., and H. Hoste. 2008. Alternative or improved methods to limit gastro-intestinal parasitism in grazing sheep and goats. Small Rumin. Res. 77:159-173.

Tzamaloukas, O., S. Athanasiadou, I. Kyriazakis, F. Jackson, and R. L. Coop. 2005. The consequences of short-term grazing of bioactive forages on established adult and incoming larvae populations of Teladorsagia circumcincta in lambs. Int. J. Parasitol. 35:329-335.

Váradyová, Z., J. Pisarčíková, M. Babják, A. Hodges, D. Mravčáková, S. Kišidayová, A. Königová, J. Vadlejch, and M. Várady. 2018. Ovicidal and larvicidal activity of extracts from medicinal-plants against Haemonchus contortus. Exp. Parasitol. 195:71-77.

Zajac, A.M., Conboy, G.A., 2012. Veterinary Clinical Parasitology, 8th ed. Wiley-Blackwell, Ames, lowa.

Zvinorova, P. I., T. E. Halimani, F. C. Muchadeyi, O. Matika, V. Riggio, and K. Dzama. 2016. Breeding for resistance to gastrointestinal nematodes the potential in low-input/output small ruminant production systems. Vet. Parasitol. 225:19-28. 


\section{CHAPTER 4}

\section{CONCLUSIONS}

The goal of this research was to determine the utility of a cranberry vine pellet in limiting gastrointestinal nematode infections in sheep. Previous research has shown in vitro and some limited in vivo evidence of anthelmintic activity of cranberry vine extracts and cranberry vine powder. The feeding trials used in this research were designed to follow-up and expand upon the previous results. In the previous study by Barone et al. (2018), cranberry vine powder was orally administered to lambs using a drench gun to ensure consumption. The treatment was given for three consecutive days, and FEC in the treated lambs showed a slight suppression compared to control lambs.

The first feeding trial of the current study used cranberry vine powder to produce a $100 \%$ cranberry vine pellet to be fed as a supplement lambs experimentally infected with gastrointestinal nematodes. Throughout the entire trial, consumption of the pellet was extremely limited and only reached half of the $600 \mathrm{~g}$ offered by the end of the six weeks. Even with limited consumption, the treatment group started to show a slight suppression of FEC at week 6 when compared to the control group. Due to the somewhat promising results observed, a second feeding trial was designed to address the issue of consumption, and palatability of the pellet was made a top priority. 
In the second feeding trial of the current study, a $50 \%$ cranberry vine pellet was formulated to be both palatable and nutritionally balanced with the commercially produced $16 \%$ sheep pellet that was being fed to the lambs. There were two treatment groups in this study, CVP250 that consumed $250 \mathrm{~g}$ of cranberry vine per day and CVP500 that consumed $500 \mathrm{~g}$ of cranberry vine per day. Consumption of the pellet was not an issue at any point throughout the trial, showing that the palatability issue from the first trial had successfully been addressed. This trial was also designed to study a natural GIN infection, versus the two previous studies that looked at experimental Haemonchus contortus infections; however, limited pasture contamination created the need for an experimental infection to be superimposed on the pasture infection. The FEC of the lambs fed $250 \mathrm{~g}$ of CVP and the control group initially rose from weeks 1 to 4 whereas there was no increase in FEC in the lambs fed $500 \mathrm{~g}$ of CVP over this same period. This would potentially be indicative of a reduction in fecundity or overall worm burden, which could be determined in future studies using larval cultures and post-mortem worm samples to calculate these parameters.

In order to better understand the effects that have been observed, as well as address issues that have arisen, further studies should include in depth investigation into the dose response of cranberry vine. In the first trial, a suppression effect appeared to occur when lambs were consuming around $300 \mathrm{~g}$ of CV per day; however, in the second trial the FEC of lambs consuming 250 g per day increased in a manner similar to the control group FEC, while 
the FEC of lambs consuming $500 \mathrm{~g}$ per day did not change. Further studies should also include analysis of the effects of CV on larval and adult stages of GIN in vivo using scanning electron microscopy, in order to further our understanding of the mechanism of action of $\mathrm{CV}$ on a gastrointestinal nematode infection. Furthermore, future studies should look into the optimal feeding time for $\mathrm{CV}$ to determine whether the utility could be increased if fed prior to infection rather than after an infection is already established.

To date, cranberry vine has shown modest anthelmintic potential against small ruminant GIN both in vitro and in vivo. The effects of CV on GIN observed are not comparable to the use of commercially produced anthelmintics, but it is possible that it could be used in conjunction with other methods to control GIN infections as well as reduce pasture contamination and reinfection. The mechanism of action and the corresponding bioactive compounds that are responsible for the observed effects are still unknown and require further investigation. 


\section{APPENDICES}

\section{Standard Operating Procedure for Blood Collection}

(Adapted protocol from the dissertation of Carly Barone; modified from Purdue University Blood Sampling in Sheep by Mitchell et al. (Retrieved on September 23 ,

2008 from http://www.ces.purdue.edu/extmedia/AS/AS-557-W.pdf))

\section{Blood Collection:}

1. Properly restrain animal holding the head parallel to the ground and at a $30^{\circ}$ angle to the side.

2. Electric clippers may be used to prepare the neck by shaving off a patch of wool approximately 4 inches wide and 8 inches long.

3. To locate the vein, apply pressure with the thumb approximately half way down the side of the neck (on either side).

4. Secure a Vacutainer needle $(21 \mathrm{G}, 112$ inch needle, Becton, Dickinson, and Company; Franklin Lakes, NJ, USA; REF \#367215) to the Vacutainer holder (Becton, Dickinson, and Company; Franklin Lakes, NJ, USA; REF \#364815) by twisting.

5. While holding off on the vein with one hand, insert the needle into the vein with the bevel facing upward.

6. Once the needle is placed, push the EDTA tube (Becton, Dickinson, and Company; Franklin Lakes, NJ, USA; REF \#367863) into the holder and onto the needle. 
7. Gently adjust the needle until blood begins to flow into the tube. Blood flow will cease once the tube is full.

8. Gently remove the tube and slowly invert eight times.

9. Remove the needle and your hand from the neck and allow the vein to relax.

10. EDTA tubes should be immediately placed in ice. 


\section{Standard Operating Procedure for Determining Packed Cell Volume}

(Adapted protocol from the dissertation of Carly Barone)

\section{Sample Preparation:}

1. Collect blood by jugular venipuncture into Vacutainer EDTA tubes, invert tube eight times, and place on ice.

2. Invert tube to mix before use.

3. Without spilling, tip tube so that blood moves toward the opening. Place one end of the micro hematocrit capillary tube (Thermo Fisher Scientific Inc., Waltham, MA, USA; REF \#22-362-574) into the blood and allow tube to fill by capillary action. Only fill tube up to $3 / 4$ of the way.

4. Place fingertip at one end of the tube to prevent leaking. Insert the other end of the tube into the white sealing wax (Critoseal, Leica Biosystems, Buffalo Grove, IL, USA; REF \#02-676-20).

5. Place capillary tubes into centrifuge rotor, making sure that the wax in the end

of the tube faces outward (not towards the center of the centrifuge). All samples should be run in duplicate and placed across from each other, keeping

the centrifuge balanced.

6. To prevent tubes from cracking, take a pin and gently push tubes against the

outer edge of the rotor.

7. Centrifuge for 3 minutes at 15,000 RPM at room temperature. 


\section{Sample Reading:}

1. Spin the PCV Reader (International Equipment Company; Needham, MA) until it reaches the 100 mark.

2. Place the capillary tube into the sample groove.

3. Align the wax/blood interface with the line at the bottom of the sample groove.

4. Spin the top plate of the PCV reader until the "swirl" aligns with the plasma/air interface.

5. Spin both plates until the "swirl" aligns with the white blood cell/red blood cell interface. The value under the red line is the PCV to be read and reported as a percentage. 


\section{Standard Operating Procedure for Fecal Egg Counts (FEC)}

(Whitlock (1948), Modified McMaster Technique)

\section{Procedure:}

1. Fecal samples are collected directly from the rectum and kept refrigerated until

analysis. Samples should be run as promptly as possible, but within seven days from the time of collection.

2. Two grams of feces are measured on a calibrated scale and placed into a I2 ounce cup.

3. Add $28 \mathrm{ml}$ Fecasol ${ }^{8}$ (Vetoquinol U.S.A., Inc., Fort Worth, TX, USA; REF \#014008-1G) to feces and soak for approximately 5 minutes.

4. Gently break up fecal pellet with a tongue depressor. Set cup aside to sit for approximately 5 minutes.

5. Pour fecal solution through a square of 2-ply cheesecloth into a new cup. Use

tongue depressor to gently press fecal solution through gauze.

6. Wet the McMaster slide (Chalex Corporation, Issaquah, WA, USA) with distilled water and gently pat dry top and bottom with paper towels.

7. Immediately pipet solution into both sides of the McMaster slide, using a 1 $\mathrm{ml}$ syringe, a sample of the suspension and fill one side of the chamber. 
8. Place slide on microscope platform and let sit, without disturbance, for 5 minutes.

9. Focus on the top layer using the low power (10x) objective. Count all eggs inside of the grid areas (greater than 12 of egg inside grid).

10. Count only trichostrongylid eggs (oval shaped, $\sim 80-90$ microns long)

11. Total egg count:

(chamber $1+$ chamber 2$) * 50$ = eggs per gram (epg) 


\section{Standard Operating Procedure for Nematode Recovery Post Mortem}

(Adapted protocol from Miller parasitology laboratory, unpublished methods)

\section{Preparation:}

1. Lambs are stunned by captive bolt and exsanguinated.

2. Gastrointestinal tract is collected as soon as possible following exsanguination.

3. Mesenteric tissue is cleaned away from the abomasum and three pieces of butcher's rope are used to tie the junction of the omasum and abomasum, the junction of the abomasum and beginning of the small intestine, and at the junction of the small intestine and large intestine.

4. The rumen, reticulum, and omasum are removed and the remaining is placed in a cooler until nematode recovery begins.

\section{Nematode Recovery:}

Abomasum Wash:

1. The abomasum is removed from the tract and cleaned of excess fat and mesenteric tissue.

2. A scalpel is used to open the abomasum along the greater curvature.

3. Contents are collected into a pan by washing with warm water. The folds of the abomasum are gently rubbed to remove any debris.

4. Once completely cleaned the abomasal contents are brought up to $2 \mathrm{~L}$.

5. The contents are mixed thoroughly using an inverted beaker and stirring in a figure eight motion. Immediately a $10 \%$ aliquot of the contents, $200 \mathrm{ml}$, is taken and placed into a $500 \mathrm{ml}$ jar. 
6. The sample is fixed with $200 \mathrm{ml} \mathrm{10 \%} \mathrm{phosphate} \mathrm{buffered} \mathrm{formalin} \mathrm{(PBF;}$ Thermo Fisher Scientific Inc., Waltham, MA, USA; REF \#SF100-20) and stored until nematode quantification and identification.

Abomasum Soak:

(A soak is performed to collect any larvae that may be embedded within the tissue of the abomasum.)

1. Once the wash is completed, the abomasum is spread out on in a pan, covered with saline.

2. The abomasum is incubated at $37 \mathrm{oC}$ overnight.

3. The contents of the soak are collected and the abomasum is gently washed with saline and collected.

4. Contents are allowed to settle for at least 2 hours.

5. In order to collect the settled contents a serological pipet is used to remove as much liquid without disturbing the bottom as possible.

6. The remaining sample is collected into $500 \mathrm{ml}$ jars, $200 \mathrm{ml}$ in each, and fixed with $200 \mathrm{ml}$ 10\% PBF each.

7. Using a No. 200 sieve, larvae will be removed from the 5\% PBF and backwashed off the sieve with water.

8. Nematodes will be pipetted onto a petri dish (with $13 \mathrm{~mm}$ grid, BD Bioscience) and stained with Lugol's lodine (Lugol's lodine, Electron Microscopy Sciences, Hatfield, PA, USA; REF \#26055-05). Sodium hypochlorite will be added to allow for counting of larvae using a dissection microscope (Zoom Stereomicroscope, Nikon ${ }^{8}$ SMZ745, MVI, Avon, MA). 
9. Adults will be identified by sex and stage of development. 


\section{Analysis of 2017 CVP composite}

\section{Dairy One Feed Analyses}

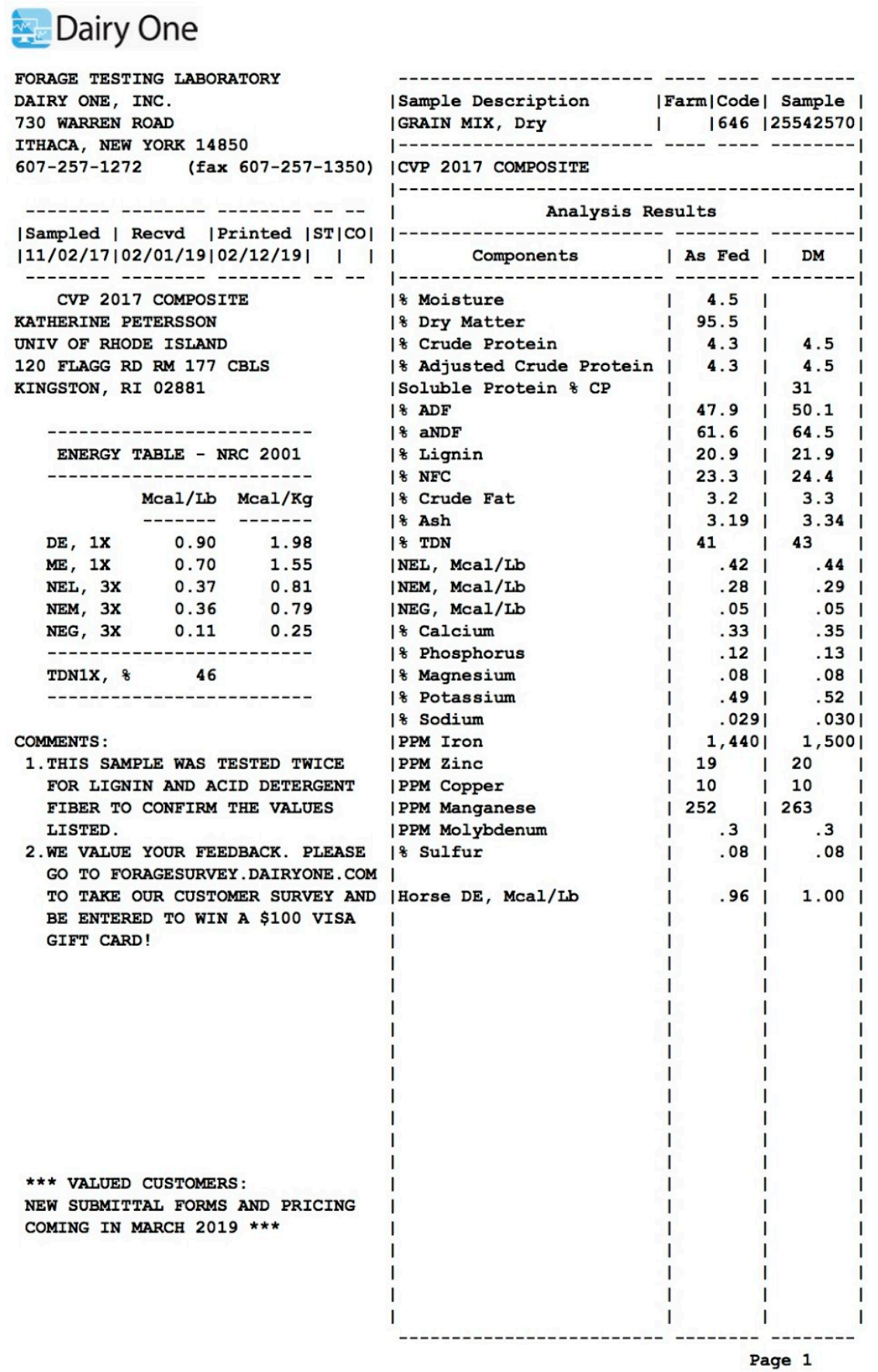




\section{Analysis 1: 2018 chopped CV}

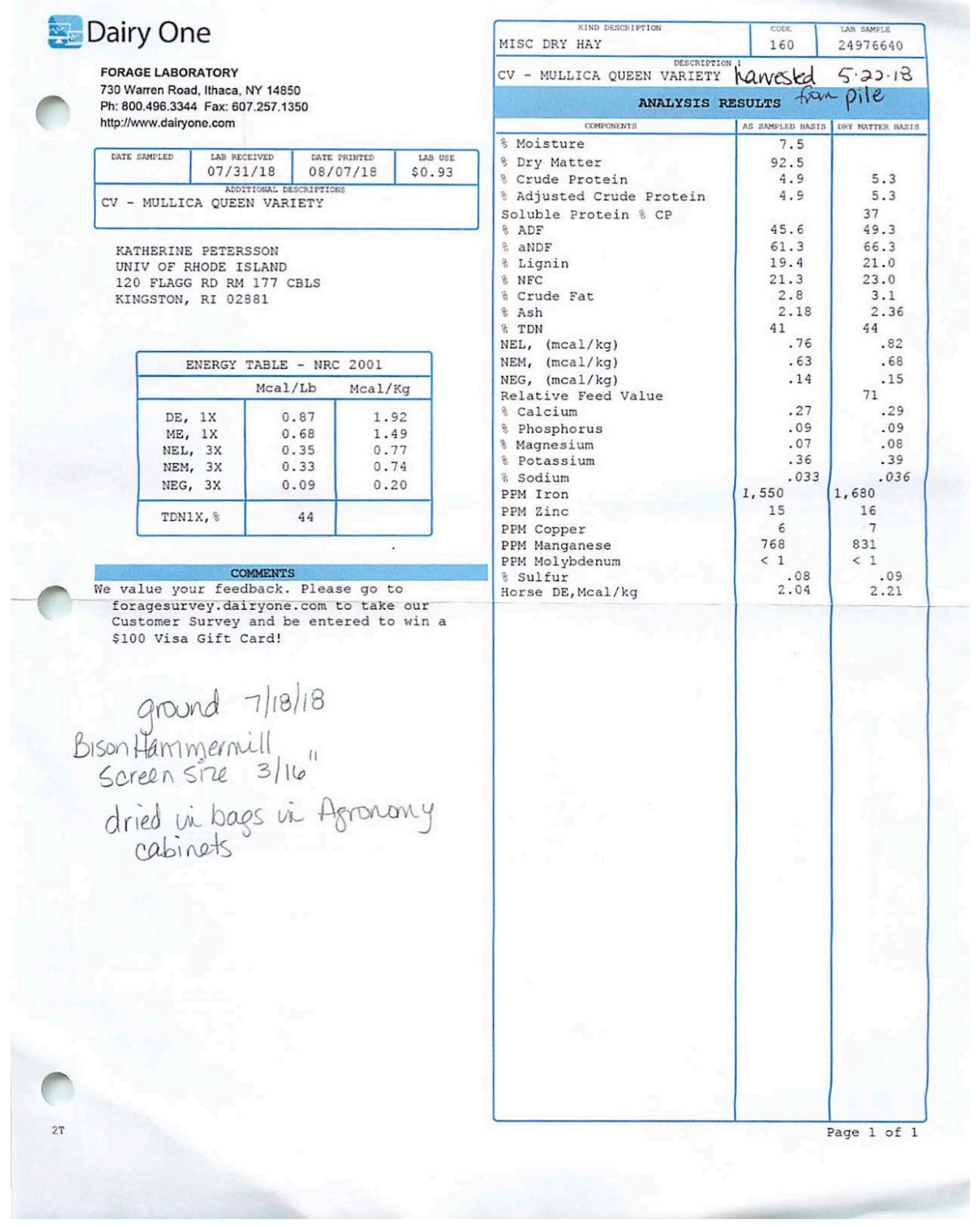


Analysis 2: 2018 chopped CV

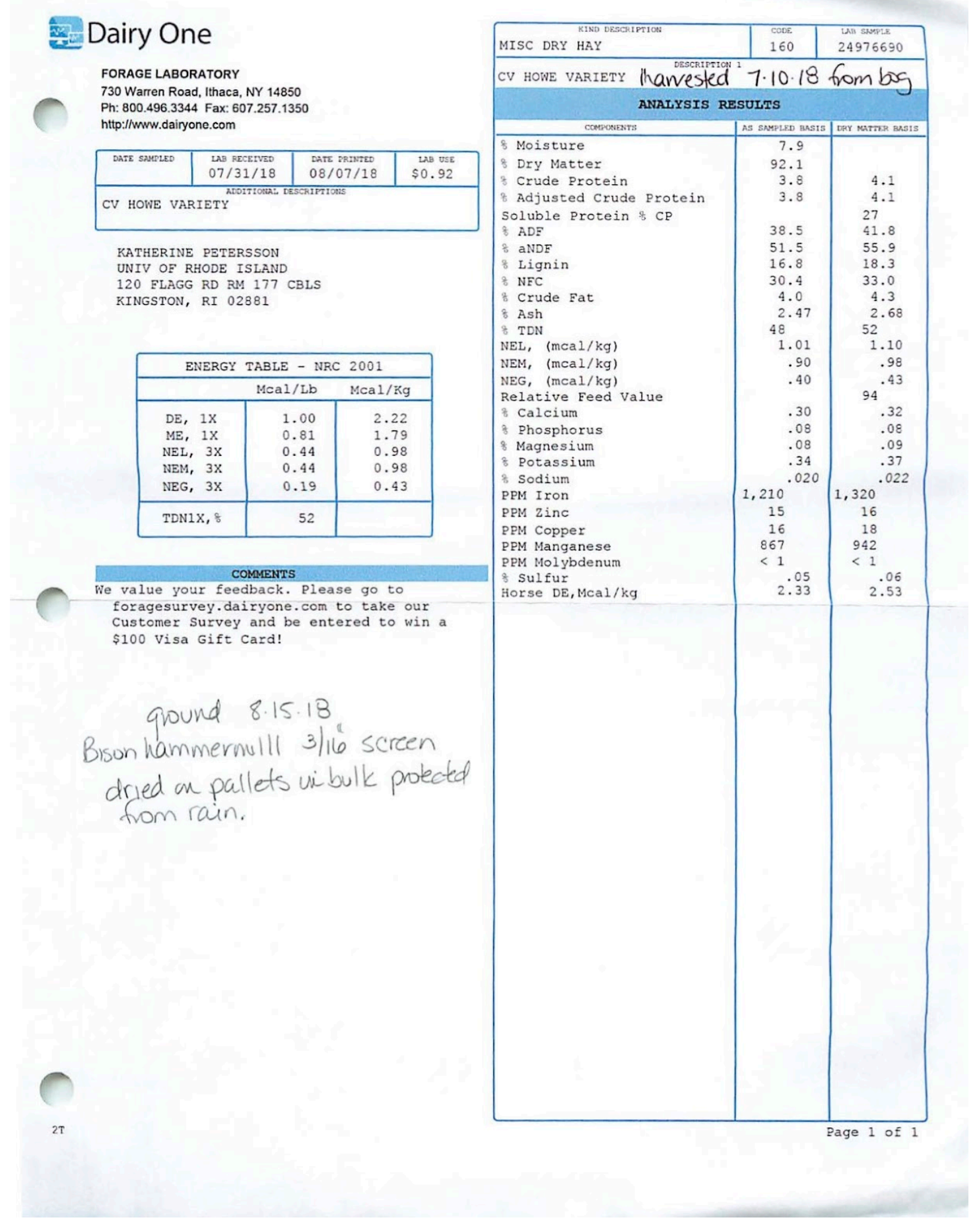




\section{Analysis 1: 2018 16\% sheep pellet}

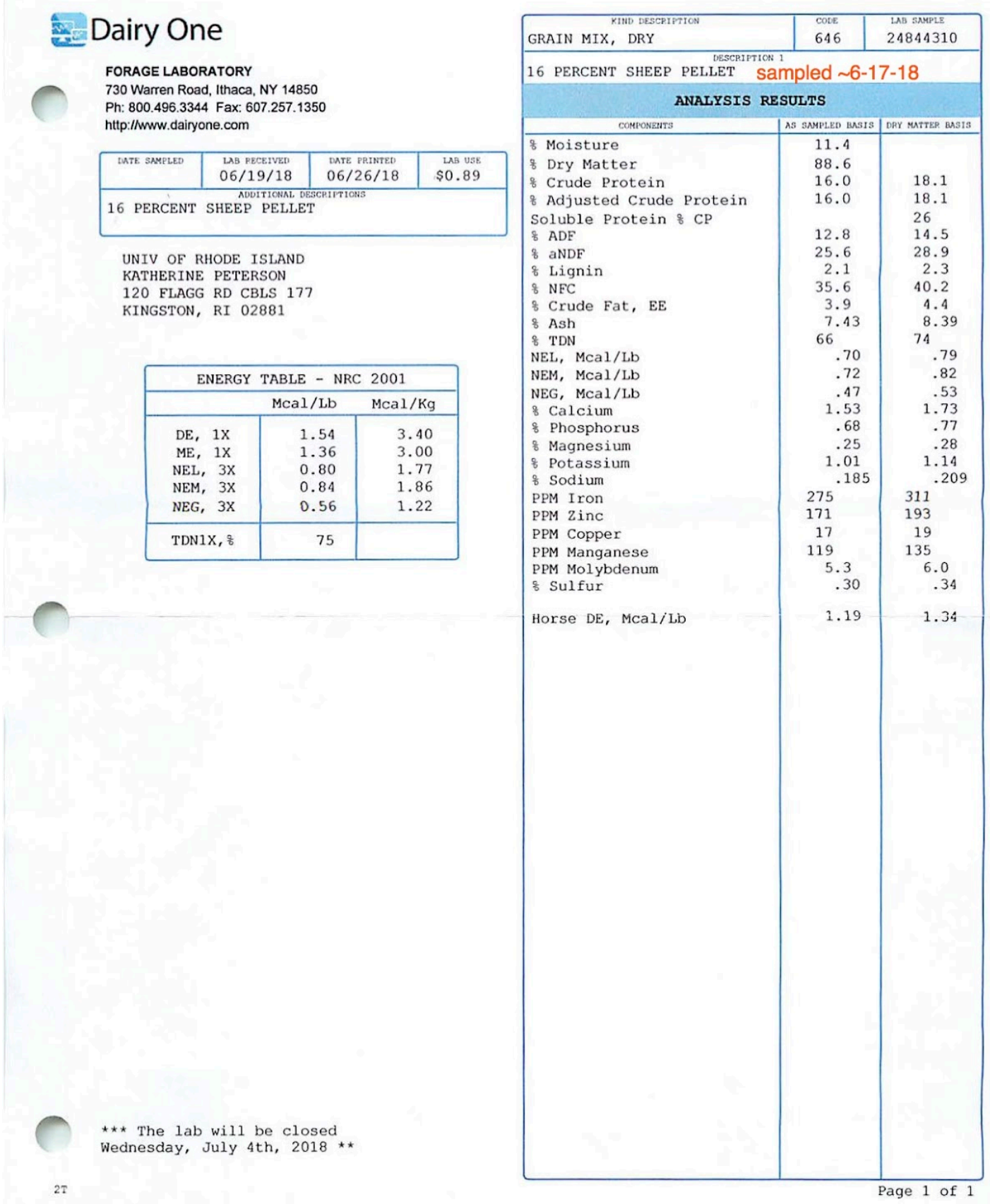




\section{Analysis 2: 2018 16\% sheep pellet}

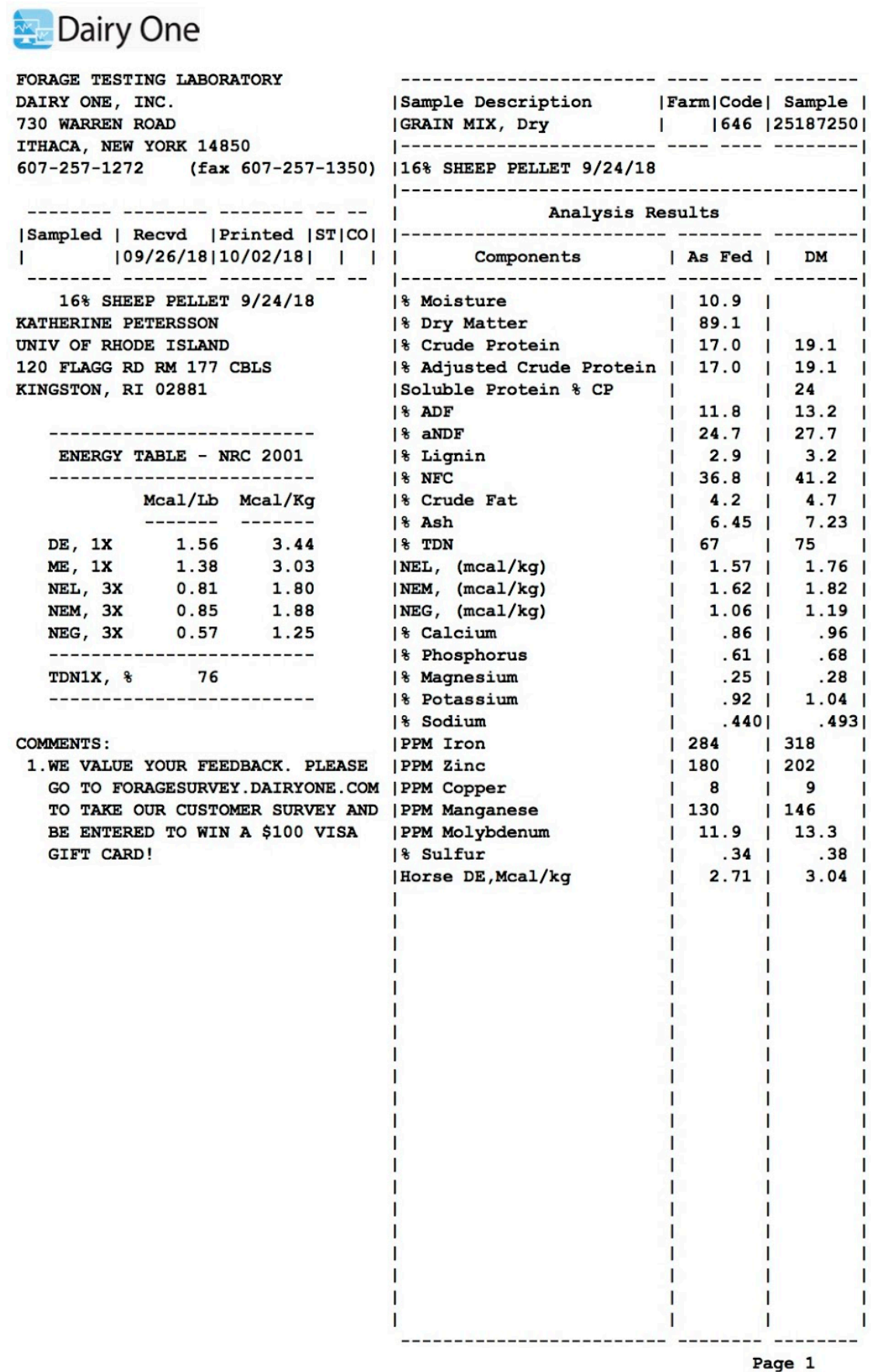




\section{Analysis of $201816 \%$ sheep pellet composite}

\begin{tabular}{|c|c|c|c|c|c|}
\hline FORAGE TESTING LABORATORY & & & ----- & & \\
\hline DAIRY ONE， INC. & | Sample Description & $\mathrm{Fa}$ & $\mathrm{rm} \mid$ Code $\mid$ & Sample & \\
\hline 730 WARREN ROAD & |GRAIN MIX，DrY & 1 & $|646|$ & |25386180 & \\
\hline ITHACA， NEW YORK 14850 & |------------------- & -- & ----- & ------ & \\
\hline $607-257-1272 \quad($ fax $607-257-1350)$ & |168 SHEEP PELLET COMPOSI & TE & $11-19-18$ & 8 & 1 \\
\hline 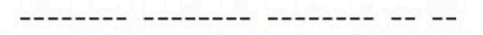 & i Analysis Re & lesu. & Its & & i \\
\hline |Sampled | Recvd |Printed |ST|CO| & I--------------- & -- & ------ & & -1 \\
\hline | $|11 / 26 / 18| 11 / 29 / 18|\quad| \quad \mid$ & I Components & 12 & As Fed & I DM & 1 \\
\hline 168 SHEEP PELLET COMPOSITE $11-1$ & 118 Moisture & I & 9.5 & I & I \\
\hline KATHERINE PETERSSON & If Dry Matter & I & 90.5 & i & I \\
\hline UNIV OF RHODE ISLAND & If Crude Protein & i & 17.1 & 18.9 & i \\
\hline 120 FLAGG RD RM 177 CBLS & If Adjusted Crude Protein & i & 17.1 & 18.9 & i \\
\hline KINGSTON，RI 02881 & | Soluble Protein \& CP & 1 & & I 24 & I \\
\hline & is $\mathrm{ADF}$ & i & 13.2 & 14.6 & i \\
\hline 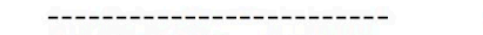 & If aNDF & 1 & 25.1 & 27.7 & I \\
\hline ENERGY TABLE - NRC 2001 & 18 Lignin & I & 3.1 & 3.4 & I \\
\hline 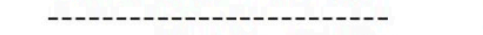 & 18 NFC & i & 37.7 & 41.6 & i \\
\hline $\mathrm{Mcal} / \mathrm{Lb}$ Mcal/Kg & I8 Crude Fat & 1 & 3.9 & 4.3 & 1 \\
\hline ------- ------- & 18 Ash & 1 & 6.71 & 7.41 & 1 \\
\hline $1.54 \quad 3.40$ & 1\% TDN & I & 67 & 74 & I \\
\hline $\mathrm{ME}, 1 \mathrm{X}$ & |NEL, Mcal/Lb & I & .71 & .79 & 1 \\
\hline NEL， $3 \mathrm{X}$ & |NEM, Mcal/Lb & I & .73 & .81 & 1 \\
\hline NEM， $3 \mathrm{X}$ & |NEG, Mcal/Lb & i & .48 & .53 & 1 \\
\hline NEG， $3 \mathrm{X}$ & If Calcium & 1 & .84 & .92 & 1 \\
\hline --------- & I8 Phosphorus & i & .59 & .65 & 1 \\
\hline TDN1X， 8 & I8 Magnesium & 1 & .26 & .28 & 1 \\
\hline 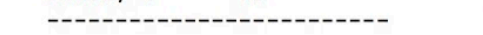 & if Potassium & i & .95 & 1.05 & 1 \\
\hline & If Sodium & i & .363 & $31 \quad .402$ & 21 \\
\hline COMMENTS : & |PPM Iron & i & 248 & | 274 & i \\
\hline 1.WE VALUE YOUR FEEDBACK. PLEASE & |PPM Zinc & & 185 & | 204 & i \\
\hline GO TO FORAGESURVEY.DAIRYONE.COM & |PPM Copper & 1 & 8 & 19 & I \\
\hline TO TAKE OUR CUSTOMER SURVEY AND & |PPM Manganese & I & 140 & 155 & I \\
\hline BE ENTERED TO WIN A $\$ 100$ VISA & | PPM Molybdenum & I & 16.8 & I 18.6 & 1 \\
\hline GIFT CARD! & If Sulfur & i & .30 & .33 & 1 \\
\hline & i & i & & i & i \\
\hline & |Horse DE, Mcal/Lb & i & 1.24 & 1.37 & 1 \\
\hline & 1 & 1 & & 1 & $\mathrm{I}$ \\
\hline & i & i & & i & i \\
\hline & I & I & & I & I \\
\hline & I & 1 & & I & 1 \\
\hline & I & 1 & & I & 1 \\
\hline & I & 1 & & I & 1 \\
\hline & 1 & 1 & & 1 & I \\
\hline & I & 1 & & 1 & I \\
\hline & I & I & & I & I \\
\hline & i & I & & i & i \\
\hline & i & i & & i & i \\
\hline & I & 1 & & I & 1 \\
\hline$\star \star \star$ THE LAB WILL BE CLOSED & i & i & & i & i \\
\hline TUESDAY， DECEMBER 25TH，2018\& & I & 1 & & 1 & I \\
\hline 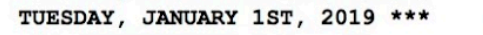 & I & I & & 1 & I \\
\hline & i & I & & i & I \\
\hline & I & 1 & & I & 1 \\
\hline & I & I & & 1 & 1 \\
\hline & I & 1 & & 1 & 1 \\
\hline
\end{tabular}




\section{Analysis of 2018 50\% CVP composite}

\begin{tabular}{|c|c|c|c|c|c|}
\hline FORAGE TESTING LABORATORY & & & & & \\
\hline DAIRY ONE， INC. & | Sample Description & & Irm | Code & Sample & \\
\hline 730 WARREN ROAD & |GRAIN MIX，Dry & I & 1646 & |25386190 & \\
\hline ITHACA， NEW YORK 14850 & |------------------- & -- & ----- & ----- & \\
\hline $607-257-1272 \quad(\operatorname{fax} 607-257-1350)$ & $\begin{array}{l}\text { |508 CV PELLET COMPOSITE } \\
\text { | }\end{array}$ & 11 & -19-18 & ------- & $\begin{array}{cl}-1 \\
-1\end{array}$ \\
\hline 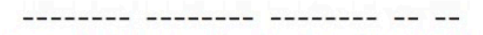 & I $\quad$ Analysis $R$ & Rest & Ilts & & i \\
\hline |Sampled | Recvd |Printed |ST|CO| & 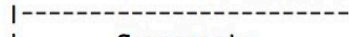 & & ----- & & -1 \\
\hline | $|11 / 26 / 18| 11 / 29 / 18|\quad| \quad \mid$ & Components & & As Fed & I DM & 1 \\
\hline 508 CV PELLET COMPOSITE $11-19-1$ & 118 Moisture & I & 8.8 & I & I \\
\hline KATHERINE PETERSSON & 18 Dry Matter & I & 91.2 & I & I \\
\hline UNIV OF RHODE ISLAND & I8 Crude Protein & 1 & 20.0 & 22.0 & 1 \\
\hline 120 FLAGG RD RM 177 CBLS & If Adjusted Crude Protein & i & 20.0 & 22.0 & i \\
\hline KINGSTON，RI 02881 & | Soluble Protein \& CP & 1 & & 12 & I \\
\hline & I8 ADF & & 21.0 & 23.0 & 1 \\
\hline 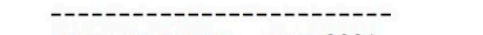 & I8 aNDF & 1 & 27.2 & 29.8 & I \\
\hline ENERGY TABLE - NRC 2001 & 18 Lignin & I & 10.2 & 11.2 & 1 \\
\hline 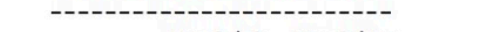 & 18 NFC & I & 32.3 & 35.4 & I \\
\hline Mcal/Lb Mcal/Kg & I8 Crude Fat & I & 3.9 & 4.2 & I \\
\hline ------- ------- & 18 Ash & 1 & 7.80 & 8.56 & 1 \\
\hline $1.38 \quad 3.03$ & I\% TDN & I & 58 & 64 & I \\
\hline $\mathrm{ME}, 1 \mathrm{X}$ & |NEL, Mcal/Lb & I & .61 & .67 & 1 \\
\hline NEL, $3 \mathrm{X}$ & |NEM，Mcal/Lb & 1 & .60 & .66 & 1 \\
\hline NEM, $3 \mathrm{X} \quad 0.72$ & |NEG, Mcal/Lb & i & .36 & .39 & 1 \\
\hline NEG， $3 \mathrm{X} \quad 0.45$ & I8 Calcium & I & 1.12 & 1.23 & 1 \\
\hline 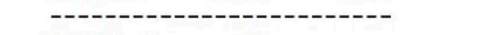 & If Phosphorus & I & .52 & .57 & 1 \\
\hline TDN1X，8 65 & 18 Magnesium & I & .29 & .32 & 1 \\
\hline -------------------- & I8 Potassium & I & .99 & 1.09 & 31 \\
\hline & I8 Sodium & 1 & .215 & .236 & 36। \\
\hline COMMENTS : & |PPM Iron & & 932 & 1,020 & 201 \\
\hline 1.WE VALUE YOUR FEEDBACK. PLEASE & |PPM Zinc & & 179 & | 196 & 1 \\
\hline GO TO FORAGESURVEY.DAIRYONE.COM & | PPM Copper & 1 & 28 & 1 31 & I \\
\hline TO TAKE OUR CUSTOMER SURVEY AND & |PPM Manganese & & 405 & I 444 & I \\
\hline BE ENTERED TO WIN A $\$ 100$ VISA & | PPM Molybdenum & 1 & 1.6 & I 1.8 & 1 \\
\hline GIFT CARD! & 18 Sulfux & I & .25 & .27 & 71 \\
\hline & 1 & 1 & & I & I \\
\hline & |Horse DE, Mcal/Lb & I & 1.17 & 1.29 & 91 \\
\hline & 1 & I & & 1 & 1 \\
\hline & I & 1 & & I & 1 \\
\hline & I & 1 & & I & 1 \\
\hline & I & I & & 1 & 1 \\
\hline & I & I & & I & 1 \\
\hline & 1 & 1 & & I & 1 \\
\hline & I & 1 & & 1 & I \\
\hline & I & 1 & & I & 1 \\
\hline & I & I & & I & I \\
\hline & I & 1 & & 1 & 1 \\
\hline & I & I & & I & I \\
\hline & I & I & & I & I \\
\hline 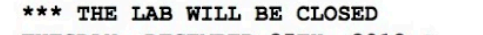 & I & I & & 1 & I \\
\hline TUESDAY， DECEMBER 25TH，2018\& & I & 1 & & 1 & 1 \\
\hline TUESDAY，JANUARY 1ST，2019 *** & I & I & & 1 & 1 \\
\hline & I & 1 & & I & 1 \\
\hline & I & 1 & & 1 & 1 \\
\hline & I & I & & 1 & 1 \\
\hline & I & I & & 1 & 1 \\
\hline
\end{tabular}




\section{Analysis of 2018 grass hay composite}

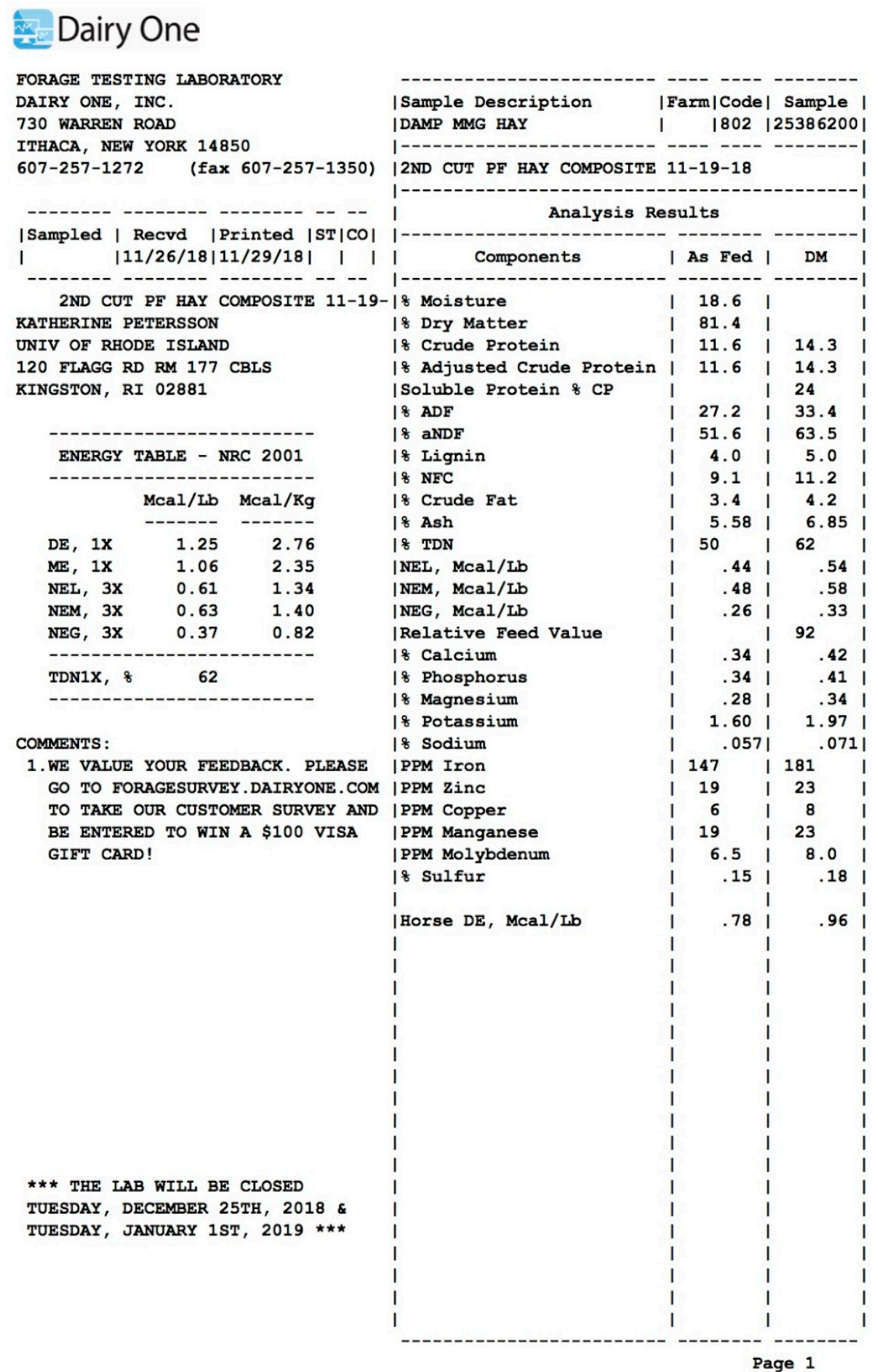


$\mathbf{5 0 \%}$ Cranberry Pellet Formulation

Feed Date mixed:

\begin{tabular}{|c|c|c|c|}
\hline Petersson $500 \mathrm{~g} \mathrm{CV}$ pellets & $8 / 27$ & 2018 & Thonney \\
\hline Ingredient & $\%$ & $\$ /$ ton & Amount \\
\hline For - Cranberry vine & 50.0 & 50 & $1,000.0$ \\
\hline Bypr - Wheat midds & 22.1 & 100 & 442.0 \\
\hline Prot - Soybean meal, 49\% & 20.0 & 372 & 400.0 \\
\hline Bypr - Molasses; sugarcane (a & 4.00 & 200 & 80.0 \\
\hline Min - Calcium carbonate & 1.30 & 150 & 26.0 \\
\hline Prmx - GRMSHEEP mineral & 1.0000 & 600 & 20.0 \\
\hline Prot - Ammonium chloride & 0.7000 & 969 & 14.0 \\
\hline Misc - Pellet binder & 0.5000 & 200 & 10.0 \\
\hline Min - Salt & 0.4000 & 50 & 8.00 \\
\hline Feed cost/ton: $\$ 145$ & & tal mix: & 2000.0 \\
\hline
\end{tabular}

DM cost/ton: $\$ 161$

\begin{tabular}{|c|c|c|c|c|c|c|c|c|c|c|c|}
\hline \multicolumn{2}{|c|}{$\begin{array}{l}010 \text { Ewe lambs: Early lactation ( } 2 \\
\text { lambs) }\end{array}$} & \multicolumn{2}{|c|}{$\begin{array}{cc}145.0 & \mathrm{lb} \\
65.0 & \mathrm{~kg}\end{array}$} & \multicolumn{3}{|c|}{ Estimated DM intake: } & $7.3 \mathrm{lb}$ or & \multicolumn{2}{|l|}{$3.3 \mathrm{~kg}$} & \multicolumn{2}{|c|}{ Ca:P2.06 } \\
\hline \multirow{5}{*}{$\begin{array}{r}\text { Feed: } \quad 90.45 \\
\text { Suggested level: } \\
\text { Feed minus level: }\end{array}$} & \multirow{2}{*}{$\begin{array}{r}\text { DDM, \% } \\
61.05\end{array}$} & $\mathrm{CP}, \%$ & NDF, $\%$ & $\begin{array}{l}\text { Indigestible } \\
\text { NDF, \% }\end{array}$ & \multicolumn{2}{|c|}{ pfNDF, \% } & $\begin{array}{l}\text { NSCHO, } \\
\% \text { (max) }\end{array}$ & $\mathrm{EE}, \%$ & Ash, \% & $\mathrm{Ca}, \%$ & $P, \%$ \\
\hline & & 18.27 & 40.36 & 22. & 86 & 17.50 & 32.89 & 1.77 & 6.67 & 1.10 & 0.53 \\
\hline & 75.00 & 16.00 & & 10. & 00 & 25.00 & 39.00 & 5.00 & 5.00 & 1.06 & 0.22 \\
\hline & -13.95 & 2.27 & & 12. & 86 & -7.50 & -6.11 & -3.23 & 1.67 & 0.03 & 0.31 \\
\hline & $K, \%$ & $\mathrm{Mg}, \%$ & $\mathrm{~S}, \%$ & I, ppm & $\mathrm{Fe}, \mathrm{ppm}$ & $\mathrm{Cu}, \mathrm{ppm}$ & m Mo, ppm & Co, ppm & $\mathrm{Mn}, \mathrm{ppm}$ & Zn, ppm & Se, ppm \\
\hline Feed: & 1.15 & 0.28 & 0.22 & 0.62 & 477.38 & 12.32 & 2.43 & 0.54 & 226.10 & 77.18 & 0.46 \\
\hline Suggested level: & 0.80 & 0.18 & 0.26 & 1.60 & 50.00 & 10.00 & 0.50 & 0.20 & 40.00 & 33.00 & 0.30 \\
\hline Feed minus level: & 0.35 & 0.10 & -0.04 & -0.98 & 427.38 & 2.32 & 1.93 & 0.34 & 186.10 & 44.18 & 0.16 \\
\hline & VitA, kIU/lb & VitD, kIU & VitE, & IU/lb & Decoquinate & e, g/lb & Monensin, m & $\mathrm{mg} / \mathrm{lb}$ & alocid, mg/ll & & \\
\hline Feed: & 4.33 & & 38 & 6.61 & 0.0000 & & 0.0 & .0 & 0.0 & & \\
\hline Suggested level: & 0.96 & & .15 & 62.00 & 0.0136 & & & & & & \\
\hline Feed minus level: & 3.37 & & .23 & -55.39 & -0.0136 & & & & & & \\
\hline
\end{tabular}

FeedForm version: 6.4: 4/11/2016

8/27/2018 4:42:32 PM
Copyright (c) 2010 by Michael L. Thonney

Page 1 of 1

\section{Cornell University Toxicology Reports}

Toxicology lamb 1810 
https://ahdc.vet.cornell.edu

Owner: University of Rhode Island

149 New Sweeden Rd

Woodstock, CT 06281

Sampled: 11/02/2018

(860) $974-2780$

\section{Toxicology}

Director Karyn Bischoff - 607-253-3900

Mineral Panel

Item

Sodium: 4663 ppm

Potassium: $6021 \mathrm{ppm}$

Copper: $12.95 \mathrm{ppm}$

Iron: 204.9 ppm

Manganese: $7.05 \mathrm{ppm}$

Zinc: $169.1 \mathrm{ppm}$

Molybdenum: $5.85 \mathrm{ppm}$

Comments: The results above, except for moisture, are given on a dry matter basis. Reference ranges for renal trace mineral concentrations for South American Camelids are given below. These ranges are calculated from data in Puls Mineral Levels in Animal Health and given on a dry matter basis.

Copper 12 to 25 ppm dry matter Iron 184 to $750 \mathrm{ppm}$ dry matter Zinc 44-125 ppm dry matter

No reference range is available for renal molybdenum concentrations in alpaca or related species. The range for sheep is 1.5 to 16 ppm dry matter.

11810 - Ovine Dorset Male Liver

Moisture: $72.07 \%$

Dry Matter: $27.93 \%$

Calcium: $184.3 \mathrm{ppm}$

Phosphorus: $14280 \mathrm{ppm}$

Magnesium: $617.8 \mathrm{ppm}$

Sodium: $2515 \mathrm{ppm}$

Potassium: 7523 ppm

Copper: $546.2 \mathrm{ppm}$

Iron: $310.4 \mathrm{ppm}$

Manganese: $49.73 \mathrm{ppm}$

Zinc: $231.6 \mathrm{ppm}$

Molybdenum: 3.99 ppm 


\section{Mineral Panel}

Comments: The liver copper concentration is higher than expected in this lamb. However, the renal copper concentration is low, so it is unlikely that this individual had clinical copper toxicosis.

The above results, except for moisture, are given on a dry matter basis. Reference ranges for liver mineral concentrations in South American camelids are calculated below on a dry matter basis from data in Puls Mineral Levels in Animal Health.

Copper 120 to 500 ppm dry matter Iron 280 to $1000 \mathrm{ppm}$ dry matter

Zinc 80 to 450 ppm dry matter

No reference range is available for hepatic molybdenum concentrations in this or closely related species. The range given for sheep liver is 1.5 to $6 \mathrm{ppm}$.

Shipping Violation Alert! If you are re-using boxes from your clinic to ship specimens to us using our discounted label program, UPS is requiring that the AHDC notify all clients of potential shipping violations caused by extra barcodes or symbols on package exteriors. As sorting mechanisms become more automated, the stray exterior marks on boxes can cause them to be routed inappropriately, causing violations for UPS with the Federal Aviation Administration (FAA) that are then passed on to us and ultimately to you. Violations also cause shipments to be sent back to you untested. PLEASE CHECK ALL SIX (6) SIDES OF YOUR BOX BEFORE SHIPPING! 


\section{Post-mortem toxicology from control and CVP500 lambs}

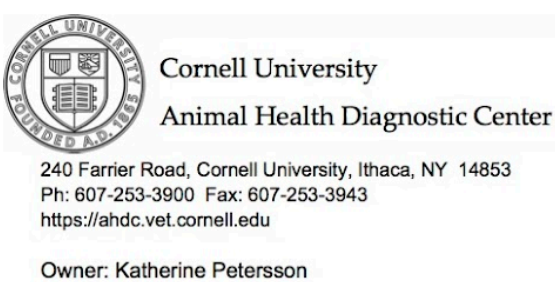

Univ of RI Peckham Farm - (268901) 55 Peckham Farm Rd

Kingston, RI 02881

(401) $874-4183$

\author{
Sampled: $11 / 14 / 2018$ \\ Received: $11 / 21 / 2018$ \\ Finalized: 11/21/2018 \\ Reference Number: Katherine Petersson
}

Moisture: $63.64 \%$ Dry Matter: $36.36 \%$ Calcium: $129.2 \mathrm{ppm}$

Phosphorus: $11660 \mathrm{ppm}$ Magnesium: $463.0 \mathrm{ppm}$ Sodium: 1963 ppm Potassium: $6316 \mathrm{ppm}$ Copper: 72.80 ppm Iron: $243.5 \mathrm{ppm}$ Manganese: $8.37 \mathrm{ppm}$ Zinc: $123.3 \mathrm{ppm}$ Molybdenum: $5.61 \mathrm{ppm}$ Moisture: $64.37 \%$ Dry Matter: $35.63 \%$

Calcium: $127.9 \mathrm{ppm}$

Phosphorus: 11980 ppm Magnesium: $456.7 \mathrm{ppm}$ Sodium: 1722 ppm

Potassium: 6807 ppm Copper: $129.9 \mathrm{ppm}$ Iron: $212.8 \mathrm{ppm}$ Manganese: $7.71 \mathrm{ppm}$

Zinc: $123.2 \mathrm{ppm}$ Molybdenum: $3.85 \mathrm{ppm}$ Moisture: $61.78 \%$ Dry Matter: $38.22 \%$

Calcium: $124.5 \mathrm{ppm}$ Phosphorus: 11610 ppm Magnesium: $468.7 \mathrm{ppm}$ Sodium: 1496 ppm

Potassium: 6705 ppm Copper: 180.0 ppm Iron: $240.0 \mathrm{ppm}$

Manganese: $9.89 \mathrm{ppm}$ 
Mineral Panel

Item

4

1815 - Ovine Dorset Male Liver

1819 - Ovine Dorset Female Liver

$6 \quad 1836$ - Ovine Dorset Male Liver
Result

Reference Interval
Zinc: $115.9 \mathrm{ppm}$

Molybdenum: $4.30 \mathrm{ppm}$

Moisture: $64.55 \%$

Dry Matter: $35.45 \%$

Calcium: $147.4 \mathrm{ppm}$

Phosphorus: $13190 \mathrm{ppm}$

Magnesium: $524.0 \mathrm{ppm}$

Sodium: 2092 ppm

Potassium: 7523 ppm

Copper: $288.1 \mathrm{ppm}$

Iron: $169.3 \mathrm{ppm}$

Manganese: $11.44 \mathrm{ppm}$

Zinc: 132.7 ppm

Molybdenum: $4.79 \mathrm{ppm}$

Moisture: $66.11 \%$

Dry Matter: $33.89 \%$

Calcium: 145.5 ppm

Phosphorus: $13140 \mathrm{ppm}$

Magnesium: 504.9 ppm

Sodium: 2058 ppm

Potassium: $7391 \mathrm{ppm}$

Copper: $448.0 \mathrm{ppm}$

Iron: $338.8 \mathrm{ppm}$

Manganese: $11.58 \mathrm{ppm}$

Zinc: $148.8 \mathrm{ppm}$

Molybdenum: $5.38 \mathrm{ppm}$

Moisture: $66.96 \%$

Dry Matter: $33.04 \%$

Calcium: $148.9 \mathrm{ppm}$

Phosphorus: $12880 \mathrm{ppm}$

Magnesium: $504.3 \mathrm{ppm}$

Sodium: 2386 ppm

Potassium: 7324 ppm

Copper: $419.4 \mathrm{ppm}$

Iron: $415.9 \mathrm{ppm}$

Manganese: $13.27 \mathrm{ppm}$

Zinc: $129.6 \mathrm{ppm}$

Molybdenum: $5.08 \mathrm{ppm}$

Comments: The above results for ovine liver except for the moisture, are given on a dry matter (moisture removed) basis. Reference ranges for trace mineral concentrations in ovine liver have been calculated based on data from Puls Mineral Levels in Animal Health, 2nd Edition (1994).

Copper 100 to 500 ppm dry matter (toxic >1000 ppm dry matter)

Iron 120 to $1500 \mathrm{ppm}$ dry matter

Zinc 120 to 375 ppm dry matter

Molybdenum 6 to $30.0 \mathrm{ppm}$ dry matter

Shipping Violation Alert! If you are re-using boxes from your clinic to ship specimens to us using our discounted label program, UPS is requiring that the AHDC notify all clients of potential shipping violations caused by extra barcodes or symbols on package exteriors. As sorting mechanisms become more automated, the stray exterior marks on boxes can cause them to be routed inappropriately, causing violations for UPS with the Federal Aviation Administration (FAA) that are then passed on to us and ultimately to you. Violations also cause shipments to be sent back to you untested. PLEASE CHECK ALL SIX (6) SIDES OF YOUR BOX BEFORE SHIPPING! 


\section{Appendices References}

Whitlock, H.V., 1948. Some modifications of the McMaster helminth eggcounting technique and apparatus. J. Counc. Sci. Res. 21, 177-180.

Zajac, A.M., Conboy, G.A., 2012. Veterinary Clinical Parasitology, 8th ed. Wiley-Blackwell, Ames, lowa. 